\title{
TOWARD ACCIDENT REDUCTION INNOVATIONS IN DRIVER EDUCATION
}

\section{SEPTEMBER 1972 - NUMBER 30}

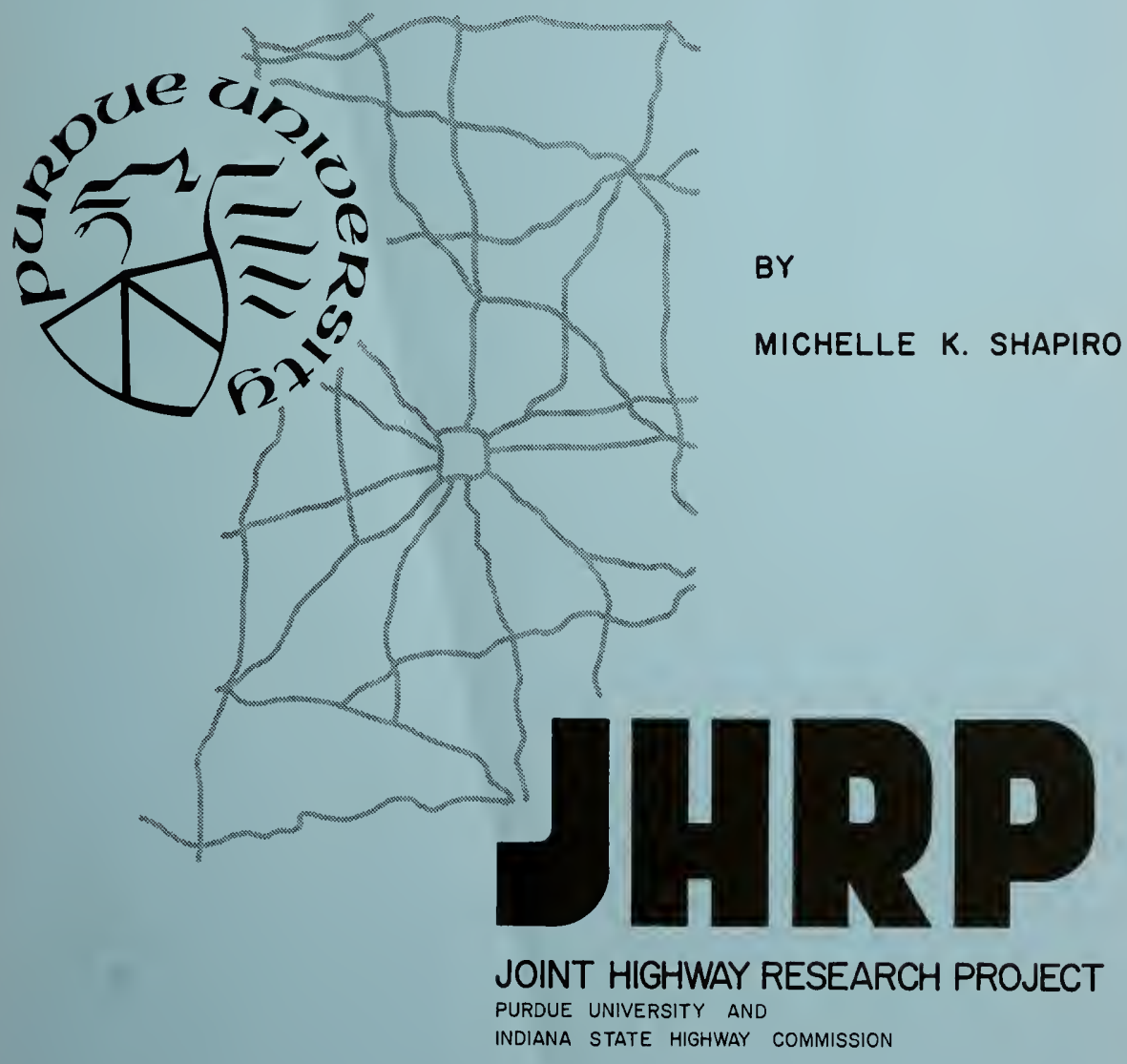



Final Report

TOWARD ACCIDENT REDUCTION INNOVATIONS IN DRIVER EDUCATION

To: J. F. McLaughlin, Director

Joint Highway Research Project

FROM: H. L. Michael, Associate Director

Joint Highway Research Project

September 7, 1972

Project: C-36-59K

File: $\quad 8-5-11$

The attached Final Report "Toward Accident Reduction Innovations in Driver Education" is submitted as fulfillment of the approved JHRP Study on accidents and driver training. The report was written and the research conducted by Michelle $K$. Shapiro, a graduate assistant in research on our staff. Professor William Asher directed the Study. Both Mrs. Shapiro and Dr. Asher are in the Department of Education at Purdue University.

The major findings of the Study are that several possible techniques can be used to change young people's driving attitudes and behavior. Modeling, reciprocal inhibition and demonstration were found to be effective techniques and it is suggested that driver education educators consider using these techniques to introduce the element of emotional control into current driver education courses.

The Report is presented to the Board for acceptance as fulfillment of the Study objectives.

Respectfully submitted,

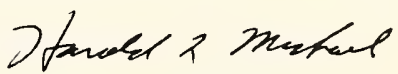

Harold L. Michael

Associate Director

HLM : ms

$\begin{array}{lll}\text { cc: W. L. Dolch } & \text { M. L. Hayes } & \text { C. F. Scholer } \\ \text { R. L. Eskew } & \text { C. W. Lovell } & \text { M. B. Scott } \\ \text { W. H. Goetz } & \text { G. W. Marks } & \text { J. A. Spooner } \\ \text { M. J. Gutzwiller } & \text { R. D. Miles } & \text { N. W. Steinkamp } \\ \text { G. K. Hallock } & \text { J. W. Miller } & \text { H. R. J. Walsh } \\ \text { R. H. Harrell } & \text { G. T. Satterly } & \text { E. J. Yoder }\end{array}$




\section{Final Report}

TOWARD ACCIDENT REDUCTION INNOVATIONS IN DRIVER EDUCATION

by

Michelle Kaylin Shapiro

Graduate Assistant in Research

Joint Highway Research Project

Project No.: C-36-59K

File No.: $8-5-11$

Conducted By

Joint Highway Research Project

Engineering Experiment Station

Purdue University

In Cooperation With

Indiana State llighway Commission

Purdue University

West Lafayette, Indiana

September 7, 1972 
Digitized by the Internet Archive in 2011 with funding from

LYRASIS members and Sloan Foundation; Indiana Department of Transportation 


\section{ACKNONLEDGMENTS}

I wish to acknowledge the guidance and advice of my major professor, William Asher, in my efforts on this project, and Ernest McDaniel and John Feldhusen for their helpful suggestions as to revisions in the preliminary drafts of my thesis and for serving on my committee. I also wish to thank Rodger Seehafer and Bruce Shertzer for serving on my committee, and Professor Harold L. Michael and the Indiana Joint Highway Research Board for supporting my work. In addition, I would like to thank those who permitted me and helped me work with their students; Rodger Seehafer of Purdue University, Willis Horn and William Barrett of Pine Village High School, and Jay Kleine, Howard Catt, and Jack Bradford at Arsenal Technfcal High School. I would especially like to thank my husband, Michael, for his patience and help. 
TABLE OF CONTENTS

Page

LIST OF TABLES

vii

LIST OF FIGURES . . . . . . . . . . . . . . . . . . xiii

ABSTRACT . . . . . . . . . . . . . . . xiv

CHAPTER I - REVIEW OF LITERATURE . . . . . . . . . 1

Characteristics of the Accident-Prone Driver . . 2

The Sex of the Driver......... 2

Personality Traits of the Accident-Prone

Driver

The Young Accident-Prone Driver. . . . . . 5

Characteristics of Accidents Involving Young

Drivers .............. . . 8

Attempts to Reduce the Automobile Accident

Rate . . . . . . . . . . . . . 10

High School Driver Education Courses . 10

Experimental Treatments to Reduce Accident

Rates................. 12

Vicarious Learning . . . . . . . . . . . . 16

Modeling as a Cognitive Process of

Labeling . . . . . . . . . . . . . . 19

Symbolic Models . . . . . . . . . . . . 20

Mode1 Characteristics... . . . . . . 22

Characteristics of subjects influenced by

Models ............. 32

Internalizing a Modei's standards : : : 37

Other Favorable Conditions for Subject

Performance of Modeled Behavior. . . . 43

Duration of Effect .......... . . 56

Conclusions ............ . . . 57

Driving Simulators............. . 61

Summary .. . . . . . . . . . . . . 63

Statement of the Probiem: . . . . . . . . . 64

CHAPTER II - METHODS . . . . . . . . . . . 65

Subjects . . . . . . . . . . . . . . 67

School Populations 67

Subjects in the Emotional Role-Playing
Trials . . . 68

Subjects in the Preliminary Demonstration

Trials . . . . . . . . . . . . 69

Subjects in the Quasi-Experimental

Studies.............. . 70

Preliminary Trials of Behavior Modification

Techniques ............. 72 
TABLE OF CONTENTS, cont.

Page

Preliminary Trials of Emotional Role-

Playing. . . . . . . . . . . . 72

Preliminary Trials of the Demonstration. . 78

The Quasi-Experimental Studies . . . . . . . . 82

Curriculum Elements . . . . . . . . . . . . 83

Major Problems with the Quasi-Experiments . 89

Criterion Variables . . . . . . . . . . . . 91

Analysis of Criterion Measures . . . . . . . . . 94

Analysis of Driving Simulator Data . . . . 94

Summary

Analysis of Attitude Test Data . . . . . . 95

CHAPTER III - RESULTS .............. . 100

Characteristics of the Criterion Measures . . . 100

Attitude Test Characteristics . . . . . . 100

Driving Simulator Characteristics:

Reliability Estimates.......... 107

Preliminary Trials . . . . . . . . . . . . . . 111

Differences Between Groups . . . . . . . . 111

Effectiveness of Treatments . . . . . . . 113

Quasi-Experiments . . . . . . . . . . . . . . 119

Differences Between High Schools A and B . 119

Effectiveness of Quasi-Experiment

Treatment: Simulator Criterion . . . . . 144

Effectiveness of Treatment: Cognitive

Summary

Test . . . . . . . . . . 157

CHAPTER IV - DISCUSSION . . . . . . . . . 167

General Variables Influencing Treatment

Effectiveness ............ . 167

Effectiveness of Treatments in Relation to
Driver Education . . . 171

Modeling and Reciprocal Inhibition . . . 171

Demonstrations . . . . . . . . . . 177

Emotional Role-Playing . . . . . . . . 182

Summary . . . . . . . . . . . . . . . 184

Effectiveness of Treatments in Relation to

Counseling Theory . . . . . . . . . . 185

Emotional Role-Playing . . . . . . . 185

Demonstrations . . . . . . . . . . . . 186

Modeling . . . . . . . . . . . . 187

Reciprocal Inhibition . . . . . . . . . 188

Effectiveness of Criterton Measures . . . . . 188

Attitude Test Criterton . . . . . . . 188

Driving Simulator Criterion. . . . . . 191 
TABLE OF CONTENTS, cont.

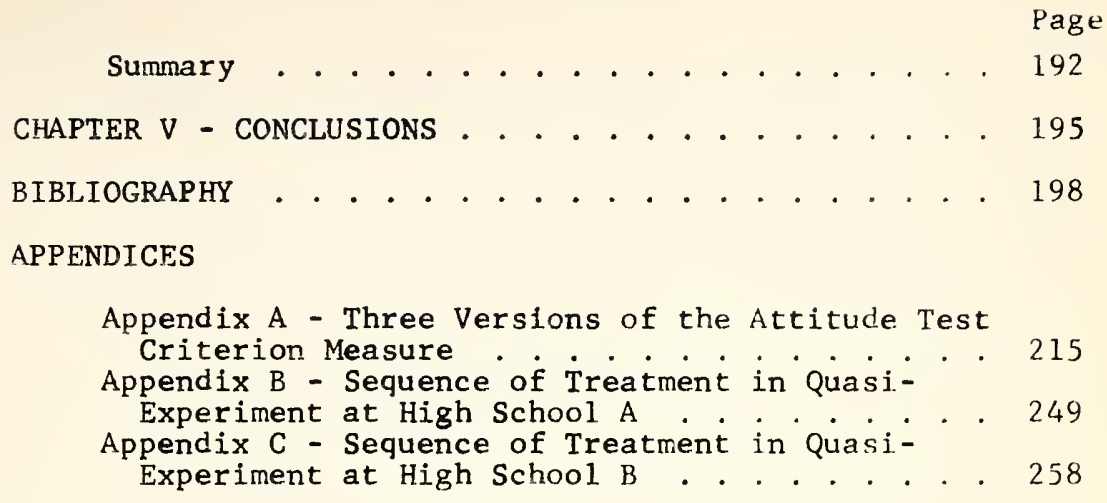

VITA 272 


\section{LIST OF TABLES}

Table

1. Means and Internal Consistency of High School A Demonstration Attitude Test . . . . . . . 102

2. Means and Internal Consistency of Attitude Test Used with University Subjects . . . . . 103

3. Means and Interna1 Consistency of the Attitude Test Used in the Quasi-Experiments . . . . . . 104

4. Means on Test Re-test Reliability Estimates of Version 1, Attitude Section (40 questions): High School Subjects

5. Means and Test-Retest Reliability Estimates of Version 2, Attitude Section (52 questions): University Subjects . . . . . . . . . . 106

6. Means and Test-Retest Reliability Estimates of Version 3: Quasi-Experiments . . . . . . 108

7. Means and Test-Retest Reliability Estimates of Driving Simulators: Lesson 1... . . . .

8. Means and Test-Retest Reliability of Driving Simulators: Lesson 2. . . . . . . . . . .

9. High School A: Analyois of Variance Considering Groups (Audience and Demonstrators) and Pre-Demonstration Attitude Section Test Scores as Main Effects... . . . . . . 112

10. High School A: Analysis of Variance Considering Groups (Demonstrators and Audience) and Pre- and Post-Demonstration Attitude Section Test Scores as Main Effects... . . . . . . . . . .

11. University Subjects: Analysis of Variance Consjdering Groups and Fre and Post-Demonstration Attitude Section Test Scores Main Effects.

1.2. University Subjects: Analysis of Variance: Considering One Group (Audience and Demonstrator) and Pre- and Post-Demonstration Test Scores as Main Effects

13. University Subjects: Analysis of Variance Considering Groups (Audience who were Non-RolePlayers and Audience Who Were Role-Players) and Pre - and Post--Demonstration 


\section{LIST OF TABLES, cont.}

Table

14. Analysis of Variance Considering Groups (Audience Members Who Had Emotional RolePlayed and Audience Members and Demonstrators Who Had not Emotional Role-Played) and PreEmotional Role-Playing and Pre- and PostDemonstration . . . . . . . . . . . .

15. Analysis of Variance Considering Groups (High Schools $A$ and $B$ ) and Pre-Treatment Biographical Section Test Scores as Main Effects . . . . . .

16. High School A: Analysis of Variance Considering Groups (Experimental and Control) and Pre-, and Post-Treatment Attitude Section Test Scores as Main Effects . . . . . . . . .

17. High School A: Analysis of Variance Considering Groups (Experimental and Control) and PreMid- and Post-Treatment Attitude Section Test Scores as Main Effects

18. High School A: Analysis of Variance Considering Groups (Experimental and Control) and Midand Post-Treatment Attitude Section Test Scores as Main Effects...............

19. High School A: Analysis of Variance Considering Groups (Experimental and Control) and Midand Post-Treatment Driving Behaviors Section Test Scores as Main Effects . . . . . . . . .

20. High School A: Analysis of Variance Considering Groups (Experimental and Control) and Midand Post-Treatment Combined Scores of Driving Behaviors and Attitude Sections as Main Effects

21. High School A: Analysis of Variance Considering Groups (Experimental and Control), Sex, and Pre-, Mid- and Post-Treatment Attitude Section Test Scores as Main Effects.... . . . .

22. High School A: Analysis of Variance Considering Groups (Experimental and Control), Sex, and Mid- and Fost-Treatment Attitude Section Test Scores as Main Effects

23. High School A: Analysis of Variance Considering Groups (Experimental and Control), Sex, and Mid- and Post-Treatment Driving Behaviors Section Test Scores as Main Fffects.. 
LIST OF TABLES, cont.

Table

Page

24. High School A: Analysis of Variance Considering Groups (Experimental and Control), Sex, and Mid- and Post-Treatment Combined Attitude and Driving Behaviors Section Test Scores as Main Effects . . . . . . . . . . .

25. High School B: Analysis of Variance Considering Groups (Experimental and Control), and Pre-, Mid- and Post-Treatment Attitude Section Test Scores as Main Effects..........

26. High School B: Analysis of Variance Considering Groups (Experimental and Control), and Preand Fost-Treatment Attitude Section Test Scores as Main Effects... . . . . . . . . . . .

27. High School B: Analysis of Variance Considering Groups (Experimental and Control), and Preand Mid-Treatment Attitude Section Scores as Main Effects

28. High School B: Analysis of Variance Considering Groups (Experimental and Control), and Mid- and Post-Treatment Attitude Section Test Scores as Main Effects . . . . . . . . . 136

29. High School B: Analysis of Variance Considering Groups (Experimental and Control), and Mid- and Post-Treatment Attitude Section Test Scores as Main Effects . . . . . . . . . .

30. High School B: Analysis of Variance Considering Groups (Experimental and Control), and Midand Post-Treatment Combined Test Scores of the Attitude and Driving Behaviors Sections as Main Effects . . . . . . . . . . . . .

31. High School B: Analysis of Variance Considering Groups (Experimental and Control), Sex, and Pre-, Mid- and Post-Treatment Attitude Section Test Scores as Main Effects . . . . . . . . .

32. High School B: Analysis of Variance Considering Groups (Experimental and Control), Sex, and Pre- and Mid-Treatment Attitude Section Attitude Test Scores as Main Effects . . . . 


\section{LIST OF TABLES, cont.}

Table

Page

33. High School B: Analysis of Variance Considering Groups (Experimental and Control), Sex, and Mid- and Post-Treatment Attitude Section Test Scores as Main Effects . . . . . . . . . . .

34. High School B: Analysis of Variance Considering Groups (Experimental and Control), Sex, and Mid-and Post-Treatment Driving Behaviors Section Test Scores as Main Effects......

35. High Schoo1 B: Analysis of Variance Considering Groups (Experimental and Control), Sex, and Mid- and Post-Treatment Combined Driving Behaviors and Attitude Sections Test Scores as Main Effects

36. High School B: Analysis of Varlance Considering Groups (Experimental and Contro1), Race, and Pre-, Mid- and Post-Treatment Attitude Section Test Scores as Main Effects.

37. High School B: Analysis of Variance Considering Groups (Experimental and Control), Race, and Mid- and Post-Treatment Attitude Section Test Scores as Main Effects . . . . . . . .

38. High School B: Analysis of Varlance Considering Groups (Experimental and Control), Race, and Mid- and Post-Treatment Driving Behaviors Section Test Scores as Main Effects..... .

39. High School B: Analysis of Variance Considering Groups (Experimental and Control), Race, and Mid- and Post-Treatment Combined Driving Behaviors and Attitude Sections Test Scores as Main Effects

40. Simulator Test Results: Analysis of Variance Considering Brake Error Scores and Groups (Experimenta1 and Contro1) as Main Effects.

41. Simulator Test Results: Analysis of Variance Considering Left Steering Errors and Groups (Experimenta1 and Control) Main Effects.

42. Simulator Test Results: Analysis of Varlance Considering Mid- and Post-Treatment Accelerator Up Error Scores and Croups (Experimental and Control) as Main Effects . . . . . . . . . 
43. Simulator Test Results: Analysis of Variance Considering Mid- and Post-Treatment Right

Steering Error Scores and Groups (Experimental and Control) as Main Effects . . . . . . . .

44. Simulator Test Results: Analysis of Variance Considering Signaling Error Scores and Groups (Experimental and Control) as Main Effects.

45. Simulator Test Results: Analysis of Variance Considering Parking Brake Error Scores and Groups (Experimental and Control) as Main Effects

46. Simulator Test Results: Analysis of Variance Considering Negative Steering Error Scores and Groups (Experimental and Control) as Main Effects

47. Simulator Test Results: Analysis of Variance Considering Total Error Scores and Groups (Experimental and Control) as Main Effects.

48. Simulator Lesson 2: Analysis of Variance Considering Mid- and Post-Treatment Brake Error Scores as a Main Effect. . . . . . . . . . .

49. Simulator Lesson 2: Analysis of Variance Considering Mid-and Post-Treatment Left Steering Error Scores as a Main Effect... . . . . 154

50. Simulator Lesson 2: Analysis of Variance Considering Mid- and Post-Treatment Accelerator Up Error Scores as a Main Effect . . . . . .

51. Simulator Lesson 2: Analysis of Variance Considerjing Mid- and Post-Treatment Right Steering Error Scores as a Main Effect... . . . .

52. Simulator Lesson 2: Analysis of Variance Considering Mid- and Post-Treatment Signaling Error Scores as a Main Effect.. . . . . . 156

53. Simulator Lesson 2: Analysis of Variance Considering Mid- and Post-Treatment Parking Brake Error Scores as Main Effect . . . . . . . . 
LIST OF TABLES, cont.

Table

54. Simulator Lesson 2: Analysis of Variance

Considering Mid- and Post-Treatment Negative

Steering Error Scores as a Main Effect

55. Simulator Lesson 2: Analysis of Variance Considering Mid- and Post-Treatment Total Error Scores as a Main Effect . . . . . . . . . . . 


\section{LIST OF FIGURES}

Figure

1. Time Sequence of Studies . . . . . . . . . 66

2. Sequence of Treatment Sections and Testing in Quasi-Experiments........... 124 


\section{ABSTRACT}

Shapiro, Michelle Kaylin. Ph.D., Purdue University, August 1972. Toward Accident Reduction Innovations in Driver Education. Major Professor: William Asher.

Emotional role-playing, demonstration, modeling and reciprocal inhibition were three behavioral modification techniques used to try to develop a curricula unit which would introduce the element of emotional control while driving into driver education courses with the ultimate aim of reducing the accident rates of young people. Preliminary trials were made using emotional role-playing and demonstration techniques, and two quasi-experiments combined these techniques and modeling and reciprocal inhibition into one curricula element. In addition, an attitude test was developed as a criterion measure and proved adequate to test the effectiveness of these treatments. However, student performances on driving simulators were found to be unreliable, and it was thus an inadequate criterion measure.

It has been shown that young drivers from lower socioeconomic families tend to have more accidents. Thus, rural and inner-city high school and university subjects from low and lower middle socio-economic families were utilized as subjects in the preliminary trials and in the 
quasi-experiments. It was found that emotional role-playing had no effect on changing the driving attitudes and behaviors of these young people. This technique apparently functioned as a "scare" technique, and subjects tended to repress their unpleasant emotional role-playing experiences. However, modeling and reciprocal inhibition and demonstration were effective techniques in changing young people's driving attitudes and behaviors, although the full benefit of these techniques may have a delayed effect; i.e., appropriate driving behavior may be elicited after the student has an accident or almost has an accident. Further, it was suggested that models be neither extremely similar or dissimilar to the observers, but that demonstrators should be similar to their audience.

It is suggested that driver education educators consider using these techniques to introduce the element of emotional control into current driver education courses in order to reduce the automobile accident rates of young people. 
CHAPTER I

REVIEW OF LITERATURE

Driver education courses are being offered in over 18,000 high schools to approximately $2 \frac{1}{2}$ million students (MacGuire \& Kersh, 1968, p. 14). Yet traffic accidents are the leading cause of death for persons aged 15-24, equaling all other causes combined (National Safety Council, 1968). Hart (1969) suggests that drivers in the late teens and the first half of the twenties have one-third of all accidents although this group of drivers constitutes on 1 y $21 \%$ of all drivers.

Several avenues have been explored in an attempt to discover the reason young people have such an appalling number of automobile accidents. Many people have blamed the design of the roads or mechanical defects in cars as contributing factors to accidents. However, improved engineering design of roads has greatly reduced environmental hazards which cause accidents. The 1966 Little report found that "in the absence of a very striking defect or failure in the roadway, the vehicle, or the driver's own medical condition, the cause of an accident is almost invariably assigned to one or another of a variety of driver errors. Thus, driver error is typically stated to be responsible for from eighty 
to ninety percent of all accidents" ( $p$. 37). Further, Baker of the Traffic Institute at Northwestern University states, "it was impossible to identify the share of accidents that are directly attributable to mechanical defects but that he believed it to be probably under five percent of all accidents, and perhaps as little as two percent of all accidents" (A. D. Little report, 1966, p. 280).

Other people have felt that there is a type of person who is accident-prone. Several people have suggested that the type of person who tends to take driver education tends not to have accidents. This literature overview will review these ideas, suggest why past attempts to rectify the problem have not worked well, and suggest a new avenue to be explored.

\section{Characteristics of the Accident-Prone Driver}

The Sex of the Driver

Not only are young people under 25 disproportionally over-represented in the number of accidents they have, but males under 25 have far more accidents than females under 25. Asher \& Shapiro (1971) found there were 4185 drivers aged 16-21 involved in an accident in 1968 in which a death or a very serious injury occurred. Seventy-eight percent of these young Indiana drivers were males. Females were drivers in only twenty-two percent of these accidents. The New York State Department of Motor Vehicles (1963) found that in the 18-20 age group, males had six times as many accidents 
as females in the same age group. Also, males aged 18-20 had more than 50 percent more accidents than males aged 21-24. Rockwe11, Galbraith \& Centre (1961) and Cohen (1956) suggest that young people take more risks generally and that males take more risks than females. Coppin (1965-67) also Found that the sex difference was a fundamental one, and that it would appear that girl drivers are more conforming and also probably more closely supervised by their parents. Indeed, McGlade \& Abercrombie (1970) found that females more often have their accidents in a non-social context, and that accidents consistently vary by the activity, situation, social nature, sex and developmental level. This may indicate the need for more homogeneous grouping of driver education students so that the educational content of the courses can be more specific.

Personality Traits of the Accident-Prone Driver

What other characteristics distinguish people who have accidents from people who do not have accidents? Evidence tends to support the possibility that people who have accidents do not have as much control over their emotional reactions as people who do not have accidents. Conger (1960) Felt that driving an automobile makes it possible for people to express hostility, discourtesy, and emotional conflict without much fear of reprisal, and often with complete anonymity. In reckless driving there may be a common factor of revolt. Brown \& Berdie (1960) and Lauer 
(1955) report relationships between personality variables and driving ability. In the study "Drivers Who Die" done by the Baylor University College of Medicine (HSL 非9-10, p. iii) it was found that over half of these accidents involved single vehicle drivers. In order to determine personality characteristics of these drivers, their family members were interviewed by a psychiatrist, then these drivers were compared with a control of 25 matched drivers randomly selected from the Houston area. This group was subjected to the same psychiatric scrutiny as the dead drivers. "The results indicated that 80 percent of the fatalities were maladjusted in that they were either alcoholics or had personality disorders or both. Only 12 percent of the control group were so classified" (HSL 非9-10, p. iil). Psychiatric stress, marital, financial, occupational, etc., was prevelant in 80 percent of the fatality group within 24 hours prior to the crash. The Baylor researchers conclude, "In general, it appears that the driver's personality pattern, a stressful event, and the resulting intrapsychic reaction coalesce to form a condition of impaired driving ability. If alcohol is added, this situation is further compromised leading to the high probability of appearance of an accident" (p. iv). Crancer \& Quiring (1969) also found that people with personality and psychoneurotic disorders have higher accident rates. Further, Erickson (1969) found that high accident groups of drivers scored higher on Bernberg's Personal Relations 
Inventory in the sado-aggressive and maso-submission scales, which suggests that some drivers use a car as an instrument to express aggression and inflict pain on others. Finally, Tillman \& Hobbs (1949) found that traffic offenders had a higher incidence of prior antisocial behavior as measured by contacts with police courts, welfare agencies, etc.

The Young Accident-Prone Driver

Conger (1959) found, that in comparison with nonaccident subjects, the accident subjects showed a tendency (1) to have less capacity for managing or controlling hostilities; (2) to be either excessively self-centered or excessively sociocentric; (3) to be excessively preoccupied with fantasy satisfactions or extremely "stimulus-bound"; (4) to be more fearful of loss of love and support; and (5) to be generally less able to tolerate tension without discharging it immediately. In addition, the accident subjects tended to be categorized more frequently as consistently or occasionally belligerent or covertly hostile, and less frequently as only appropriately assertive, or unassertive. Shaw (1965), in a later study carried out in South Africa, confirmed Conger's general findings.

Rommel (1959) made a study of high school students in Pennsylvania. On the basis of a Driver Attitude Inventory and a test of emotional and personal adjustment, he concluded that youthful drivers having accidents tended to score high, and those free of accidents tended to score low, with regard 
to several attitudes: 1) an attitude to driving as an activity which relieves psychic tension; 2) an attitude toward driving as a form of behavior by which youthfulness may be compensated for and the role of an adult may be assumed; 3) an attitude toward driving which does not consider speed as an element of danger or, if it is considered dangerous, an attitude manifesting desire for danger; 4) an attitude toward driving which places greater emphasis on the power of a vehicle than on its type or utility. In personality tests he found that accident-incurring youths showed more disregard of social mores, and more defiance of authority. Beamish \& Malfetti (1962) used two groups of 16-19 year old male adolescents as subjects; 84 young male violators who had been referred to a juvenile court for two or more traffic violations; and a control group of 186 non-violators matched with respect to age, education, miles driven annually, and principal use made of the car. They found that the violator group had certain common psychological characteristics: they do not give much thought to the implications of their behavior for themselves and others; they tend to be in disagreement or conflict with others and perceive themselves as held down and imposed upon; they are rebellious and selfish; and their hypersensitiveness, lack of self-confidence and feelings of personal unworthiness may lead them to overcompensate with erratic and ill-considered action resulting in traffic violations. Also, Levonian (1969) found that there was a positive relationship hetween the number of 
violations and expediency (orientated to self benefit at the expense of others), among driver education students even after controlling for four other personality measures, as well as for sex, driving experience and socio-economic status.

Asher \& Dodson (1969) found that students likely to have more accidents stay up late on weekends, have great interest in cars, have high access to cars, and more important, are not well acclimated in school, turn in sloppy assignments and are inattentive in class. Gutshall, Harper $\&$ Burke (1968) found that a group of males with lower intelligence differed from a group of males with average IQ scores, but interestedly, not from a high IQ group of males, on the factors of combined accidents and violations. Asher \& Dodson (1970) studied young people who had completed the Project TALENT questionnaire (which was given to 425,000 U.S. high school students in 1960) and who were found to have died in an automobile accident in Indiana between May, 1960 and October, 1969. This Indiana fatality group had less education, had more trouble reading, were less mature, learned to drive younger, had more access to cars, and may have taken more driver training. Their parents were of lower socioeconomic status, had homes of less value, had less income and less education than parents of the nonfatalities. Kraus, Steele, Ghent \& Thompson (1970) found that of drivers under 21, those having accidents more often falled one or more grades in or before grade 
eight, had been in vocational high school courses, tended to be regular cigarette smokers before age 16, had a full time job at or before aged 17, or were likely to have been charged with a criminal offense. Carson \& Klein (1970) found that for young people, traffic offenses correlate strongly with non-traffic offenses, and they suggested that the two types of offenses are not casually related but stem from an upbringing that stresses deviant rather than normative values.

Asher \& Shapiro (1971) studied the records of 4185 young drivers involved in an accident in Indiana in 1968 in which there was a serious injury or a death. Of these drivers 78 percent were male, 20 percent of whom had been drinking. Of the female drivers only six percent had been drinking. Furthermore, 64 percent of these Indiana drivers were going straight ahead, on a straight, level, blacktop, dry road with unobscured vision. This further supports the conjecture that for this high accident age group, the driver and not the road, is to blame. Males were usually driving faster than females. Also, the driver had no physical defects, and was a resident of the county in which the accident occurred.

\section{Characteristics of Accidents Involving Young Drivers}

Waller \& Goo (1969) found in studying accident reports that young drivers have larger proportions of crashes of a king that suggest reckless behavior. Shaw \& 
Sichel (1970) found, in their summary of the research on driving and accidents, that a disportionate number of teenage drivers are involved in certain kinds of accidents such as single car accidents, particularly those involving funning off the roadway, overturning in the roadway, and colliding with fixed objects. In a number of studies it has been shown that excessive speed was a major characteristic of teenage driving accidents (Garwood \& Jeffcoate, 1955). Quenault, Golby \& Pryer (1968) found that young drivers recelve more pleasure from overtaking other cars, are more competitive drivers, and feel that accidents are inevitable, caused by road conditions. It is interesting, however, that Pollock (1970) found that the incident of accidents decreases with the number of passengers in the car.

When reaction times are shortest, night vision and glare resistance are best, and the ability to learn coordinated skills highest in the late teens and early twenties, the evidence is that accident rates are disproportionately high. This presents the paradox that the driver is most susceptible to accidents at the time of his greatest potential, physically, in operating skills. As MacFarland \& Moore (1960), who reviewed the role of the automobile in the cultural and behavioral patterns of young people, suggest: "The automobile is a symbol of economic and social worth, gives a vicarious sense of power, represents 
freedom and escape, both real and symbolic release from parental control and supervision, and is an important factor in adolescent culture in the sense that in many groups, to date a girl, a boy must be able to provide a car for transportation." Further, Klein (1971) suggests that teachers, textbooks, and the mass media teach students these values which promulgate accidents: 1) competitiveness of an aggressive nature is socially desirable; 2) one should actively seek challenge and excitement; and 3) risk-taking is justified in meeting a challenge.

\section{Attempts to Reduce the Automobile Accident Rate}

High School Driver Education Courses

Driver education courses were practically non-existent prior to 1930 (Warner, 1972), but by 1968, driver education courses were being offered to more than $2 \frac{1}{2}$ million students at 18,000 high schools (MacGuire \& Kersh, 1968, p. 14). However, the high rate of traffic accidents for young people still persists. Further, Pelz \& Schumann (1971) suggest that crash and violation peaks are only delayed one or two years when young men learn to drive at age 15 . Why do driver education courses not reduce the appalling number of automobile accidents young people have? Pexhaps part of this answer is given by Rainey, Conger \& Walsmith (1961) who found that students who take driver education differ emotionally from those who do not take it. Those not taking it have a higher activity level, 
more interest in social participation, and more masculine interests. Tesser \& Grossman (1969) found that it was likely that individuals, especially males, who sought to take driver education felt that they had some control on their environment, whereas fate-orientated individuals tended not to seek information on their own. In this context, it is interesting to note that traffic accident repeaters generally feel that fate controls their actions (ENO Foundation for Highway Traffic Control, 1948).

Asher (1968) also found in a U.S. sample that students who take driver education courses differ from students who do not take driver education courses in ways which relate to fatal accidents. More important, Asher \& Dodson (1969) found that taking driver education as such does not reduce accidents. Further they found (1970) that Indiana fatalities took driver education more. This suggests that driver training courses might actually increase the possibility of the student having an accident because he could get a license at a younger age, and thus have more exposure by driving a car.

It is apparent, then, that driver education is not taken by many of the young people who are potentially the most hazardous. Further, in reviewing a standard driver education text, Sportsmanlike Driving (American Automobile Association, 1965), one finds little metion of controlling emotions, and minimizes attention to problems which occur when driving while angry or drinking. Most of the emphasis 
is on rules of the road and the physical operation of the car. Yet it is apparent, from examining the kind of accidents young people have and the type of young person who is accident-prone, that many young people tend to use the car to release their emotions. Lewis (1969) felt that a driver education program should be a reinforcement of all positive social experiences, not merely the process of learning to manipulate an auto or memorice laws and rules. Also, Kenel (1972) stated that "competent drivers do not just guide motor vehicles; they are involved in a complex, constant process of observation, evaluation, decisionmaking and execution" (p. 19). Kenel also felt that "students should be able to determine methods for preventing various psychological, social, and other factors from having an adverse effect on one's ability to perform" (p. 19). From the above data, it would appear that current driver education courses are missing an important variable: emotional control in relation to driving.

\section{Experimental Treatments to Reduce Accident Rates}

Several methods have been tried to reduce the number of accidents people have. Apparently the most promising, a pilot study, presented evidence that high school seniors reduced accident rates by $50 \%$ when compared to a control group during a two-year follow-up period, although, possibly due to the small sample $(n=19)$, the results were not significant (Schuman, McConochie, \& Pelz, 1971). Nineteen 
seniors who had previously taken driver education participated in a series of seven two-hour workshops over a seven week period. The objective of these workshops was to provide an open, informal setting for discussion of actual road experiences, diagnosis of components of accident situations, and an understanding of the stages of decision-making behind the wheel which occur either "consciously or unconsciously, deliberately or impulsively, depending on the maturity of the driver". Two members of the research staff led these sessions. The first content area emphasized was personal factors in driving; i.e., ways of coping with emotions in driving; and "trigger films" to trigger discussions were used. These films were one to three minutes in length and showed an emotional factor, such as an argument between father and son, ending with the son leaving in a car. The second content area was situational factors in the driving environment. The third area was current driving experiences, and students were encouraged to keep notes of their road experiences, which the group later analyzed. Finally, the fourth area was personal involvement and self-awareness, i.e., to encourage students to examine their own driving skills and to improve their driving. Letters were sent to students six and twelve months after the workshop which congratulated the drivers for an accident-free record, or expressed mild concern if they had had an accident.

A number of other experimental treatments to reduce accidents have been tried. Drivers who had accumulated a 
past record of crashes or violations were asked to attend a "Driver Improvement Meeting" group discussion led by a driving, analyst, but no reduction in accidents that could have been attributed to the meeting was found (Coppin, Ferdun \& Peck, 1965). Rimm (1971) used systematic desensitization to reduce anger felt in driving situations. For both subjective anger ratings and GSR, the desensitization group showed a greater reduction that did either the placebo or control (non-treated) groups. These differences were maintained at a two week follow-up. Coppin, Peck, Lew, et al. (1969) reported that male and female drivers who attended a single individual hearing had no reduction in accidents, although the number of citations did decrease. McBride \& Peck (1969) attempted to influence driving behavior through several types of warning letters varying in threat intensity and degree of personalized style. The treatment included a follow-up congratulatory letter issued to accident-free drivers seven months after the initial

letter was sent. All letter-treatment combinations resulted in lower accident and violation rates when compared to the control group, with the low-threat treatment group having significantly lower accident rates than other groups.

Marsh (1965) compared a number of treatments for negligent drivers ranging from warning letters to group educational meetings and regular individual hearings. The records of these drivers were followed for one year. When records for males and females were combined, only the group 
educational meeting resulted in a significantly lower collision rate. Another successful field trial was conducted with a military population at Lackland Air Force Base, and a $50 \%$ reduction in crash rates over a one-year period was found (Barmack \& Payne, 1964). However, although one component was an intensive communications campaign concerning safe driving practices aimed at all persons on the base, the second componenet was an administrative review of their military record and possible referral to the base psychiatrist for persons who had had an accident. Thus, it was found that modification of driving persons in a military population was feasible. Also, Scott (1966) found that airmen under 25 had fewer accidents when advised of their immediate superiors' ratings of their driving attitudes and behaviors.

Most of the above studies dealt with somewhat older drivers than those usually found in driver education classes. Thus, these methods maybe inappropriate for students just learning to drive. Levonian (1969) mentions that it is probably easier to develop desired driving behaviors at the initial training. Therefore, to alter the driving behavior of beginning drivers which undertaken during emotional stress tends to precipitate accidents, it was hypothesized that behavioral modification techniques from psychology could be of use. Several of these techniques depend on vicarlous learning. 


\section{Vicarious Learning}

"Virtually all learning phenomenon resulting from direct experiences can occur on a vicarious basis through observation of another person's behavior and its consequences for them" (Bandura, 1969, p. 118). Bandura (1969) feels that by observing a model the observer can acquire a new response pattern that was not in his repertoire before. The observer can observe the model's behavior and its consequences, which will strengthen or weaken inhibitory responses of the observer; and the observer will be able to discriminate stimuli, because observing the model will facilitate previously learned responses in the same general class.

Modeling and imitation are not new subjects for psychology. Morgan (1896), Tarde (1903) and McDougal1 (1908) all thought that modeling was an innate propensity. This dissuaded further empirical investigation until the work of Humphrey (1921), Allport (1924), and Holt (1931), after the instinct theory fell in disrepute. These men described the modeling effect in terms of temporal contiguity between the model stimulus and the imitator's matching response, which they felt was sufficient for imitation to occur. Holt, for example, felt that adults copied the responses of their children, and children then repeated the adults' behavior. If during the spontaneous mutual imitation, the adult did a new thing, the child would imitate it. Thus, the adults' behavior became an effective stimulus for the child. 
Miller \& Dollard (1941) felt that the model's actions served as a cue for matching responses in motivated subjects, and subjects would imitate a performance by the model which would lead to a direct reward to the subjects, similar to the reward the model received. This theory is based on the idea of drive reduction to strengthen imitative responses, and is concerned only with previously learned matching responses. It does not explain how the response was acquired. Skinner (1953) felt that through a history of discrimination training, a repertoire of matching responses is established in every child. Repeated reinforcement of the imitated response results in a selective imitation due to the differential reinforcement of imitated behavior. However, neither Miller and Dollard nor Skinner account for socialization by imitative learning.

Mowrer (1960a, b) developed his proprioceptive theory. $A$ may make a response and reinforces $B$, and $A$ then takes on secondary rewarding value for $B$ and $B$ then tries to reproduce $A^{\prime}$ 's response when $A$ does not perform the action necessary for reinforcement. On the other hand, empathetic learning may be involved, when A models the behavior and gets reinforced, and $B$ experiences sensory consequences of $A$ 's behavior as $A$ experiences it, and $B$ intuits A's satisfaction or dissatisfaction. Berger (1961, 1962) with his vicarious instigation hypotheses, suggests that experimenters should be concerned with isolating vicarious learning processes from the effects of direct reinforcenent to the 
observer. Vicarious instigation was defined as behavior in which a person experiences an emotional response in conjunction with the unconditioned emotional response of the performer, and pseudovicarious instigation occurs when other cues elicited observer responses. He further suggests that observational learning may be the result of an ongoing tendency for the observer to practice the modeled behavior during the exposure period. Bandura, however, expressed his contiguity or no trial learning hypothesis, in which perceptual, symbolic and sensory events possess cue properties that later serve as discriminate stimuli for some overt response similar to those that had been observed, and thus, subjects learned to associate a certain response with observed conditions. This occurred without practice of actual behavior when subjects are in a similar position as the model had been and when subjects are sufficiently motivated to act. Thus, the imaginal and verbal responses of the model were stimuli to constitute enduring learning products of observer experiences (Bandura, 1965b).

Finally, Gerwitz \& Stingle (1968) tried to enlarge the scope of current theory. Imitation to them was a type of learned stimulus control over a class of functionally related (imitated) responses that are acquired by extrinsic reinforcement, i.e., the early reinforcement of an infant's imitative responses of an adult. Experience gave repeated success so that it became a class of functionally related 
equivalent behaviors which were acquired (a generalized tendency to imitate) because all the behaviors shared the common fate of reinforcement in the context of a particular stimuli (model's cues). In this instance, then, copying is a generalized process and is not response specific. Maintenance of imitation occurs because in daily life innumerable copying behaviors are extrinsically rewarded, at least intermittently. Thus, this model can be extended to explain acquisition of general attitudes, values, or motives of others.

In short, modeling and imitative learning are still being explored to determine exactly what occurs. Various theories have tried to account for these processes, from ideas that modeling was an innate propensity, to stimulusrelated theories, to a special kind of social learning mechanism. The development of these might well go into some areas of modeling theory and imitative learning which have been, or are being explored.

Modeling as a Cognitive Process of Labeling Bandura, Grusec \& Menlove (1966) had children watch complex sequences of models on film. One group of subjects watched the film, another group of subjects gave the novel verbal responses as the model gave them, and the third group counted rapidly in order that they could not verbally code the responses. The children who verbally labeled the responses did better in matching the responses than the 
children who only viewed the film or the children that counted rapidly. Dubanoski \& Parton (1971) suggest that a model may facilitate the acquisition of aggressive imitative responses by eliciting covert labeling of events.

Gerst (1971) had subjects watch a filmed model perform complex motor responses varying in the ease with which they could be verbally coded. Gerst found coding the items into vivid images, concrete verbal descriptions of the response elements or convenient summary labels that incorporated the essential ingredients of the responses enhanced observational learning. Concise labeling and imaginal codes were equally effective in aiding immediate reproduction of the modeled responses, and both systems were better in this respect than using the concrete verbal form. However, concise labeling produced the best retention of the model response. Labeling, then, appears to be better than not labeling, and concise labeling appears to be best to aid retention, especially if the model's behavior involves complex tasks.

\section{Symbolic Models}

In general, symbolic models (recordings, films, etc.,) appear to be as effective in obtaining a subject's imitative response as models who are physically present while demonstrating the behavior.

Sheffield \& Maccoby (1958) found that jet mechanics learned faster by films than by actually engaging in and being reinforced in the learning process. However, most 
studies indicate that symbolic models are as effective as live models, although symbolic models are not more effective than live models. Lovaas (1961) found that nursery school age children, after seeing models who operated aggressive toys, showed more aggressive behavior than when they saw models in films who were non-aggressive. Bandura, Ross \& Ross (1963c) found that children, after viewing live or filmed models behaved more aggressively than if they was a non-aggressive model. There appeared to be no difference between children who saw a live aggressive model or a filmed aggressive model, in their total aggressive behavior. Also, Bandura \& Mischel (1965) presented both live and verbally presented symbolic models, behavior changes were less stable over time.

Venn (1970) found that filmed models can affect vicarious fear conditioning and vicarious positive emotional conditioning, but only briefly. Bandura \& Menlove (1968) found that live models were more powerful than symbolic models on film in reducing children's fear, but they suggested that if the films included a broader range of models and aversive stimuli, symbolic models would produce as much an effect as live models. Final1y, Atkinson (1971) found that videotaped social models and reinforcement were as effective as cue presentation (asking a question) and systematic reinforcement in getting students to do more counselor suggested activities. 
In short, it would appear that, in general, symbolic models were effective in eliciting observer behavior changes, but that behavior changes might be less stable over time and that the effectiveness might depend on the place in the observer's behavioral hierarchy of the response the symbolic model displayed. Thus, symbolic models might not be as effective as live models if the responses desired were greatly inhibited.

Model characteristics

Bandura \& Walters (1963) suggest that a model is most likely to be imitated if he is perceived as having social power (which they defined as the ability to influence the behavior of others). The model with the most social power is likely to be perceived as rewarding, prestigeful, competent, and having high status and having more control over rewarding resources. Also, a warm, nurturant model is more likely to be imitated than a cold, distant model (Bandura \& Huston, 1961).

Staub (1971) suggests that nurturance has an independent effect on behavior, and subjects may have less fear of disapproval for possibly inappropriate actions. Grusec (1971) suggests that nurturance of a model encourages imitation of only neutral behavior, whereas a model perceived as powerful encourages the Imitation of neutral, self-denial, or aversive behavior. Jasperse \& van Hekken (1971) found that a model's nurturance enhances imitation of relevant, 
not irrelevant task behavior in solving Porteous Mazes. However, Hannifan (1970) found that neither different levels of power nor the presence of nurturance had significant effects on the frequency with which children imitated the experimenter. Hannifan felt nurturance increased imitation only if a child's expectation of receiving a valuable resource was unclear or unresolved.

An example of a model possessing high status due to competence is given in the Rosenbaum \& Tucker (1962) study. The experimenters told college students to guess the results of an imaginary horse race after being given the results of other "subjects" who, as models, were $80 \%$, $50 \%$ or $20 \%$ correct on guessing which horse would win on various trials. The more successful and competent the model was made out to be by the experimenters, the more the students imitated the model's behavior. The control group of subjects was reinforced for not imitating the models' behavior, and this group of subjects was not affected by the differences in the models' success rates. This confirmed the Mausner \& Block (1957) study, which suggested that students were more apt to imitate models' behavior if the model was seen as competent.

Lefkowitz, Blake \& Mouton (1955) found that when models were differentially attred in clothes to simulate high or low status people, subjects (random groups of individuals on various street corners in Austin, Texas) were more likely to Imitate the high status models. Aisch 
(1948), Maccoby (1959), Mussen \& Distler (1959), Mausner (1953), Krumboltz, Varenhorst \& Thoresen (1967), and Lipton (1971) found that models perceived as prestigeful were more likely to be imitated than models not perceived as prestigeful. Bandura, Ross \& Ross (1963a) found that models perceived as powerful were more likely to be imitated. Further, Kagan (1958) found that the desire of the individual to maximize similarity to the model was an important characteristic of the model; the observer was more likely to imitate the modeled behavior to share vicariously in resources. Burstein, Stotland \& Zander (1961) found that children accepted preferences of models as their own more readily when the models were introduced to the children as having a background similar to that of the children. Sapolsky (1960) matches subjects with experimenters on the basis of personality tests; if the experimenter and the subject had similar scores they were said to be compatible. Subjects who were "compatible" to the experimenter to whom they were assigned were conditioned better than subjects who were said to be incompatible with their experimenter. Berger (1971) found that a perr model whose expressed opinions were similar to the observer's could differentially affect the observer's perserverance on a task. McCullough (1971) found that when a teacher reinforced high school students (models) in the class for desired behaviors, the observers (other students in the class) also performed the behavior. 
McCullough also found that model group size appeared to be a non-significant variable. Satterwhite (1971) found that the percentage of observers (boys aged seven to eleven) who imitated a model depended on whether the observer and the model were similar in conceptual tempo. Also, observers tended to imitate the model more if the observers and the model had similar cognitive styles.

The above studies suggest that models who are perceived as powerful, competent, prestigeful, and similar to the observers, such as peer models, are most effective in eliciting desired behaviors from observers.

Adolescents might be especially apt to imitate peer models. Havighurst \& Neugarten (1962) found that the peer group is a powerful force to mold the behavior of other adolescents, because the adolescent is subordinate to adults, and thus, is more likely to turn to his peers who have equal status with him. Grinder (1965) suggests that parents relax controls on adolescents, and thus, peer and school models "burgeon in their salience as administrators for cultural rewards and punishments." Coleman (1961) found that in 10 high school subcultures the student subcultures centered around non-academic status and that having good grades had low status. More status was conferred on the basis of athletic success, dating success and extra-curricula activities. Gordon (1957) found that the social organizations of high schools were centered on four groups: athletic, music and club, dating, and academic. Tannenbaum (1960) 
found that the most popular student was the bright, but not studious, student who was athletically inclined. Thus, it would appear that high school students were most sensitive to and possibly respondent to the athletic and social success of their peers. (These studies were sociometric studies, without reference to a behavioral criterion.)

Peer models for adolescents do appear to be superior to adult models. Krumboltz, et al. (1967) used a tape of a low attention counselor, who did not smile or who doodled or sorted cards while counseling a student, and a tape of a high attentive model who smiled, nodded, and fully attended to the counselee. The experimenters made introductory statements to vary counselor prestiege before the subjects saw the films. The behavior of the model counselee was the same on both films. The experimenters found that the student observers primarily attended to the student model and ignored the counselor, 1.e., varying the prestige of the counselor model failed to significantly affect the observers' information seeking behavior, (the criterion measure). Also, athletic models were found to elicit observers' imitative responses. Thoresen \& Krumboltz (1968) found that subjects exposed to high success athletic models demonstrated more observer emulation than subjects exposed to an athletic model of low or moderate success, when the criterion was the amount of information-seeking behavior done in a three week period following counseling. Also, 
surprisingly variations in social success levels did not appear to produce significant differences in the extent to which students sought educational and career information. Thoresen, Hosford \& Krumboltz (1970) found that while the kind of success (academic, social, or athletic) ascribed to the model did not significantly affect the extent to which subjects increased their information-seeking behavior, the degree of athletic and academic success did. When subjects were exposed to peer models of high or medium success they carried out more, and a greater variety of, information-seeking behavior than subjects exposed to models of low success, but that low self-concept subjects, who percelved themselves as low athletically, socially, or academically, and who aspired to high success, sought more information after exposure to a low or medium success model, not to a high status model. "It may be said that the social distance between aspiring subjects and high models was sufficiently great that the model in effect became an aversive stimulus." Also, Liebert, Swenson \& Iiebert (1971) found that against low risk players, observers evaluated opponents more favorably and played less well themselves in a competitive game situation. Meichenbaum (1971) found that female undergraduates who had an extreme fear of snakes responded best to a model who first displayed fearful behavior, then coped with situation, then achieved mastery of the situation, rather than a model who mastered the situation 
immediately. Thus, not only social distance, but distance between the observer's possible mastery of the situation and the model's apparent mastery of the situation, may become in effect an aversive stimulus.

Another variable that seems to play a part in determining if subjects will acquire and perform the imitated behavior is the sex of the model. Krumboltz \& Schroeder (1965) used an eleventh grade male as a counselee, and out of nine counselors, only one was a male. It was found that model reinforcement counseling (observing a model, and then being reinforced for imitating the behaviors of the model during a counseling session) produced more of the desired response in boys, and reinforcement counseling (being reinforced for the criterion behavior while in the counseling session only) produced more of the desired criterion behavior in girls. Rosenblith (1959) found that male experimenters were more effective than females in influencing kindergarten children's behavior. Bandura, Ross \& Ross (1961) found that when one half of the subjects were exposed to a model of the same sex, and the rest of the subjects to a model of the opposite sex, an aggressive male model provided a more powerful stimulus for imitative aggressive behavior for both sexes than did an aggressive female mode1. Thoresen, Krumboltz \& Varenhorst (1965) used four types of social model audio tapes: 1) male counselor and male student; 2) male counselor and female student; 3) female counselor 
and male student; 4) female counselor and female student. For male subjects, a male counselor-male student model was most effective when presented by a male counselor. However, for females, it made little difference whether a male or female model was used; the significant variable was the sex of the counselor. Both models were more effective when presented by a male counselor. Also, Bandura (1965) found that boys produced more imitative responses than girls, especially under conditions in which the model's behavior was punished. Similarily, Brown (1956, 1952) found that boys were more susceptible to influence by male models than girls. Female subjects displayed ambivalence to the masculine role preference exhibited by the male models.

Cohen (1971) found that preschool children responded more rapidly to a male experimenter than to a female experimenter. Slaby \& Parke (1971) found that young boys who saw a filmed male peer rewarded for touching prohibited toys deviated more than those who saw the model punished. Also, response consequences appeared to have no effect on girls. Schuh (1970) suggested that girls high on social dependency imitated a model more than girls low on social dependency. Hicks (1965) found a residual effect six months after subjects saw an aggressive male model. It was interesting, however, that Newman (1971) found that high IQ first grade students performed more irrelevant task behaviors when a female model was used, but that the sex of the model did not affect low IQ students' irrelevant responses. 
Fauls \& Smith (1956) suggest that individuals learn to imitate models of the same sex because parents have reinforced sex-appropriate behavior and have punished sexinappropriate behavior. In the Krumboltz \& Schroeder (1965) and the Krumboltz \& Thoresen (1964) studies, for example, the models discussed typically male-orientated concerns and decisions, and thus, the model was more suitable for male imitation. Bandura, Ross \& Ross (1963a) found that male subjects exposed to a female controller of rewards in the presence of a powerless and ignored male imitated the male more than the female controller, although in every other treatment condition (male dominant-female consumer; male dominant-female ignored; female dominant-male consumer) the controller of resources was the more strongly imitated. Finally, Heilbrun (1964) found that adolescent males raised in homes of more masculine and nurturant fathers displayed more sex-appropriate behaviors than did males raised in less masculine and less nurturant homes.

Finally, it appears that models actually performing the behavior rather than just describing the behavior are more effective in getting observers to imitate the model's behavior. Thoresen \& Hamilton (1969) used eleventh grade male students as subjects and video presented a peer social model to some subjects, and video presented a peer social model and a set of structured stimulus materials to other subjects, and then had the subjects take a knowledge test and a slinulated vocational test, and tallied the frequency and varicily 
of career exploratory behavior performed by the subjects. They found that no one treatment was effective consistently across all schools. In this study the models only talked about the behavior to be performed, but did not perform it. In summary, it appears that, models who are perceived as rewarding, prestigeful, competent, having high status and having more control over resources, and as warm and nurturant are more likely to be effective than models not possessing these attributes. Also, models perceived as being similar to the subject, and especially peer models when adolescent subjects are involved, appear to be most effective. However, when a model is perceived as being quite different from a subject, the model can become an aversive stimulus to the subject. Also, perhaps because boys are reinforced for masculine sex-role behavior imitation when growing up and girls are reinforced for female sex-role behavior imitation, male subjects usually imitated male models, even if the model was perceived as powerless and ignored. However, female subjects displayed ambivalence to the masculine role preferences exhibited by male models or were sometimes more apt to imitate the behavior displayed by a male model (perhaps because the female is generally taught to look up to males as leaders). Finally, models who actually performed the criterion behavior were more effective than models who only described the criterion behavior. 
Characteristics of Subjects Influenced by Models

Subjects are more likely to imitate a model's behavior if they perceive themselves as incompetent (Kanareff $\&$ Lanzetta, 1960), and lacking self-esteem (deCharms \& Rosenbaum, 1960; Gelfand, 1961), although Tasch (1971) found no evidence that low esteem preschool children in a Head Start program did not imitate a model more than high esteem preschool children. However, Tasch did find that high esteem subjects imitated verbal task instructions more, and that high esteem subjects were more attracted to the model. Also, subjects are more apt to imitate a model if they are dependent (Kagan \& Mussen, 1956), and are frequently rewarded for imitated behavior (Lanzetta \& Kanareff, 1959 ; Miller \& Dollard, 1941). However, Thoresen, Hamilton \& Bergland (1969) found that the imitative behavior of eleventh grade males was not related to perceptual field organization (independence-dependence) or personality type (intraversion-extraversion). But Lipton (1971) found that a field dependent subject imitated a model more than a field independent subject (the subjects were kindergarteners). Also, when subjects perceive themselves as similar to the model they are more likely to imitate the model's behavior (Burstein, et a1., 1961, Berger, 1971, and Sapo1sky, 1960). However, Thoresen, Hosford \& Krumboltz (1970) suggest that low self-concept subjects who perceived themselves as low academtcally, socially, or athletically; but who aspired to 
high success, sought more information (the criterion behavior) after exposure to low or medium success models, because, as the authors suggest, the social distance between the aspiring subjects and the high success models was sufficiently great that the models, in effect, became aversive stimuli.

Sex of the subject also plays an important part in determining if the subject is likely to imitate the model. Krumboltz \& Schroeder (1965) used 54 high school juniors and tried to obtain information-seeking behavior from these subjects. The subjects heard an audio tape of a counselorstudent interview in which the male counselee modeled the desired behavior and was verbally reinforced by the counselor each time he displayed the criterion behavior. Then the subject himself was rewarded by the counselor in an interview when the subject gave verbal responses that indicated that he was imitating the model's behavior. Another group of subjects did not hear the tape, but were verbally or nonverbally rewarded by the counselor for criterion behavior displayed when in a counseling session. Three weeks later a follow up interview was held, and the experimental subjects were asked what information-seeking behavior they performed outside the counseling situation. It was found that the experimental subjects did more of this behavior than the controls. Also, female subjects who received reinforcement counseling only, but did not see a mudel, did more external information-seeking behavior than controls, hut this result did not hold for males. Models and reinforcement counseling 
produced more external information seeking behavior among males than controls, but not among female experimental subjects. However, eight of the nine counselors involved in this study were females. Krumboltz \& Thoresen (1964) replicated and extended the above study by using dyadic or small group settings. The model reinforcement and the reinforcement groups were once again more significant in affecting information seeking behavior than the controls. Also, once again, the model reinforcement counsel ing (saw models and then received reinforcement for imitation in a counseling situation) produced more of an effect on males than reinforcement counseling. It was interesting that group model reinforcement counseling also was more effective on males than individual model reinforcement counseling.

Atkinson (1971) found that tenth grade girls responded best to cue presentation (asking questions to elicit the desired response) and systematic reinforcement, and boys responded best to a videotaped social model plus reinforcement, when he desired the students to perform counselor suggested activities. Bandura (1965a) found that children who observed a model who was either generously rewarded or was not given any response consequence after performing a sequence of novel physical and verbal aggressive responses spontaneously performed a greater variety of imitative responses. Boys produced more aggressive responses than girls, especially when the model was punished fur cxhibiting aggressive actions. If a reward was given to all children 
to imitate the models' behavior, no sex difference appeared. These studies indicate that internalized social norms can alter the effect of the model, i.e., boys have fewer restrictions on them than girls, and boys felt freer to openly express aggressive behavior than girls, even in the situation where the model was punished for aggressive behavior. Finally, if boys in a group can agree to change their behavior (modify rules) to behavior which perhaps is not so maleorientated, such as information-seeking, as opposed to athletic powress, the males will be more likely to exhibit the behavior, although if the treatment is applied to each one singly, the individual boy may be afraid that if he performed the behavior which may not be strongly identified as "masculine", his behavior will not conform to the norm, and he may loose status. However, Newman (1971) found that high IQ subjects ( 110 or above) performed more taks relevant, imitative responses regardless of the sex of the model or of the subjects, but that high IQ subjects produced more irrelevant behaviors when a female model was used.

The attitude or affective state of the subject may influence his adoption of the model's behavior. Patterson, Littman \& Brown (1968) found that "negative set" which was measured by the number of times a child altered his initial choice on a picture preference test after an adult model made the same choice, was significant in influencing hohavior. 
It was found that the model had little effect on children who had high "negative set". Agosta (1971) found no significant difference in aggression due to pre-model treatment of verbally attacking the subjects (undergraduate males) by an accomplice, or the aggression (low, medium or high) of the model. However, there was a correlation between overt aggression and the subjects' rating of their own interpersonal aggression and hostility and guilt.

The race and the socio-economic status of ths subject may be important variables. Price (1971) found that lower socio-economic males (fifth to eighth graders) had more physical self-esteem and percelved hostility from white females. Price felt that as lower socio-economic males grow older they tend to interpret a white model as hostile to blacks. Baker (1970) found that middle class children made most imitative responses, and low socio-economic boys in a Head Start program made least imitative responses. However, children will imitate a model's behavior if instructed to do so, and although incentive-orientated instructions had a significantly positive effect for lower socio-economic girls, they did not have this effect for lower socioeconomic boys.

In short, if the subject perceives himself as incompetent, lacking self-esteem, dependent, and is frequently rewarded for imitative responses, and aspires to high success but does not percelve himself as extremely different from the 
model, he is more likely to imitate the model's behavior. Also, the sex of the subject plays a part, perhaps influenced by the subject being rewarded for performing and imitating behaviors "appropriate" to his sex and being punished for performing deviant behaviors; adolescent boys in groups who see models and are then reinforced for imitating the model's behavior are more apt to imitate the model's behavior than Individual boys in the same process or boys who only get reinforcement and do not see models. Also, boys are more likely to imitate male models, even when the male model is ignored or punished for his actions. Finally, race and socio-economic status and the affective state of the subject may influence the subject's decision to adopt the model's behavior.

Internalizing a Model's Standards

Subjects who observe models may change their moral behavior. Bandura \& McDonald (1963) used children who exhibited a predominate subjective moral orientation as subjects. The children then either observed adult models who expressed objective moral judgments, or had no exposure to the adult models, but were positively reinforced whenever they expressed objective moral judgments that ran counter to their dominant evaluative tendencies. The provision of models was found to be highly effective in altering the chfldren's judgmental responses. The reinforcement procedure alone did. 11ttle to change the children's 
judgments. The authors felt that in the latter case the subjects lacked the response or the response was very low in the subjects' behavioral repertoire. Thus, it is possible for models to cause a change in subjects' moral judgments. The prototypic experiment in this area was done by Bandura \& Kupers (1964). The model adopted either a high or low criterion for the task he performed. If his criterion was low, he expressed posttive self-evaluations when he met it. When the criterion was high, he denied himself reinforcement and acted in a self-derogatory way. 'The observer then performed the task and received a predetermined range of scores. The scores were recorded for the performances the subjects rewarded themselves. If the subjects saw a low standard model, they had high selfreward for mediocre performances. If the model was stringent in giving himself rewards, the subjects denied themselves reward and were dissatisfied with themselves for their performances, while the other group had given themselves rewards for simflar performances. Thus, people generally adopted the standard for reinforcement exhibited by the models, and evaluated their own performance relative to the performance standard, and served as their own reinforcing agent. Also, peer models were less effective in setting standards of reinforcement of low-level performances, because the subjects took more magnitude of rewards than taken by the model. 
Self-standards are generally quite high. Bandura \& Perloff (1967) did an experiment in which one group was given a reward when the subjects reached a set standard score, a second group of subjects selected their own achievement standard, a third group did the task and received reinforcement on a non-contingent basis, and the fourth group had no incentives to estimate the amount of behavior they should perform. The self-monitored and the externally imposed reinforcement groups sustained behavior longer, and there was no difference between the nonreinforcement and noncontingency reinforced groups. The self-monitored groups imposed higher standards for themselves: half the children chose the highest possible achievement level to be rewarded for and one-third of the children later altered their standard to a higher level. Thus, with a self-reinforcement system, higher standards of behavior are usually set.

other studies show that self-standards can be modified through modeling procedures. Carlin (1965) found that young children showed more deferred gratification if they saw an adult model display positive affective reactions while waiting for delayed reinforcement than if the children saw models express an emotional reaction and devalued their goals. Lovaas (1966) found that self-reinforcement gradually replaced social reinforcement, which in turn replaced food as reinforcement for autistic children to imitate verbal responses when trying to improve their speech. However, 
Malcolm (1971) found that if the subjects (fourth grade males) had previously made objective moral judgments, either an adult or peer model influenced their moral judgments, but watching models produced no change in subjects who made subjective moral judgments. Thelen \& Fryer (1971) found that 96 black and Caucasian 15-17 year old male delinquents, after observing either a black or a Caucasian model who employed liberal or stringent standards of selfreinforcement, even given explicit normative data, clearly imitated the self-reward standards of the model. In addition, both black and Caucasian subjects imitated a liberal Caucasion model more than a liberal black model, but imitated the stringent black and Caucasian models about equally. An evaluative semantic differential rating of racial attitudes showed little relationship to the imitation of self-reward.

People also reinforce others differently after observing a mode1. Marston (1965) found that adult subjects reinforced other people at a higher rate after observation of a high self reinforcement rate model. Mischel \& Liebert (1966) found that the criteria observing subjects imposed on other children was identical with the criteria they imposed upon themselves. Harris (1971) exposed third and fourth graders to a model who shared with them, gave to a mental health charity, or refused to share. He found specific and generalized imitation by the children. Altruism 
and salience of sharing appeared to be strongly related to actual sharing and weakly related to experimental conditions.

Previous success or failure also seems to influence a person's self-standards. Bandura \& Whalen's (1966) study had subjects succeed or fail on games that "measured" physical strength, problem solving ability or psychomotor dexterity. Models then set high, moderately high or low criterla for self-rewards on a minature bowling game. Subjects whose scores were set high on the minature bowling game with high prior success experience were not influenced by their past experience of success or failure. Of subjects whose scores were set low, subjects who had prior failure experience rewarded themselves less after seeing the inferfor models, and children in a prior success condition took more rewards than these who observed equally competent superior models. This study suggests a complex interaction between modeling cues, prior history and current performance as determinants of the adoption of criteria for self reward.

Bandura, Grusec \& Menlove (1966) found that observation of model reinforcement based on strict self reinforcement criterla resulted in adoption of more stringent criteria, while model nurturance and additional exposure to lenient peer models led the subjects to adopt more lenient criterla for self-rewards. It would appear that model nutturance and peer models influence the adoption of selfreinforcement criteria. 
Liebert \& Allen (1967) found that pairing rules for appropriate self-rewards with observations of such behavior in a model tended to affect verbal and material selfrewards differently. Increased structure increased the children's self-administration of verbal praise and criticism, and decreased the self-administration of tokens that were exchangeable for packaged prizes. The magnitude of the available reward did not affect the frequency of the child taking undeserved self-rewards. Thus high structure of rules increased self-rewarding verbalizations, with verbal behavior similar to that of the model, but lowered the amount of physical reward (tokens).

Therefore, observation of models can cause a change in subjects' moral judgments and in the criteria for which they will reward others. Self-standards are generally rather strict. Previous success or failure experiences, current performance, model nuturance and type of model (peer or adult models influence subjects who are children differently) appear to have an influence on the adoption of criteria for self-reward. Also, the amount of structure in the rules (such as the model verbalizing the rules) seems to influence the subjects to adhere more strictly to the rules, although stricter rules increased verbalizations of praise and criticisms, but decreased the amount of physical reward taken. These interactions and the amounts of structure in the rules should be researched further. 
Other Favorable Conditions for Subject

Performance of Modeled Behavior

Performance of the modeled behavior. The models must perform the behavior, not just describe it or talk about it. Thoresen \& Hamilton (1969) found that when models only talked about the criterion behavior, no one treatment was effective across all schools consistent1y. Frankel (1971) found that just giving a list of counseling skills to students did not affect their counseling behavior, although videotape modeling and videotape feedback, or a combination of the two did affect student micro-counseling behavior. It is interesting, however, that either a single presentation of a videotape model or videotape feedback, or a combined videotape model and videotape feedback increased only the frequency, not the accuracy, of counselor focus on client feeling in the micro-counseling situation. Goldberg (1970) also found that modeling was more effective than just giving instructions, and that seeing a model and receiving instructions was most potent in teaching complex verbal interviewing skills. Finally, Lewis \& Baker (1971) found that seeing a video-tape model talk about educational information-seeking to a friend who gave verbal reinforcement, or seeing a model describe his activities and scenes illustrating his activities, did not affect the total number of resources named or used by male undergraduates. Modeling and guided participation. Modeling and graduated guided participation seems to be more effective 
than desensitization, or just observing a model if the criterion response is quite inhibited. Bandura, Blanchard \& Ritter (1968) used adolescent and adult subjects who had a phobia of snakes. A pretest was taken by rating each subjects' behavior with a snake, and then subjects were matched on the basis of their scores to a group. The first group saw a film which depicted a child, adolescent and adult engaging in progressively threatening interaction with a large king snake. The subjects had been taught relaxation techniques and each subject had a remote control for starting and reversing the film. If the subject was anxious, he stopped and reversed the film and saw the whole sequence until he was not anxious. This, then, was the self desensitization group. A second group of subjects saw a model gradually approach the snake and interact with it. At each stage the subjects were to perform the actions of the model, and if they could not, the model helped them do it until they could do it alone. This was the graduated model and guided participation group. A third group used Wolpe's desensitization techiques, and the fourth group, the control group, had no treatment.

The results were that in group one there were substantial reductions in the subjects' avoidance behaviors. In group two, $92 \%$ of the subjects had extinguished their avoidance response and were not anxious. Group three (desensitization) subfects had less emotional arrousal when 
going near the snake, but they were more anxious than subjects in groups one and two. In group four (control group) there was no change. Furthermore, the subjects generalized the extinction of emotional arrousal and avoidance responses from the treated stimuli to related anxiety-evoking stimuli (a familiar and an unfamiliar snake were used in the tests). They were also able to cope with other anxiety-evoking scenes better, probably because they experienced the positive reinforcement of success. At the end of the experiment, all subjects who could still not go near the snake were given treatment two (guided participation), and all subjects extinguished their fear. A one month follow-up was performed and the subjects still did not fear the snake. The effect had generalized to real life situations. It was hypotheslzed that the participant model had an effect in three ways: 1) the observer saw the behavior exhibited and the model was not punished for it; and 2) incidental information was received about the feared object; and 3) the subjects had direct personal contact with the feared object and there were no bad effects, and thus, they were not rewarded for their avoidance behaviors.

Blanchard (1969) explored the above hypothesis further. He matched subjects in terms of their snake avoidance behavior, and found that observing a model contributed $60 \%$ of the behavior change, and $80 \%$ in changes in attitude and fear arrousal; and guided participation gave the remaining increment of $90 \%$. Just giving information about the feared 
object had no effect. In Ritter's (1969) study, acrophoblc subjects saw a model climb increasingly higher. The model then helped the observing subfect do the same thing. This modeling and guided participation group showed the most change. Another group saw the model demonstrate the desired behavior, and then heard the model tell them to perform the desired behavior. This group showed the second most amount of change. A third group just observed the model performing the desired behavior, and this group showed the least change. Bandura (1969, P. 192) conceptualized modeling and guided participation as follows: "Repeated modeling of approach responses decreases the arousal potential of aversive stimuli below the threshold for activating avoidance responses, thus enabling persons to engage, albeit somewhat anxiously, in approach behavior. Direct contact with threats that are no longer objectively justifled provides a variety of new experiences that, if favorable, further extinguish residual anxiety and avoldance tendencies. Without the benefit of prior vicarious extinction, the reinstatement of severely inhibited behavior generally requires a tedious and protracted program. After the approach behavior toward formally avolded objects has been fully restored, the resultant new experiences give rise to substantial reorganization of attitudes. Thus, when strongly inhlbited responses are the criterton behavior, modeling and guided participation produce the best effects." 
Utilitarian value of the modeled behavior. Bruning (1965) suggests that imitation of behavior is governed by its utilitarian value. If the subject sees the model reinforced, for example, with candy, but the observer does not want the candy, he will not perform the desired behavior. But if the reward the model receives is desired by the subject, he will imitate the model's behavior, especially if he perceives the model as being competent. Stugart (1971) found that the treatment consisting of a rewarded model produced more vocational information-seeking behaviur, and that there was no difference among subjects due to race (black or Caucasian) or age (peer or adult) of the model. Another important factor concerning the utilitarian value of behavior is whether the subjects are reinforced for imitating the model's behavior. Masters \& Morris (1971) found that four year old girls and boys contingently rewarded by a model showed more subsequent general imitation than children receiving non-contingent prepayment. Finch (1971) found that observers receiving direct monetary or social reinforcement imitated the model more than observers receiving vicarious monetary or social reinforcement. Thus, direct reinforcement appears to be more potent than vicarious reinforcement. Also, subjects in the vicarious social reinforcement treatment imitated the model more than subjects receiving vicarious monetary reinforcement. Dohme (1971) suggests that the effects of direct and vicarious 
reinforcement are independent and that imitative behavior occurs most when both sources of reinforcement are maximized.

On the other hand, if the model is not reinforced for a behavior, the subjects will not perform it. Bandura, Ross \& Ross $(1961,1963 c$ ) found that when the subjects saw the model punished for aggressive behavior, the subjects were more likely not going to imitate the behavior, but the subjects, when asked, could describe the punished behavior with great accuracy. Also, if subjects are reinforced for not imitating the model's behavior, the subjects are not affected by the model's behavior. Rosenbaum \& Tucker (1962) presented models as being $80 \%$, $50 \%$ or $20 \%$ correct in predicting the outcome of imaginery horse races, and the subjects imitated the models who were perceived as most competent, except for the subjects who were reinforced for not imitating the model's behavior. Finally, the subjects must be able to discriminate the cues for the appropriate behavior and what the appropriate behavior is. McDavid (1964) found that when groups of children were rewarded for imitating the model's behavior or for responding to a color cue, both groups learned the task equally well. However, a third group was rewarded inconsistently, sometimes for imitating the model's behavior and sometimes for responding to color cues. These subjects were confused and in general, resorted to blindly imitating the model. Britt (1971) suggests that subjects in an ambiguous, competitive 
situation tend to imitate confederates of the experimenter to the extent the confederates are perceived as competent, and that the relationship between the probability of reinforcement and the imitation grows considerably stronger when stooges agreed on their behavior. Britt also suggests that stable consistent social stimuli are imitated more than inconsistent social stimuli, and that credibility appears to be the crucial variable.

Subject practice of modeled behavior. Bandura (1969, p. 142) suggests that if a lot of motor factors are involved in the model's behavior, overt practice is needed for the observer to perform the criterion behavior. For example, an opera singer may see and hear his teacher perform a piece from an opera, but unless the opera singer has practiced, and has a wide enough range, etc., he may not be able to imitate his teacher. Covert rehearsal enhances retention of the modeled behavior (Michael \& Maccoby, 1961; McFall \& Lillesand, 1971). Also, symbolic rehearsal significantly improves later performance (Morrisett, 1956; Perry, 1939; Twining, 1949; Vande11, Davis \& Augston, 1943). Finally Berger (1966) suggests that the majority of observers practice the response while they are observing the model's performance. The retention of the imitated response is a function of the magnitude of the practice the observer performs, either overt or covert, and the observer performs this practice even if he is told by the experimenter he will not be required to perform the modeled behavior later. 
Dominance of the modeled behavior. The more dominate the behavior is in the subject's behavioral repertoire, the more likely the subject is to perform the imitated hehavior. Bandura \& Huston (1961) used children as subjects. Some subjects had a warm nurturant session with the model hefore observing the modeled behavior and some subjects had a non-nurturant session, where the model ignored the child. Subjects who interacted with the nurturant models exhibited more of the model's stylistic behavior than the children who had a session with a non-nurturant model. However, there was a high rate of aggressive responses made by the subjects regardless of whether the model was nurturant or nonnurturant. Smith \& Marston (1965) agree that when the critical response class includes many class members already in the subject's repertolre, there was greater ease of conditioning through vicarious reinforcement. This was found in an experiment which found that the use of high frequency words resulted in better learning than the use of low frequency words, because there was greater clarity of the response-reinforcement contingencies, and thus, information was provided more quickly when high frequency words were used. Also, Bandura \& Barab (1971) found that kindergarten children continued to perform nonrewarded matching responses which were difficult to discriminate from rewarded imitations, and discontinued imitative responses which were easily distinguishable from rewarded behaviors. Other 
important factors are that the model increases his own effectiveness over trial blocks (the model is seen as more competent), and in particular, that the behavior occurs during acquisition. McDonald (1970) suggests that although modeling is most effective in early phases, learning and feedback systems are needed to maintain the learning. Kanfer \& Duerfeldt (1967) found that vicarious trials early in the subject's own acquisition process yielded benefits similar to those obtained in direct reinforcement trials, although vicarious trials late in the subject's own acquisiton had a disruptive effect: model competence alone did not affect learning significantly.

The presence of other people. Kanfer \& Marston (1963) had college students respond alternately with another subject on a verbal learning task. The co-learner was actually a tape-recorded confederate whose responses were experimentally programmed. Following an appropriate response by either the model or the subject, correct responses were verbally reinforced by the experimenter according to the treatment condition. It was found that listening to a tape of a reinforced model was sufficient to produce significant learning, and in fact, the further addition of reinforcement for the subject did not greatly enhance learning. On the other hand, when the model gave the same verbal response but was not reinforced, subjects did not imitate the model's verbal behavior. Krumboltz \& Thoresen (1964) found that 
boys in small groups were more apt to perform the criterion behavior than if taken Individually, after first observing a model and then being reinforced for the behavior. However, Marston \& Kanfer (1963) found that decreasing the proportion of reinforced vicarlous responses by adding group members resulted in significantly slower learning. Once again, the addition of direct reinforcement to vicarious reinforcement did not signiflcantly increase learning (in the same verbal conditloning task as mentioned above). The number of people needed to maximize vicarious learning needs to be further investigated, although the addition of at least one other person (i.e., to run the subjects in groups) who is reinforced for his behavior apparently increases the effect of vicarious learning. Zajonc (1965) suggests that the mere presence of another organism increases general arousal level, and hence acts as an energizer of all response tendencies, and this is one hypothesis which may account for the increased vicarious learning.

Emotional arrousal of the subject. The emotional arrousal of the subject is a concern. For, example, Janis \& Mann (1965) used heavy smokers as subjects and had the subjects play the role of patients being told by a "doctor" (the experimenter) that they had developed lung cancer. The subjects were guided to include emotional expressions assoclated with threat of pain, hospitalization and early death. A comparison group 1 istened to the tape recordings 
of one of these sessions, but did not play the role themselves, and a control group was simply given the same reports on smoking behaviors and attitudes. Even at an 18 month follow-up, the subjects who had participated in emotional role-playing showed significantly less cigarette consumption than the other groups of subjects (Mann \& Janis, 1968). A cognitive role-playing procedure, in which subjects enacted a debate and argued against smoking, was also less effective in changing smoking habits than the emotional roleplaying (Mann, 1967). Information alone about the results of smoking decreased smoking only temporarily in untreated controls (Mann \& Janis, 1968). Lichtenstein, Keutzer \& Himes (1969) found, after repeating Janis and Mann's experiment, no clearcut advantage of role-playing over passive listening to a taped role-playing session, although some attitude changes were found for subjects in both groups. They suggest that the Surgeon General's Report came out in 1963, after the Janis and Mann data were collected, and this altered the situation and the subjects were probably better immunized or defended against fear manipulations. DiLollo \& Berger (1965) used female college students as subjects. The subjects observed a model who supposed1y was shocked during a series of trials in an alleged reaction time experiment. For some subjects the model manifested pain cues by moving her arm, while other subjects only observed the alleged administration of shock and the model did not move. Controls witnessed movement or no movement 
by the model but were not told the model had been shocked. Reaction time of the subjects on the same task was much shorter when both shock and movement had been vicariously experienced. When the model gave no pain cues, the observer's reaction time was not affected. When the model gave no evidence of the presumed shock by arm movements, 23 of the 25 subjects on postexperimental questioning expressed their belief that the performer had recelved only a mild shock or was not shocked at all. Thus subjective interpretation by the observer may have been sufficient to reduce vicarious arousal in the presence of a scene in which aversive stimulation was alledgedly given to the model. Thus, it appears that the subject must be arroused emotionally in order to perform the imitated behavior, and to retain the imitated behavior. However, Bandura and Rosenthal (1966) found that when subjects were highly arroused, and observed a model who alledgedly was shocked and exhibited pain cues, the subjects attempted to divert their attention away from the model's pain by generating competing responses, such as thinking about something else. Craig (1968) and Craig \& Wood (1969) found that direct arousal (as versus imagined stress and vicarious stress) produced changes that lasted over a Ionger period of time. Respiration rate increased during the vicarious and imagined conditions, but decreased during the actual experience. Heart rate increased for the direct stress and imagined stress conditions, but not for the 
vicarious condition. Skin conductance measures showed greater increases with direct experience, than with vicarious experience, but the imagined stress did not differ significantly from either the direct or vicarious condition. For example, Waldman (1971) found that nonaggressive models reduced subsequent aggression of observers on1y when subjects were not subjected to prior anger arrousal against the victim. Also, motion pictures can raise psychological stress (Lazarus, Speisman, Mordkoff, \& Davidson (1962), and observing a mode] failing or succeeding can change autonomic functioning (Craig \& Weinstein, 1965; Kobasigawa, 1965). Therefore, the emotional arousal helps determine what cues the subjects pay attention to and the acquisition and retention of behavior. Emotional arousal can be caused by observing a model's success or failure, or from perceptions of direct, vicarious or imagined stresses, such as seeing movies of models, and physiological autonomic functioning can be measured to try to determine the amount of arousal. However, highly aroused subjects may try to ignore the model; the optimal level of arousal when observing a model must still be looked into.

Modeling more effective than shaping. O'Connor (1971) compared modeling and shaping (social reinforcing). Sixty social isolates from four nursery schools participated in the study. Half of the students saw a modeling film depicting proper social behavior, and the other half of the subjects 
saw a regular film. Then half of each group was shaped for peer interaction. $0^{\prime}$ Connor found that the modeling effect with the film was most powerful, that shaping did not further enhance the modeling effect, and that shaping alone produced some interaction against the group by some individuals. Also, the modeling effect was more rapidly found than the shaping effect, and the shaping effect was somewhat unreliable. Finally, modeling and shaping were found to be more efficient than shaping alone.

Summary. If the models perform the behavior and not just describe it, if the subjects are in groups (for males especially), if the subjects are emotionally aroused to the extent that they pay attention to modeling cues, if the subjects perform the behavior and the affective state associated with the criterion behavior, and if the subjects rehearse the behavior; all of these help determine if the subject will perform the criterion behavior. Other probable determinants are the place in the subjects' behavioral hierarchy the criterion response elements are; whether the subject is able to adequately discriminate what the desired response is and when to make it; and also, if the observer sees the model while in the acquisition phase, the observer is more likely to perform the criterion behavior.

\section{Duration of Effect}

Bandura, Ross \& Ross (1963c) did an experiment to determine whether a symbolic model was as effective as a 
live model, and it was found that they were when the criterion behavior was aggressive behavior. Hicks (1965) replicated the above study and did a follow-up six months after the initial experiment, and found that there were small residual effects, especially when the model was a male. Also, Mann \& Janis (1968) did an eighteen month followup of subjects in an experiment that explored the effectiveness of emotional role-playing, listening to a tape of roleplaying: or reading about the dangers of smoking, to inhibit the subjects from smoking. They found that emotional role-playing subjects showed signiflcantly less cigarette consumption than the other groups of subjects. However, most studies determinedif an effect existed immediately after the treatment, or at most, included a follow-up one month later, such as Bandura, Grusec \& Menlove (1967) who found that after the treatment nursery school children's fear of dogs was reduced, and the fear was still reduced one month after the treatment. Thus, this area needs further exploration.

\section{Conclusions}

First, no one theory explains all vicarious learning. This, it might be best to divide studies on the following basis (Kanfer \& Phill1ps, 1970, P. 193-195):

1. Matched-dependent designs which require the subject to follow the example of a leader, with rewarding consequences for the subject. The subject is rewarded either directly or indirectly for coyping or by the achievement of a reward for which the imitative behavior is essential. 
2. Identification studies which deal with the acquisition of non-instrumental idiosyncratic behaviors of a model by an observing subject. In the context of the subject's performance some specific instrumental responses may be rewarded, but imitation of the model's style is the target of direct reinforcement.

3. Co-learning designs which study the effects of observation of the performance of a model engaged in the same learning task as the subject, usually with alternate opportunities for watching and doing. Influence of social motivation and utilization of observed information are evaluated in the observer's performance increments.

4. No-trial learning designs which examine subject behaviors following observation of a model, without apparent practice or contingent reinforcement of the observer's performance. The observer is given the opportunity to perform the same task as the model and the occurrence of instrumental and stylistic imitative responses can be measured.

5. Vicarious classical conditioning designs which study the responses of a subject witnessing the administration of an unconditioned stimulus for an emotional response, or the response itself. The impact of observation of contitioned emotional states in others on the subject's further observation, learning and performance can be measured.

Second, vicarious learning appears to be a central process, and concise labeling helps to retain the response, although for immediate recall, any type of labeling is superior to not labeling the model's performance.

Third, if a response is fairly high in the observer's behavioral repertoire, symbolic models are as effective as live models, for immediate recall of the behavior, but over periods of time, there is more retention when live models are used. If the response is low in the observer's hierarchy, symbolic models are not as effective as live models, but it is suggested that this may be overcome by using films which display a wide range of models and stimuli. 
Fourth, if a model is perceived as rewarding, prestigeful, competent, having high status, having control over resources, and being warm and nuturant, he is more likely to be imitated. Male models appear to be more potent than female models, especially for male subjects. If the model is perceived as being similar to the subject, he is more likely to be imitated, and indeed, teenage subjects are more likely to imitate their peers than an adult model. Finally, when models actually perform the behavior, and not just talk about it, they are more likely to be imitated. Fifth, if a subject perceives himself as having low competence, lacking self-esteem, and thus, aspiring to success, and if the model is not considered so very competent that the subject cannot emulate him, the subject is more 11 kely to imitate the model's behavior. Also, particularly for males, subjects run in groups are more likely to imitate the model's behavior than if the subjects are run singly, especially if the modeled behavior is not strictly defined as "masculine". Also, the subject's affective state is important, he must be willing to observe and to perform the modeled behavior.

Sixth, it is possible to modify a subject's selfstandards, by observational learning. This may also change the way he treats others. However, the model must be consistent: he must talk about and do the behavior he mentions, if he is inconsistent, he is not likely to be 
imitated. If the rules are clearly defined, the sulject appears to give himself more verbal praise, but less physical reward (such as tokens). This may be a method to have lower class children stand for delayed, rather than immediate gratification; to modify a subject's standards if he has more ability than he thinks he does, such as a very intelligent person deciding not to go to college, etc. However, this also demonstrates that it may he easy to impose one person's standards on other people, and the extent and duration of modifying subject's self standards should be further looked into.

Seventh, other conditions that appear to play a part in vicarious learning are the utilitarian value of the imitation of behavior. If the behavior will achieve a desired reward 1t will probably be imitated; if it will not, it will most likely not be imitated. The discriminahility of what the behavior to be imitated is and when to do it, is important; it was found that if cues are confusing the subject may blindly follow the model's behavior. Also, practice is needed, either overt or covert, to enhance the effects of imitation, and the person's arousal is necessary to observe the model and to desire to perform the action. If the response is high in subject's behavioral hierarchy it is easier to elicit; and if 1 t is not, modeling and guided participation appear to be most forceful in achieveing an effect. 
Finally, little work has been done to observe the duration of the effect of vicarious learning, and this must be looked into more fully.

In short, more work must be done in this field to determine such constructs as the duration of the effect, the amount of arousal needed to achieve maximum results, whether a symbolic model can be made as effective as a live model, exactly how much more competent than the subject the model should be to achieve maximum results, and also, what controls can be put upon imitative learning. It was also shown that subjects may internalize the standards of models. Indeed, Wilkins (1971) suggests that vicarious learning of contingencies of behavior through instructed imagination alone is needed for desentization therapy. Therefore, it is necessary to study vicarious learning more thoroughly.

\section{Driving Simulators}

Change in the subjects' behavior in the desired direction is expected after the application of behavior modification techniques. In the following driver education studies, it is hypothesized that students, after the experimental treatment, will tend not to release their strong emotions while driving. In either case, in the event of an accident, the experimenter and/or the subjects' high schoul may be held liable. Therefore, it was decided to test for possible changes in driving behavior by using driving simulators rather than cars. 
Schuster (1971) did several studies using the Link simulator of Singer General Precision, Inc., Model No. SS-6 12. He found: 1) that the validity of the simulator in training experienced drivers to improve their skills is suspect; 2) the simulator performance criteria (error count by type) are marginally satisfactory in reliability and need improvement: only the brakes criterion is acceptably satisfactory at this time and work needs to be done to improve the steering, signals, and speed criteria; and 3) the simulator performance measures must be considered as independent criteria; it is a mistake to add them to get a total errors criterion. Kimball, Ellingstad \& Hagen (1971) found that various groups of subject with differing levels of driving experience could be reliably discriminated on the basis of a battery of psychomotor performance measures, when using a point light source simulator and validating it against on the road criteria. These experimenters felt that a multivariate approach to analysis and evaluation of the driving task should be undertaken: one should not test just isolated skills. Edwards, Hahn \& Fleishman (1969) found there were some significant relations between perceptualmotor performances and simulator performances, but that there was a higher similarity between the drivers (300 taxi operators) performances on two simulators. Further, age and driving experience were found to be the more consistent predictors of simulator performance. 
In short, although the reliability and validity of driving simulators is much lower than optimum, driving simulator performances were used as a criterion measure because of the concern (and possible liability) for the student subjects injuring themselves while driving a car.

\section{Summary}

From the literature review it is evident that young drivers, age 15 to 24 , have a disportionate number of automobile accidents. The circumstances of these accidents generally do not involve the highway or mechanical defects of the car. The young drivers who have accidents or are traffic fatalities tend to have trouble in school. Many studies indicate that they also are likely to have personality problems, lack emotional control, and may act out their depressions, elations, frustrations, anger, etc. while driving. It appears that the relationships between emotional control and safe driving have not been extensively presented in most driver education courses.

Thus, the major dimensions of the present study emerge from the review of research in safety education: if young male drivers can be taught to control their behavior while under emotional stress, the number of accidents in this group should be reduced. It is hypothesized that young drivers can be taught via behavior modification procedures to use alternative behaviors which preclude the high risk driving behaviors generally associated with emotional stress. 


\section{Statement of the Problem}

The principal problem of the following studies was the preliminary development and evaluation of a new aspect of curriculum in high school driver education courses; emotional control in relation to driving. In particular, behavior modification techniques generally used in clinical situations were modifled for use in high school driver education courses. The modifications of the behavior modification techniques were then evaluated as to effectiveness in teaching emotional control in relation to driving in high school driver education courses. Then a systematic program based on the modified behavior modjfication techniques was developed, and was evaluated with driver education students who were most 11kely to have accidents; i.e., high school students from lower socio-economic families with lower grades, particularly males.

The ultimate purpose of the development of this new aspect of high school driver education courses was to reduce the motor vehicle accident property damage, personal. injury, and mortality rate among young drivers. 
CHAPTER II

METHODS

Since behavior modification techniques have generally not been used in driver education courses, several preliminary trials were made to adapt behavior modification techn:ques for this purpose. Two techniques were employed for modifying driving behavior: (1) Emotional role-playing, in which the subject is told to imagine, act and feel himself in a given situation; and (2) demonstrations, in which a driver with a poor driving record describes a situation in which he has had an accident and then performs the driving behaviors which would have prevented the accident.

Subjects for these preliminary trials were from two available pools of subjects; a rural high school with many students from lower and lower middle class families, and a college driver education methods class composed mainly of seniors.

In addition to the preliminary studies, two quasiexperimental studies were done in which emotional roleplaying, trigger films (used to stimulate discussions on how emotions relate to driving behaviors), reciprocal inhibition (getting students to perform an action which precludes driving when under great emotional stress), and demonstrations 
were combined. The subjects for these two studies came from two high schools; the one descilbed briefly abofe, and the second an inner-city high school in which most students came from lower socio-economic families. Abu ut half of these students were black. (See figure I for the sequence of the studies.)

I. Preliminary trials

A. Emotional role-playing

1. Rural high school students

2. College students

B. Demonstrations

1. Rural high school students

2. Co1lege students

II. Simultaneous quasi-experimental studies at the rural high school and at the inner city high school.

Figure 1

Time Sequence of studies

An attitude test was developed in the early phases of the research. Change in attitude as measured by this instrument was used as one criterion of change induced by the behavioral modification techniques. Another criterion measure, which was available at the inner city high school, was the students' performances on driving simulators in two conditions. (Unfortunately, driving simulators did not become available in time for use with the rural high school.) 
In this chapter, the schools from which the subjects were drawn and the subjects who participated in the studies are described. The general procedure used in the emotional role-playing trials, the demonstrations, and the quasiexperimental studies are presented. The description of procedures include changes made in procedures due to experimenter observations and student comments obtained during the preliminary trials. Finally, the criterion variables and the methods for analysis of these variables are described.

\section{Subjects}

\section{School Populations}

High School A. Students from a small (140 students) rural high school participated in both the preliminary trials, and later, in one quasi-experimental study. Approximately $40 \%$ of the students were from a lower class background, and the rest were from a lower middle class background. Most of the students' parents were farmers or worked in clerical or service positions at a university located 20 miles away. About $35 \%$ of the students go to college each year and about $20 \%$ go to specialized vocational schools. All students were Caucasian.

\section{High School B. Students from a large (over 4000} students) inner city high school took part in one of the two quasi-experimental studies. About $1.5 \%$ of the students dropped out between the first and second semestor. Furcher, 
more students continued to drop out during the second semester or were absent from school for periods of time during the semester. Fifty-two percent of the students were black.

University. University subjects participated in some preliminary trials of emotional role-playing and demonstrations. The university was a large (approximately 25,000 students), Midwestern, landgrant institution. Most of its undergraduates were from within the state and were Caucasian.

Subjects in the Emotional Role-Playing Trials

Emotional role-playing was first tried at high school A with four groups of students, and then at the university with six groups of students.

Subjects at High School A. Eleven boys and five girls volunteered. These students were sophomores and juniors, aged 15-18. All but one boy knew how to drive. About half of the students first learned to drive while taking driver education. Almost $75 \%$ of the students drove more than 24 miles a week even though their parents had placed restrictions on their use of a car. Eight students had average grades, seven had above average grades, and one student had below average grades. Half of the students planned to go to college, although on 1 y $21 \%$ of their fathers had training beyond high school.

Subjects at the University. Of twenty-seven males enrolled in the driver education methods class at the 
university, eleven volunteered to participate in these trials. The other sixteen students composed the control group.

University: Experimental group. Ten Caucasian males and one black male composed the experimental group. Nine were seniors, one was a junior and one was a graduate student. All but one student had average or above average grades. Al1 students owned their own cars. Five students had been drivers involved in a minor accident. Five students had received warning tickets for moving violations, and six students had received tickets for moving violations. Only three of their fathers had schooling beyond high school. University: Control group. Sixteen Caucasian male students composed the control group. All but two were seniors. All but one student had average or above average grades. All but one student owned their own cars. Eight students had been drivers in minor accidents, five had received warning tickets for moving violations, and six had received tickets for moving violations. Only seven of their fathers had had education beyond high school.

Subjects in the Preliminary Demonstration Trials

Students at both high school $\mathrm{A}$ and the university participated in these trials.

Demonstrators at High School A. Two male juniors who had had automobile accidents volunteered to act as demonstrators. One boy had above average grades and planned to go to college, and the other boy had average grades. 
Both boys had nearly unlimited access to a car; one boy owned a "souped up" sports car.

Audience at High School A. Thirteen males and twelve females, all sophomores, composed the audience to whom the demonstrations were made. All but one student had above average or average grades. All students had parental restrictions placed on their use of a car, and $92 \%$ had neither received a ticket for a moving violation nor been a driver involved in an accident.

Demonstrator at the university. One male Caucasian student, a senior, who had below average grades, was the demonstrator. He had had several automobile accidents. He was enrolled in the driver education methods course. Audience at the university. Eight seniors and one junior, all males, all Caucasian but one who was black, who were enrolled in the driver education methods course, volunteered to compose the audience. All students had above average or average grades. Five students had been drivers involved in minor accidents, three had received warning tickets for moving violations, and one student had received a ticket for a moving violation.

Subjects in the Quasi-Experimental Studies

All subjects in these studies were enrolled in a driver education course during the spring semester, 1972. All subjects were from lower or lower middle socio-economic families. Students taking driver education at high school A 
were mostly freshmen and sophomores, while primarlly juniors and seniors took driver education at high school B. Students at high school A generally learned to drive while aged 9-14, and had operated tractors, and cars, etc., on their parents' farms, while students at high school B generally did not learn to drive until at least aged 15. All students at high school A were Caucasian, and about half the students at high school B were Caucasian and half were black. Several students at high school B dropped out of school during the semester. Also, several students were transferred out of their driver education class after spring vacation, because they had not gotten their driver learner permit, or they could not pay the driving fee of $\$ 2.00$.

High School A: Experimental Group. Ten girls and eight boys, aged 15-18, composed the experimental group. One boy was a senfor, and the other students were freshmen and sophomores. All but two students had average or above average grades. All students had been passengers in a car involved in a minor accident, and two were passengers when a severe accident occurred.

High School A: Contro1 Group. Eight boys and three girls, all sophomores, composed the control group. All but two had average or above average grades. Most students had been passengers in a car involved in a minor accident, and two were passengers when a severe accident occurred.

High School B: Experimental Group. Fifty-one students originally composed the experimental group: 18 black and 
13 Caucasian females, and 11 black and eight Caucasian males. However, one boy dropped the class within the first few days, and three males and two females dropped out of school by spring vacation. In addition, two males and one female were transferred out of class by spring vacation. Most students were juniors and seniors. All students had above average or average grades. Two students had been passengers in a car involved in a severe accident, and $44 \%$ had been in a car involved in a minor accident.

High School B: Control Group. Thirty-eight students originally composed the control group: 16 black and 10 Caucasian females, and 11 black and one Caucasian male. However, five females dropped the class within a few days. Also, two males and one female were transferred out of the class by spring vacation. Further, two females were continually absent after spring vacation. All but three students were juniors and seniors. All but one student had average or above average grades. Two students had been in a car involved in a serious accident, and $44 \%$ had been in a car involved in a minor accident.

\section{Preliminary Trials of Behavior Modificatior Techniques}

Preliminary Trials of Emotional Role-Playing

Emotional role-playing was first tried at high school $A$ and later tried at the university in order to see if subjects' reactions might differ due to differences in 
amount of driving experience, age, and/or general background. Further, as most subjects at the university were training to become driver education teachers, it was hoped they might make suggestions about possible modifications of the techniques. In addition, it was thought that it would be useful to know the reaction of future driver education teachers to these new techniques.

Purpose of emotional role-playing. The literature review suggested that students who took an active role, rather than just being given information, in determining how accidents due to emotional stress might occur and the results of such accidents, might be more careful when driving under emotional stress.

General procedure. The same general procedures were used at high school $\mathrm{A}$ and at the university.

Students at high school A were divided into three groups of three boys and one girl and one group of two boys and two girls. Students at the university were arranged in six groups of from one to three students each.

Al1 students took an attitude test, consisting of a biographical section and a section dealing with attitudes toward driving (See Appendix $A$ and the Criterion section, p. 91 ). Students at high school $\mathrm{A}$ then sat in chairs that had been arranged to resemble seating in a car; two chairs in front and two chairs in back facing the same direction. Students at the university sat in a car parked in a rarely used parking lot at the university. The students were told 
that they were going to role-play an automobile accident. Role-playing was explained to the students as acting (as in a play) as if the student were actually in a given situation.

Students in each group were asked to describe their experiences if they had been either a driver or a passenger in a car involved in an automobile accident. Then three of the students' accident situations were chosen to be roleplayed. Students were told to pretend they had been seriously hurt in the first accident to be role-played, and that they were shaken up or received minor bruises in the second and third accidents that they role-played.

A court situation was then role-played. Students were asked to imagine themselves in court, with the experimenter taking the part of the prosecuting attorney. The students took the parts of the judge, responsible driver, the other driver, or of a passenger. Students were alternated in the role they assumed, but the accused driver was always a male. Accidents in which the driver was definitely at fault, from the students' own experiences, were the situations presented to be role-played. The university subjects, except for the first group which went to an unused classroon, stayed in the parked car for the court situation. Also, in groups four, five and six of the university subjects, the court situation was changed to a deposition sequence because several students had given depositions after an accident. The deposition sequence was similar to the court situation, except there was no judge. 
All subjects retook the attitude section of the attitude test one week after the pretest.

Changes in procedure. As a result of observations made by the experimenter and student comments in the preliminary emotional role-playing trials, the following changes in emotional role-playing procedures were made:

1. Students at high school A had trouble role-playing because they had had little experience in acting. Thus, the experimenter demonstrated how a person might react in a minor accident to the last two groups of high school subjects.

2. High school subjects could not imagine themselves being seriously hurt. Thus, the severe accident section was reduced in time for the last two groups of high school subjects. However, the university subjects responded well to this section because many of them had been hurt seriously while playing sports, and this section was not reduced in time for the university subjects.

3. Most high school students reported that they could imagine themselves shaken up in a minor accident, and this role-play section was extended in time for the last two high school groups.

4. The group of two boys and two girls at the high school appeared to respond best. Students in this high school group reported that they were not 
embarrassed by role-playing. Thus, the experimenter felt that, if possible, a mixed group of boys and girls (preferably half and half) would be formed when doing emotional role-playing in the later studies.

5. In the last two high school groups, an older colleague of the experimenter (a faculty member of the university) played the part of the other driver who had been injured in the accident. Students appeared to be more concerned when an older driver was the other driver, and mentioned that their parents would be furious with them if they were in an accident.

6. High school students felt that the accident sequences were not very realistic because sitting in school chairs in a school office did not give the feeling of being in a car. For this reason, the university subjects were seated in a car while emotional role-playing.

7. The first group of university subjects went to an unused classroom for directions for the session, and then went to the car for role-playing. The students returned to the classroom for the court situation. However, this procedure consumed too much time (groups met for 55 minutes). A11 other university groups went immediately to the 
car and stayed in the car for the court situation. The difference in procedure did not appear to affect the court-room role-play results.

8. University students in the first group did not like playing the role of the accident causing driver in the court situation. Students in this group went so far as to invent extenuating circumstances, such as a stoplight not working (which was working all right in the original version of the accident), or changing the situation to one in which bad weather played a role, etc., to relieve their feelings of discomfort. Also, some university students made attempts to have the experimenter select a situation in which there was a question as to whether the driver was guilty of negligence. As a result of these experiences, all accidents developed for the court-room role-play with university subjects were ones in which there was no question that the driver was guilty.

Suggestions for emotional role-playing in quasiexperiments. As a result of the preliminary trials, it was decided that a short demonstration of role-playing be made with subjects of high school age. Also, the severe accident sequence would not be used with high school aged subjects, because they apparently had trouble imagining themselves being severely hurt as the result of a severe 
accident. Further, it would not be practical to use a car, because a car could only hold four to six subjects. Thus, the accident sequences were eliminated in the quasiexperiments. Also, the court-room role-play and the deposition role-play sequences appeared to be perceived by the subjects as realistic, and it was decided to use these sequences in the quasi-experiments. Finally, it was found that a mixed group of boys and girls reacted best to emotional role-playing, and thus, it was decided to try to use mixed groups of boys and girls when dealing with high school aged subjects.

Preliminary Trials of the Demonstration Demonstrations were first tried at high school $\mathrm{A}$ and then at the university. Students with poorer driving records were chosen as demonstrators, described circumstances of their accidents, and performed proper driving behaviors which would have avoided their accidents to students who composed their audience. Thus, the demonstrators would keep in mind circumstances surrounding their accidents and would practice correct driving behaviors. In addition, they might be socially reinforced by their peers for correct driving behaviors. Finally, the students in the audience would learn that a peer could have an accident, some dangerous circumstances that could lead to an accident, and how to avoid an accident in the given situation. 
University students were included in the trials in order to discover if differences in age, driving experience, and/or general background made a difference in the effectiveness of the demonstration. It was hoped also that the future driver education teachers would suggest improvements in the technique.

General procedure. The same general procedure was used at both high school $\mathrm{A}$ and the university.

A few days before giving the demonstration for an audience, each student demonstrator met with the experimenter and described several accidents he had been in. The student and the experimenter then. went to the student's personal car to rehearse the student's demonstration.

The demonstration for each of three accidents was arranged in two parts: first, the circumstances of the accident were described (time of day, location, etc.); second, the driving behaviors which could have avoided the accident were described and performed (although the engine of the car was not started), 1.e., if the student said he should have checked his rear view mirror, he turned his head and looked at his rear view mirror, etc. Students in the audience could ask questions or make comments after each accident description.

Students composing the audience for the high school demonstrators were chosen by the experimenter to go to the demonstrators' cars in groups of four, each group containing both males and females. The university subjects formed two 
groups, one of five students and one of four students, to act as an audience.

Immediately preceding the demonstration, high school subjects took the attitude test, as a pretest (See Appendix A). One week after the demonstration the high schoo1 students retook the attitude section of the attitude test. University subjects had previously taken the pretest, and returned the attitude section of the attitude test one and a half weeks after the demonstration.

Changes made in demonstration procedure. As a result of the comments of the high school students and the observations made by the experimenter, more time was allowed for the students in the audience to discuss the demonstrations or ask questions of the demonstrator in the demonstrations made by the university demonstrator.

Suggested use of demonstrations in the quasi-experiments. First, cars could only seat four to six students at a time. Also, cars could not be started due to the possibility of an accident, even though this might have added realism. Thus, demonstrations would be made in the classroom, not in a car.

Second, demonstrations eppeared to make the dmonstrators think and recall the feelings about the circumstances of and their bad driving behaviors which led to an accident. One of the high schonl demonstrators gave more detalled descriptions for each group in the audience, and the college demonstrator became quite serious and made 
comments about how he had changed his ideas after the accident, i.e., if one is very drunk, he should not drive, etc. Thus, it appeared that giving demonstrations had some effect on poorer drivers, even though they could not adequately practice correct driving behaviors because the car could not be started. Thus, it might be useful to remind these drivers of their poor habits or attitudes and feelings relative to driving.

Third, both poor and good students should be chosen as demonstrators. Members of the college audience who had had accidents seemed quite receptive to the college demonstrator (who had below average grades) and nodded or verbally agreed with the demonstrator. These students also discussed their own accidents. However, the better students in the college audience appeared to be disgusted particularly when the college demonstrator mentioned that an accident occurred when he and his friends were drunk. Thus, the poorer students seemed to respond best to a demonstrator who was a poorer student, and it is speculated that better students would respond best to better students.

Finally, the demonstrations appeared to work best as triggers for discussion and analysis of accidents. Thus, it would probably work well for the demonstrator to make his demonstration to a large group of students in the classroom, and then for the audience to discuss and analyze the causes of the accident. 
The Quasi-Experimental Studies

Emotional role-playing did not fully examine how to avoid emotionally related accidents. Instead, this technique appeared to emphasize only that one is responsible for the consequences of an accident. Demonstrations dealt with how to avoid some emotionally related accidents, but may not have fully dealt with emotional control in relation to all emotionally related accidents. Thus, it was hypothesized that if emotional role-playing and demonstration activities, plus reciprocal inhibition (introduced through modeling techniques) were combined into a curricular unit for inclusion in current high school driver education courses, this would introduce more of the dimension of emotional control into driver education courses.

Subjects. Two driver education classes were held at high school A during the second semester. The morning class, consisting of eight boys and three girls composed the control group. The afternoon class of eight boys and ten girls composed the experimental group.

Two driver education classes were held at high school B during the second semester. The nine a.m. class, originally composed of 38 students was chosen as the control group. Ten students were transferred out of the class or dropped out of school during the semester. The 9:45 a.m. class originally composed of 51 students (nine students either dropped out of school or were transferred out during the scmester) formed the experimental group. 


\section{Curriculum Elements}

There were four curriculum elements involved in the treatment. These elements will be described in the general order in which they were introduced in the students.

Element 1: A warm-up game. "First impression" was played during the first treatment session at high school B. The purpose of this game was to encourage students in the experimental group at high school B to exchange personal information, such as their names, hobbies, etc., with each other in order to become acquainted with each other. (Students were placed in this class on the basis of whether they had the time slot free; thus, many students did not know any other students in the class.) It was thought that if students knew each other, they would feel freer to discuss their feelings and emotional behaviors with others. This game was not played at high school $\mathrm{A}$ in which, because of its size, the students were well acquainted with each other. "First impression" is played in the following manner. Students are told to sit next to one other student who they do not know or do not know wel1, and to exchange names and tell each other something about themselves (age, plans for after high school, interests, etc.). After five minutes each pair is told to join one other pair of students and to exchange names and information about each other. After five minutes students are told to take one slip of paper for each of the other three students in the group, put the first name of each of the three other students on top of 
one of the three pieces of paper, and then to write what their first impression was of each of the other three students. The experimenter gave examples of first impressions such as friendly, nice, handsome, etc. Then students pass the slips of paper they have to the person whose name was on top of the slip of paper. Each student then reads the comments on the slips of paper, and can question the other members of the group about the comments they have made about him.

Element 2: Reciprocal inhibition through modeling. Video-taped and live models were used to present emotionallyloaded situations and behaviors to perform while under emotional stress which would preclude driving. The driver education teachers at each high school chose the models (primarily male athletes). The models then met with the experimenter who told the models the purpose of the treatment and the general plot of the video-taped situations. The models then developed the situation in more detail; i.e., the models provided the words and slang used, and in some cases suggested alternative behaviors they felt the viewing students might believe they would do. For example, many models said they would never write their grievances, but they might go talk to a friend or kick a locker when angry.

When the video-tape machine was inoperative, it was not always possible to get the original models to perform the skit live. In these cases, alternative models (also 
members of athletic teams) generally would rehearse the skit beforehand with the experimenter. However, on one or two occasions, the skit was performed live without rehearsal.

The following situations were presented to the experimental groups. First, attractive girls responded to the experimenter's question on the topic of boys'reckless driving behaviors. The girls stressed that they did not expect boys to show off. Further, they suggested that girls tell their boyfriends when they are driving poorly, and that reckless driving by a boy with a date implied lack of respect for the girl. This segment was to encourage girls to talk to boys about their driving habits, and to encourage boys to drive more cautiously, i.e., gixls do not expect boys to drive recklessly.

Second, male athletes spontaneously responded to the experimenter's questions about boys' reckless driving behaviors. These athletes mentioned that boys are not sissies if they drive safely. Further, boys should not drive when under great emotional stress because their driving behaviors are poorer in this condition. Also, these athletes stressed that boys should not drive while drinking or taking drugs because they would be more likely to have an accident. This segment was shown to let the subjects know that they were not expected by their peers to drive poorly, and indeed, they should drive as safely as possible. These 
first two segments were used to try to get the students in a more receptive mood when they saw the other segments. Third, several segments showing situations in which the models became angered, excited or discouraged, lasting a maximum of three minutes were shown. The purpose of these segments was to encourage students to identify what emotion the models portrayed, and how the model.s' behavior was influenced by their emotions. In addition, students were encouraged to identify how they. themselves reacted while under emotional stress, particularly in relation to driving. The general plot in all situations was that the model was going to go to his car after having shown an emotion, but instead decided to perform an alternative behavior which precluded driving, such as going off for a coke with his friends while he told them his grievances, etc. Further, the model would then return to rectify the original situation; i.e., the model would return to talk calmly to the person at whom he was mad.

The anger situations were: 1) male athlete angry at a friend (not shown at high school A due to lack of time); 2) male athiete angry at a parent; 3) male athlete angry at a teacher. (Fuller descriptions of these situations are presented in Appendices $B$ and $C$ ). The excitement situations for both schools were similar; male athletes on the basketball teams were extremely excited after winning the sectional basketball contest. Also, the discouragement situations presented at both high schools $A$ and $B$ were similar; 
male athletes on the basketball team were extremely discouraged and angry after loosing the regional basketball contest. (Both high schools A and B happened to actually win their sectional basketball tournament but lost their regional basketbal1 games.)

At the conclusion of the modeling situations, the game "break-in" was played at high school B and "break-in" and "break-out" were played at high school A. "Break-in" consists of having students stand in a circle with one person on the outside who is trying to get within the circle. "Break-out" consists of having the students form a circle with one person on the inside of the circle trying to get to the outside of the circle. The purpose of playing these games was to test the students' identification of emotions felt and the relation of these emotions to the students' behavior. Further, the question of how driving behaviors, while the student was under emotional stress, would differ from driving behaviors when the student was not under emotional stress was discussed.

Element 3: Demonstrations. Demonstrations were given by students with poorer driving records (who had had accidents, received tickets for moving violations, etc.). The demonstrators were students at the high school at which the the demonstration was made. The demonstrators would talk about accidents they had had or situations in which they had almost had an accident. They would first describe the situation surrounding the accident, 1.e., 
weather conditions, who the passengers, if any, were, time of day of the accident, etc. Then they would describe how the accident occurred. Finally, the experimenter would ask students questions, such as was the driver angry at the time of his accident, how could the driver's emotional state have affected his driving, how could the driver have avoided the accident, etc., to stimulate discussion and analysis of the cause of the accident and possible measures the driver could have taken to prevent it. Thus, the demonstration was used to trigger discussion of the accidents and identify emotions the driver felt, and his driving behaviors while under the influence of a strong emotion which led to an accident or to a situation in which an accident almostoccurred.

Element 4: Emotional role-playing. The deposition scene was emotionally role-played, as it seemed to be effective in the preliminary trials. Several males in the class played the part of the accused drivers and some of the other students in the class played the part of passengers in the car, the other driver, etc., who were giving testimony: The purpose of this section was to remind students of their responsibility for the safety of themselves and theix passengers, as well as to encourage avoidance of situations which might lead to accidents. In addition, students role-played such situations as a mother and daughter talking about the daughter going out that night, and how the daughter should have better handled the situation (by not demanding one's own way, etc.,), in order to 
not let the situation get so explosive that the student would get really angry, etc.

See Appendices B and C for a more detailed description of the procedures at each school.

Major Problems with the Quasi-Experiments

There were several major problems with the quasiexperiments. First, due to the division of the experimental group at high school $B$ into four sections, one section going to the simulators each day and students from other sections going to the cars, only $2 / 3$ of the students were in the classroom on any day. Further, a different $2 / 3$ were in the classroom each day, becalise the sections rotated assignments. Thus, the experimenter only met with a portion of the class each time she came, and many times some of the students present had not been present in the classroom the preceding time the experimenter came. Thus, many of these students did not receive the entire treatment.

Second, the driver education class at high school $B$ lasted only 40 minutes each day, whereas at high school A, the driver education class lasted one hour each day. In arder to give the entixe treatment to students at high chon 1 , the experimenter came twice a week. However, after the third seek, the experimenter came only once a neek because the studencs were behind in their regular classroom work. Thus, the amount of time the exporimenter spent presenting the treatment at high school $B$ was less than 
the amount of time the experimenter had to present the treatment at high school A.

Third, the video-tape equipment was unreliable. Thus, it was necessary on two occasions to have unrehearsed models present the problem situation live at high school B, and these presentations became long and confused. On the other occasions the video-tape machine broke down, however, it was possible to rehearse the problem situation skits in advance before a live presentation.

Fourth, it was necessary to work with large groups of students. Thus, it was not possible to try the minor accident emotional role-playing segment, because to be more realistic, (as discovered in the preliminary trials) students would have had to be seated in a car, and a car can only accomdate four to six persons at a time.

Finally, it was difficult to presuade students at high school $B$ to act as demonstrators. The students at high school $B$ who had had severe accidents or several minor accidents generally were poorer students who frequently absented themselves from school. When finally contacted, these students refused to be demonstrators even after being offered payment. Thus, it was necessary to use a student with higher grades as a demonstrator at high school B, and to read descriptions of accidents university students had had. Also, most students at both high schools $A$ and $B$ had not had severe accidents, and thus, the demonstrators had had only minor accidents to present. 


\section{Criterion Variables}

Two criterion variables were available for use with high school B; students' performances on driving simulators and results from an attitude test. However, only the attitude test was available for use as a criterion variable with high school $A$ and with the university subjects.

Students' performances on driving simulators. High school $B$ had twelve Aetna Drfvotrainer Simulators (Model \# DX) on its campus. Each driving simulator lesson consisted of a twenty-minute film which was displayed on the screen in the Eront of the semi-trailer the simulators were in. Students sat at mock-ups of the driver portion of a car, and could use the rear-view mirror, turn the steering wheel, etc., as if they were in a car. Students watched the film, which was photographed as from the front seat of a car, and as the car in the film made a turn, etc., the student did the same, using his simulator controls. A simple computer automatically indicated the number and type of errors (braking error, etc.) each student made on a. print-out.

The performances of the students on driving simulators on the sane 1essons in two conditions were compared. Both performances occured ruring regular class periods. However, the students were aroused to anger prior to the second test of Lesson 1. The experimenter informed them without giving explanations or permitting questions, that they would have to return to the simulator trajtor either after school or on Saturday 
at nine a.m. for one hour, and that no absences were permitted. In addition, the reliability of the students' performances on the simulator was tested. Another lesson was given twice, once near the beginning and once near the end of the semester.

Simulators were used because they were considered less dangerous than permitting a student to drive a car while angered. Also, larger groups of students could be tested at the same time (12 students) than in a car ( 1 student), which would cause less disruption of the students' class schedules.

An attitude test. An attitude test was developed while the preliminary trials were made. Based on the literature review, the hypothesis was made that the poorer drivers would be younger, would tend to do worse in school, would tend to have animosity toward the world, and would tend not to accurately assess the effects that strong emotions would have on their behavior, particularly their driving behavior. The poorer driver would tend to use a car to release his strong emotions, and would tend to drive a sports car or a souped up car and to save money to buy his own car. Further, the poorer driver would tend to be a male.

Therefore, the attitude test was composed of two parts. The first part of the attitude test consisted of asking for biographical information, in order to determine the students family's socio-economic status, to discover 
what kind of car he drove, to determine his age, his grades in school, whether lie was saving to buy a car, etc. This section was given once, be ore the treatment in the pretest. The second part consisted of questions designed to discover the students' attitudes toward drinking and driving, whether the students appreciated the effect strong enotions might have on their driving behaviors, what kind of driving behaviors the students currently performed, etc. This second part was given in the pretest, along with the biographical section, and again after each treatment in the preliminary tryouts. However, in the experimental studies, the fifteen guestions dealing with driving behaviors was made into a separate section since it was assumed that most sutdents would not have driven much until. they received their driver's license. The second part, then, in the experimental studies, was given at the pretest, and egain, with the part dealing with driving behsviors, at the enct of element two (videotaped and/or live models) and at the conclusion of the traatment (See Apperdix A).

The followitg limitations were placed on this questionnaire. First, the students had to be able to understand the language used in the attitude test, and' if they did not, the test was modified. Second, the test had to be short enough that even poor readers could complete it in one class period. Thus, the attitude test aimed at high school students was shorter than that for the college students since college students could complete the test in much 
shorter time. Third, slight changes were made due to the differences betheen populations used as subjects, i.e., when college subjects were used, the ages $i$ in the biographical section were changed to $18-25$ or older, etc. Also, when high school driver education students were subjects, the section dealing with driving behaviors was delayed until they had had some driving experience with their driver education instructor (See Appendix A).

\section{Analysis of Criterion Measures}

Analysis of Driving Simulator Data

The reliability of the driving simulator was determined by comparing the results of each of two lessons that were given twice, once during the middle of the semester and once at the end of the semester. Unfortinately, due to the short time available to students to use the driving simulators, it was not possible to check the reliability of more lessons. The analysis compared both the total number of exroxs the scudents male each time, and the number of exrors of each type (Braking, etc.) made each time. The program TRJCoR iFurdue University Computing Center, Document G IRECOR was used to determine the tést-retest reliability coefficiont for these two lessons.

Treatment effects were determined by comparing the results of the same lesson given twice, once while the scudents were in a "heutral" mood and once when they were in an emotional state (anger). The andysis compared 
both the total number of errors the students made each time, and the number of errors of each type made each time. The program ANOVAR (Veldman, 1967) was used to obtain an analysis of variance for repeated measures for two groups (experimental and control) on the eight criterion measures (each type of error and total errors).

Analysis of Attitude Test Data

First, estimates of test-retest reliability were computed by using the program TRECOR (Purdue University Computer Center, Document G2 TRECOR). During the preliminary trials of demonstration and emotional role-playing, the attitude section of the attitude test was given immediately before and approximately one week after each treatment. During the quasi-experiments, the first test of the attitude section was given before the treatment, the first retest was given after approximately four weeks of the treatment, and the second retest was given approximately four weeks after the first retest. In addition, during the quasiexperiment, the driving behaviors section was first given four weeks into the treatment, and was given again approximately four weeks later, at the conclusion of the treatment. However, in the preliminary trials, many times no control group was used. Also, when a control group was used either during the preliminary trials or the quasi-experiment, the number of students in the control group was so small that the test scores of the control and experimental group 
subjects were combined to compute the reliability estimates. Therefore, it is possible that the given treatment affected the test scores systematically so that the test-retest reliabilities were underestimated.

Second, the internal consistency coefficient (alpha) (Staniey, 19?1) was determined for each attitude test vexsion by using the TESTAY (VeIdman, 1967) computer program. Alphas were run for the pretests (bicgraphical section, attitude section and totai score) for each of the various segments, on the preliminary trials questionnaires. In addition, alphas were obtained for the quasj-experimental cuestionnaire. First, the program TESTAT (Veldman, 1967) was used to obtain internal consistency coefficients for the pre-treatment test of the biographical section, the attitude section, and combined attitude and biographical sections test scores. Internal consistency coefficients were also obcained for the mid-treatment testing, which included the atcitude section, driving behaviors section, and the combined core of these two sections.

Third, two analyses of variance which considered groups (experimental and control), schools (high schools A and 3) and either the biographical section test scores or artitude section test scores as mair effects woic made using the program ANOVAR (Veldman, 1967) in order to discover differences between groups, and schools.

Fourth, an anslysis of variance for repeated measures was made by using AHOVAR (VeIdman, 1967) which considered 
groups (experimental and control) and pre- and post-emotional role-playing attitude section test scores as main effects, in order to detormine the effectiveness of the emotional role-playing treatment at the university.

Fifth, several anjiyses of variance for repeated measures were made using ANOVAR (Veldman, 1967) to consider the effectiveness of the demenstration technique. The first analyses were mede using university subjects' data. One analysis of variance considered one group, composed of the audience and demonstrators, and pre- and post-demonstration attitude section test scores as main effects. The next analysis considered two groups, subjects who had not also been emotional role-players, and subjects who had also heen emotional role-players, and pre- and post-demonstration sttitude section test scores as main effacts. The last Enalysis considered the two groups just mentioned, and preenotional role-playing, pre-demonstration, and postdewonstration attitude section test scores as main effects. Finally, an analysis was made to consider two groups, demonstrators and rudience, and pre-and post-demonstration attitude soction test scores as main effects to determine the effectiveness of the demonstration 'technique at high school A.

Sixth, several analyses of variance for repeated measuxes using attitude test scores obtained during the guasi-arperiments were determined by using the program ANGVAK (Veldman, 1967). Anelyses of vartance were made separately 
for each high school. An analysis was made which considered groups (experimental or control) and pre-, mid-, and posttreatment attitude section test scores to determine whether differences due to main effects were significant and if there was a significant interaction effect. Also, three more analyses of variance for repeated measures were made. A11 tiree cousidered groups (experimental and control) as main effects, but also considered mid-anci posi-treatment attitude section test scores, dxiving behaviors section test scores, or the combined attitude section and diving behaviors section test scores as a main effect. Av2Blw (Purdue University Conputing Center, Document Go-FY STAT).

Seventh, analyses of variance for repeated measures using AV2BiW (Purdue Unjursity Computing Conter, Document CO-ED STAY) seperately for each school were made to consider the main effect of sex. Other analyses of variance were made to corsidex the efrects of race at high school B only, by using AV2B1w (Purdue University Computing Center, Document GO-ED STAT). AII analyses considered experimentaI

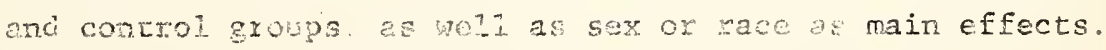
addich, oj ther pre- and midmtreatment. wid- and post-reatment, or pue wid and post-treatmert attitude section test scores were conicierei as man efiecis. Analyses were also conputed consübürig ejther mid-and post-sreatment driving behaviors section test dcores or mid-and posttreatment combined iniving beheviors and attitude section 
test scores, as well as sex at high school A, and sex or race at high school $\mathrm{b}$, as main effects. Thus, the effect of sex, race, and treatment, and any significant interaction effects could be determined.

Finaliy, if there was a significant interaction effect, a Noman-Keuls Sequentjai. Means Test (Purdue University Computing Centex, Document G4 MK Test) was computed to decermine which differences among means ware significant.

\section{Summary}

First, the schools which participated in the studies were described as were the subjects participating in each study. The preliminaxy trials were described together with changes in procedures which were suggested by the preliminary trials. Then, the general procedures used in the quasiexperimental studies were described.

Finally the criterion measures and the methods of analysis made explicit. The results of the data analyses ara presented in the next chapter. 
CHAPTER III

RESULTS

This chapter describes the criteria test results before and after each preliminary trial of emotional roleplaying and demonstration, and before, during, and after the treatments at each high school for the quasi-experiments. Also, the differences between the groups of subjects in the preliminary trials and in the quasi-experiments will be described. Finally, answers given by subjects to cognitive questions will be 1 isted.

These studies were done to develop new techniques to achieve emotional control in relation to driving which could be used in current driver education courses. In order that the maximum amount of information be retained, results will be described as significant when significant at the .05 level, and of borderline significance when significant between the .05 and .10 levels.

\section{Characterj.stics of the Criterion Measures}

Attitude Test Characteristics

As indicated previously, there were three versions of the attitude test criterion (See Appendix A). One version was created for the high school population participating in 
the preliminary trials of emotional role-playing and demonstrations. The version for the university suljects participating in the preliminary trials of emotional role-playing and demonstrations was slightly longer than the version given to the high school subjects. The last version of the attitude test was for high school subjects who were taking driver education courses during the time of the quasiexperiments, and thus, were assumed not to have driven before or not driven very much before. In the first two versions, the attitude test consisted of a biographical section, given once, and an attitude section given before and after the treatment. The version created for the students taking driver education during the time of the treatment consisted of three sections; a biographical section, given before the treatment; an attitude section, given before, during and after the greatment; and a section on driving behaviors, given during and after the treatment. The characteristics of internal consistency and reliability of these three attitude tests will be described and the populations with which they were used. In addition, indications of the reliability of the simulator criterion is given.

Internal consistency. The interrial consistency coefficient alpha vas determined for the three versions of the attitude test (See Appendix A). These coefficients are cescribed in Tables 1,2 and 3.

The internal consistency for the first version of the attitude test coefficient was .47 fox the hiographical 
section (20 questions, $n=26$ ) and .82 for the attitude section ( 40 questions, $n=26$ ). The internal consistency coefficient for the entire test (combined attitude section and biographical section, 60 questions) was .84 and is presented in Table 1.

Table 1

Means and Internal Consistency of High School A Demonstration Attitude Test

Test section

1. Biographical

2. Attitude

3. Total (Sum of 1 and 2)

$\begin{array}{cccc}\begin{array}{c}\text { Alpha } \\ \text { Coefficient }\end{array} & \begin{array}{c}\text { \# of } \\ \text { Questions }\end{array} & \frac{\bar{x} \text { scores }}{.47} & \frac{\mathrm{n}}{26} \\ .82 & 40 & 122.50 & 26 \\ .82 & 60 & 175.62 & 26\end{array}$

The attitude test used with university subjects during the preliminary trials of emotional role-playing and the demonstration also consisted of two sections (See Appendix A). The internal consistency coefficient of the biographical section ( 24 questions, $n=27$ ) was .39 , and the internal consistency coefficient for the attitude section (52 questions, $\mathrm{n}=27$ ) was .68 . The internal consistency coefficient for the total test (biographical section and attitude section combined, 55 questions, $n=27$ ) was .68 . These coefficients are presented in Table 2 .

The attitude test used with subjects participating in the quasi-experiments consisted of three sections (See Appendix A). The biographical section was given once 
Table 2

Means and Internal Consistency of Attitude Test Used with University Subjects

\section{Test section}

1. Biographical

2. Attitude

3. Tota1 (Sum of 1 and 2)
Alpha 非 of Coefficient Questions $\overline{\mathrm{X}}$ scores $\mathrm{n}$ .39 24 $59.70 \quad 27$ .68

52 155.12 .68

(19 questions), the attitude section was given three times, befire, during and after the treatments (36 questions) and the section on driving behaviors was given twice, during and after the treatment ( 15 questions). The internal consistency coefficient was determined separately for high schools A and $B$, because of the different populations of students at each schoo1. At high school A, the first testing consisted of the biographical section ( $a 1$ pha $=.62, n=29$ ) and the attitude section (Alpha $=.71, n=29$ ), and the internal consistency coefficient of these two sections combined (55 questions) was $.73(n=29)$. The second testing consisted of the attitude section (alpha $=.72$ ) and the driving behaviors section (alpha $=.73)$. The internal consistency coefficient of the combined sections was .83. These are presented in Table 3.

At high school B, the first testing also consisted of the biographical section ( $a 1$ pha $=.32, n=73$ ) and the attitude section (alpha $=.66, \mathrm{n}=73,36$ questions). The internal consistency coefficient for the combined sections was .68 
Tab1e 3

Means and Internal Consistency of the Attitude Test Used in the Quasi-Experiments

Pretest

Test Section

High School A

Alpha $\overline{\text { X Score }}$

.62

44.41

.32

49.67

2. Attitude

(36 questions)

.71

117.07

.66

116.21

3. Tota1 (Sections 1 and 2)

(55 questions)
161.48

.68

165.89

Second Testing

Test Section

1. Attitude

(36 questions)

2. Driving Behaviors

(15 questions)

3. Tota1 (Sections 1 and 2)

(51 questions)
High School A $(n=29)$ -

Alpha

$\underline{X}$ Score

.74

117.97

.73

48.28

$.83 \quad 166.24$
$.69 \quad 115.95$

$.69 \quad 115.95$

$.87 \quad 49.66$

$.87 \quad 49.66$

High Schoo1 B Alpha $\mathrm{X}$ Score

$.82 \quad 165.61$

( $n=73,55$ questions). At the second testing the attitude section was given again ( $\mathrm{a} 1 \mathrm{pha}=.69, \mathrm{n}=62,36$ questions). The driving behaviors section was given (alpha $=.87, n=62$, 15 questions) and the internal consistency coefficient for both sections combined ( 51 questions) was $.82, n=62$. These internal consistency coefficients are presented in Table 3. 
Estimates of test-retest reliability. Test-retest reliability estimates were also determined for the three versions of the attitude test.

The attitude section (40 questions) of the attitude test given at high school $\mathrm{A}$ before and after the preliminary trials of the demonstration had a test-retest reliability estimate of $.79(n=25)$. This is found in Table 4. (Two students in the audience were absent at the time of the retest.

\section{Table 4}

Means on Test Re-test Reliability Estimates of Version 1, Attitude Section (40 questions): High School Subjects
$\overline{\mathrm{X}}$ Score Pretest
122.20
25
$\overline{\mathrm{X}}$ Score Posttest
121.00
25
$r=.79$

The attitude section (52 questions) of the attitude test the university subjects completed was given three times, before the emotional role-playing trials, after the emotional role-playing trials, and after the demonstration trials. The test-retest reliability before and after the emotional role-playing trials was $.72(n=26)$. The test-retest reliability estimates of the attitude section completed after the emotional role-playing trials and after the demonstration trials was $.93(n=10)$. The test-retest reliability estimates of the attitude section completed before the 
emotional role-playing trials and after the demonstration trials was $.94(n=10)$. These reliability coefficients are presented in Table 5.

\section{Table 5}

Means and Test-Retest Reliability Estimates of Version 2, Attitude Section (52 questions): University Subjects

Before and After Emotional Role-Playing

$\begin{array}{llc}\overline{\mathrm{X}} \text { Score Pretest } & 155.19 & 2 \frac{\mathrm{n}}{\mathrm{\sigma}} \\ \overline{\mathrm{X}} \text { Score Posttest } & 156.96 & 26\end{array}$

Before and After the Demonstration

$\overrightarrow{\mathrm{X}}$ Score Pretest

$\overline{\mathrm{X}}$ Score Posttest

Before Enotional Role-Playing and After the

$\begin{array}{lcc}\overline{\mathrm{X}} \text { Score Time } 1 & 152.30 & 1 \frac{\mathrm{n}}{\mathrm{0}} \mathrm{r}=.94 \\ \overline{\mathrm{X}} \text { Score Time 2 } & 156.10 & 10\end{array}$

The attitude test given during the quasi-experiments was composed of three sections. The biographical section, as with the above attitude tests, was given only before the experimental treatment. The attitude section (36 questions) was given before, during, and after the treatment. At high school A, the test-retest reliability estimates of the attitude section given before and during the treatment was 
$.80(n=29)$, and the test-retest reliability of this section given during and after the treatment was.80 ( $n=29)$. A1so, the test-retest reliability coefficient of the attitude section given before and after the treatment at high school A, was $.70(n=29)$. At high schoo1 $B$, the test-retest reliability estimates of the attitude section given before and during the treatment was .66 $(n=54)$, during and after the treatment $.80 \quad(n=60)$, and before and after the treatment $.56(n=54)$. These internal consistency coefficients are presented in Table 6.

The third section of the attitude test given during the quasi-experiments consisted of questions pertaining to the driving behaviors of the students (15 questions), and was given during and after the experimental treatment. At high school A, the test-retest reliability estimates of this section is $.87(n=29)$, and at high school B, .44 $(n=60)$. The test-retest reliability estimates of the attitude section and the driving behaviors section combined (51 questions), both given during and after the treatment, at high school A is .89 $(n=29)$, and at high school B is .70 $(n=60)$. These reliability estimates are also presented in Table 6 .

Driving Simulator Characteristics:

Reliability Estimates

Test-retest reliability estimates were determined for two driving simulator lessons. Both lessons were given 
Table 6

Means and Test-Retest Reliability Estimates of Version 3:

Quasi-Experiments

Before and During the Treatment: Attitude Section (36 questions)

High School A, $\mathrm{n}=29$

$\overline{\mathrm{X}}$ Score Time 1

$\overline{\mathrm{X}}$ Score Time 2

$r=.80$
High_School B, $n=54$

$\overline{\mathrm{X}}$ Score Time 1

$\overline{\mathrm{X}}$ Score Time 2

116.11

117.97

$r=.66$

During and After the Treatment

High School A, $n=29$

$\frac{\text { Attitude Section }}{\text { (36 questions) }}$

$\overline{\mathrm{X}}$ Score Time 1

$\overline{\mathrm{X}}$ Score Time 2

$r=.80$
High Schoo1 B, $n=60$

$\frac{\text { Attitude Section }}{(36 \text { questions })}$

117.97

$\overline{\mathrm{X}}$ Score Time 1

115.73

116.48

$\overline{\mathrm{X}}$ Score Time 2

115.13

$r=.80$

\section{Driving Behaviors Section (15 questions)}

$\overline{\mathrm{X}}$ Score Time 1

48.28

$\overline{\mathrm{X}}$ Score Time 1

49.63

$\overrightarrow{\mathrm{X}}$ Score Time 2

48.45

$\overline{\mathrm{X}}$ Score Time 2

50.12

$r=.87$

$$
r=.44
$$

Attitude and Driving Behaviors Combined ( 51 questions)

$\overline{\mathrm{X}}$ Score Time 1

166.24

$\overline{\mathrm{X}}$ Score Time 1

165.37

$\overline{\mathrm{X}}$ Score Time 2

164.93

$\overline{\mathrm{X}}$ Score Time 2

165.25

$r=.89$

$r=.70$ 
Table 6, cont.

Before and After the Treatment: Attitude Section (36 questions)

High School A, $\mathrm{n}=29$

$\overline{\mathrm{X}}$ Score Time 1

117.07

High School B, $n=54$

$\overline{\mathrm{X}}$ Score Time 2

116.48

$\overline{\mathrm{X}}$ Score Time 1

116.11

$x$ Score Time 2

$r=.70$

$\overline{\mathrm{X}}$ Score Time 2

115.02

$r=.56$

twice; once at the middle and once at the end of the semester. However, one lesson (Lesson one) was retested after students were aroused to anger (driving simulators were used on1y at high school B).

Students made eight general kinds of errors: 1) brake errors (not braking, not braking hard enough, etc.); 2) left steering errors (not turning left, not turning sharp enough left, etc.); 3) accelerator up errors (not easing off the accelerator, etc.); 4) right steering errors (not turning right, etc.); 5) signaling errors; 6) parking brake errors (not putting on the parking brake, etc.); 7) negative steering errors (not putting the car in neutral, etc.); and 8) total errors. Test-retest reliabilities were calculated for each general category of error.

Test-retest reliabilities estimates for Lesson one ( $n=$ 50 for each category) are: 1) brake errors, .21;2) left steering errors, $-.06 ; 3$ ) accelerator up errors, .24;4) right steering errors, .03; 5) signaling errors, -.04;6) parking brake errors, .07; 7) negative steering errors, 
-.04 ; and 8) total errors, .50. These reliability coefficients are presented in Table 7.

\section{Table 7}

Means and Test-Retest Reliability Estimates of Driving Simulators: Lesson 1

$\begin{array}{lcccc}\text { Types of Errors } & \frac{\text { Test 1 }}{\underline{\underline{x} \text { Score }}} & \frac{\text { Retest }}{\overline{\mathrm{X} \text { Score }}} & \underline{\mathbf{r}} & \underline{\mathrm{n}} \\ \text { Brake } & .76 & .66 & .21 & 50 \\ \text { Left Steering } & .46 & .12 & -.06 & 50 \\ \text { Accelerator Up } & .40 & .48 & .24 & 50 \\ \text { Right Steering } & .38 & .14 & .03 & 50 \\ \text { Signaling } & .18 & .14 & -.04 & 50 \\ \text { Parking Brake } & .14 & .08 & .07 & 50 \\ \text { Negative Steering } & .04 & .04 & -.04 & 50 \\ \text { Total errors } & 2.36 & 1.68 & .50 & 50\end{array}$

Test-retest reliabilities for Lesson two $(n=29$ for each category) are: 1) brake errors, .14; 2) left steering errors, .00; 3) accelerator up errors, .01; 4) right steering errors, .08; 5) signaling errors, .20; 6) parking brake errors, .00; 7) negative steering errors, .02; and 8) total errors, -.06. These reliability coefficient are presented in Table 8. 
Table 8

Means and Test-Retest Reliability of Driving Simulators:

Lesson 2

Types of Errors

Brake

Left Steering

Accelerator Up

Right steering

Signaling

Parking Brake

Negative Steering

Total errors

$I^{*}=$ indeterminate (division by zero)

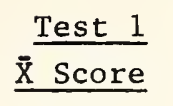

.93

.14

.14

.52

.21

.03

.35

2.11 $\frac{\text { Retest }}{\overline{\bar{X} \text { Score }}}$

.62

.00

.48

.35

.07

.00

.17

1.69

$-.06$

.02

\section{Preliminary Trials}

\section{Differences Between Groups}

Demonstration at high school A. Drivers who had had accidents and/or received tickets were chosen as demonstrators. They described the circumstances of three accidents they had had to several groups of students, while all subjects were seated in a car. The demonstrators then described and performed the driving behaviors which would have avoided each accident. No significant difference was found between the two high school juniors chosen as demonstrators and their audience (high school sophomores) on 
information given on the biographical section of the attitude test. An analysis of variance (presented in Table 9) using pre-demonstration attitude test scores showed a difference of borderline significance (.10 level) between the demonstrators and their audience on the attitude section of the attitude test.

\section{Table 9}

High School A: Analysis of Variance Considering Groups (Audience and Demonstrators) and Pre-Demonstration Attitude Section Test Scores as Main Effects

$\begin{array}{lcccc}\text { Source } & \text { M.S. } & \text { D.F. } & \text { F-ratio } & \text { P } \\ \text { Total } & 172.50 & 24 & & \\ \text { Groups } & 469.76 & 1 & 2.94 & .10 \\ \text { Error (G) } & 159.58 & 23 & \\ & \text { Group Means } & \\ \text { Audience } & 123.48 & \\ \text { Demonstrators } 107.50\end{array}$

Emotional role-playing at the university. Students were told to imagine themselves and act as if they were in a serious accident, in which they were seriously hurt, and in two minot accidents, in which they were bruised. They were then asked to imagine themselves in a court-room, giving testimony. Each student had a chance to play the part of the accused driver, and the other students played the parts of witnesses to the accident. There was no 
significance in background between the emotional roleplayers at the university and the control group as described by information given on the biographical section of the attitude test $(t=-.22, \mathrm{df}=25)$ or in attitudes toward driving, as described by answers given to the attitude section of the attitude test $(F(1,24)=.19)$.

\section{Effectiveness of Treatments}

There were two general treatments that were tried in the preliminary trials; emotional role-playing and demonstrations. Emotional role-playing consisted of students acting and feeling as if they were in a severe accident in which they were seriously hurt, in two minor accidents in which they were bruised. Students also emotionally roleplayed a court-room scene, in which one student was chosen to play the role of the accused driver, and the other students played the part of the other driver or passengers in the cars, and the students gave testimony. Some groups at the university emotionally role-played a deposition scene, instead of a court-room scene. The only difference was that there was no judge in the deposition scene.

In addition, preliminary trials were made of the demonstration technique. Students who had had accidents were chosen to be demonstrators. Each demonstrator described the circumstances of three accidents he had had, and then described and performed the driving behavior except for starting the engine, which would have avoided each 
accident. The demonstrations were made in cars: each demonstrator and from four to six students who acted as his audience were seated in a car. Each demonstrator repeated his presentation for several groups of students.

Demonstration at High School A. There was no significant difference between the audience's scores on the attitude section on the pretest or the posttest. Trials were also not a significant effect. There was a borderline (.09 level) significant group $\mathrm{x}$ treatment interaction. A Newman-Keuls Sequential Range test was then computed to determine which differences among the means were significant. It was found that there was a significant difference (.05 leve1) between the pretest attitude test scores of the demonstrators and the audience, and between the post-test scores of the audience and the pretest scores of the demonstrators. Although not a significant change, the demonstrators' pretest.mean score was 107.50 and their posttest mean score was 117.00. Further, there was no significant difference between the posttest scores of the audience and the posttest or pretest scores of the audience. These analyses are presented in Table 10.

Emotional role-playing at the university. No significant difference was found due to treatment or due to groups (role-players and control group) or an interaction between groups and treatments. This analysis is presented in Table 11. 
Table 10

High School A: Analysis of Variance Considering Groups (Demonstrators and Audience) and Pre- and PostDemonstration Attitude Section Test Scores as Main Effects

$\begin{array}{lrrrr}\text { Source } & \text { M.S. } & \text { D.F. } & \text { F-ratio } & \text { P } \\ \text { Total } & 196.61 & 49 & & \\ \text { Between } & 357.54 & 24 & & \\ \text { Groups } & 380.10 & 1 & 1.07 & .31 \\ \text { Error(G) } & 356.56 & 23 & & \\ \text { Within } & 42.12 & 25 & .46 & .51 \\ \text { Trials } & 18.00 & 1 & 3.14 & .09 \\ \text { Gx T } & 124.45 & 1 & & \\ \text { Error(T) } & 39.59 & 23 & \end{array}$

Ranked Means ( $\mathrm{G} \times \mathrm{T}$ )

1. 123.48 Audience, pretreatment $n=23$

2. 121.35 Audience, post-treatment $n=23$

3. 117.00 Demonstrators, post-treatment $n=2$

4. 107.50 Demonstrators, pretreatment $n=2$

Table of Differences Among Means

\begin{tabular}{|c|c|c|}
\hline Rank & 4 & 3 \\
\hline 1 & $15.98 *$ & 6.48 \\
\hline 2 & $13.85^{*}$ & 4.35 \\
\hline 3 & 9.50 & \\
\hline
\end{tabular}


Table 11

University Subjects: Analysis of Variance Considering Groups and Pre- and Post-Demonstration Attitude Section Test Scores Main Effects

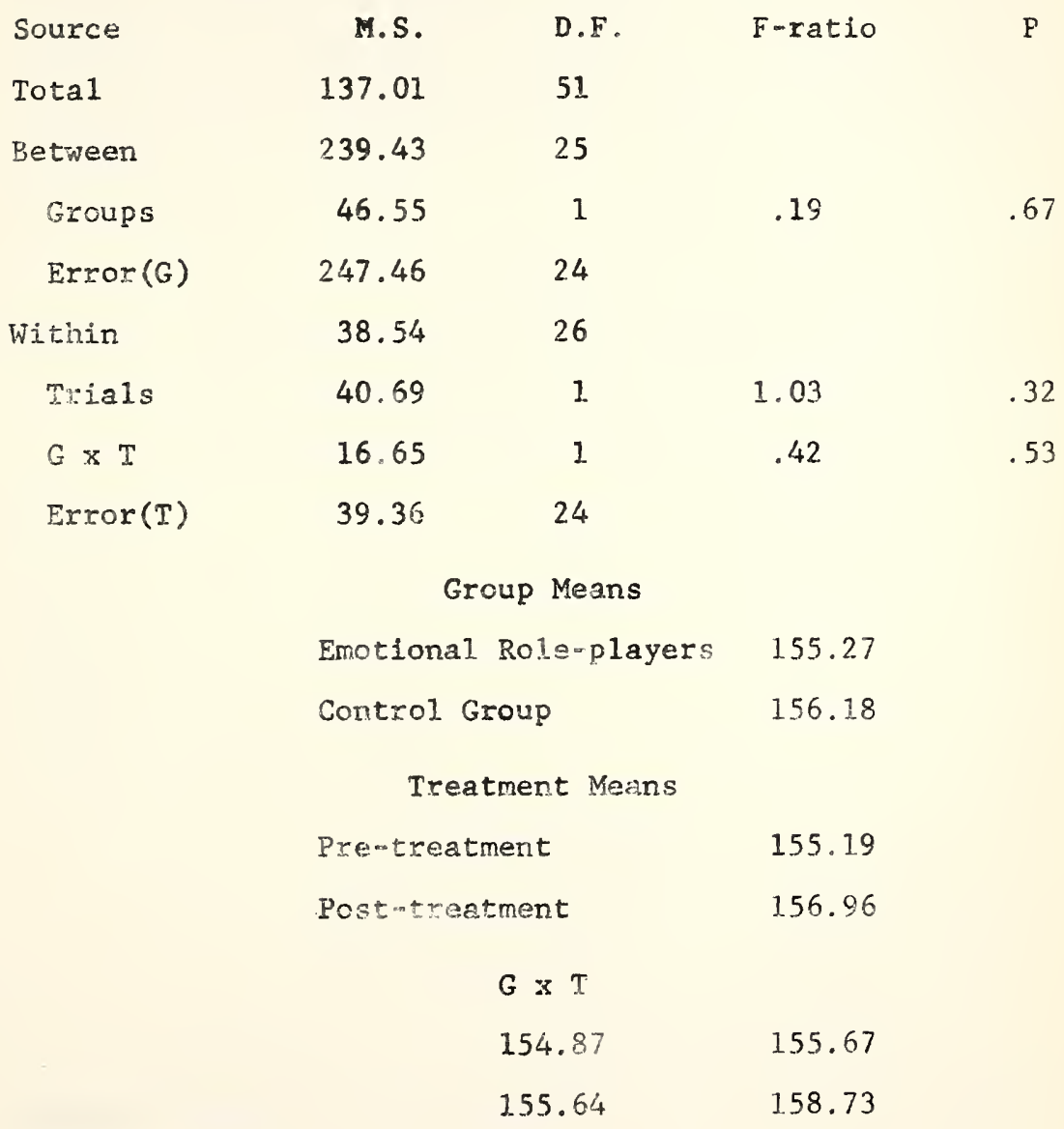


Demonstration at the university. As there was only one demonstrator, the demonstrator and audience $(n=9)$ scores were considered together and pre- and post-treatment test scores were considered in an analysis of variance for repeated measures (presented in Table 12), as main effects. A difference of borderline significance (.06 level) between attitude section scores before and after the demonstration was found.

Table 12

University Subjects: Analysis of Variance: Considering One Group (Audience and Demonstrator) and Pre- and Post-Demonstration Test Scores as Main Effects

$\begin{array}{lrrrc}\text { Source } & \text { M.S. } & \text { D.F. } & \text { F-ratio } & \text { P } \\ \text { Tota1 } & 114.69 & 19 & & \\ \text { Between } & 230.58 & 9 & & \\ \text { Trials } & 33.80 & 1 & 4.33 & .06 \\ \quad \text { Error (T) } & 7.80 & 9 & & \end{array}$

Treatment Means

$\begin{array}{ll}\text { Pre-demonstration } & 153.50 \\ \text { Post-demonstration } & 156.10\end{array}$

In addition, two other analysis of variance for repeated measures were computed. As some of the members of the audience had previously participated in an emotional role-playing trial, which may have had an influence on the effectiveness of the demonstration, subjects were divided 
into two groups, members of the audience who had also been emotional role-players and members of the audierce who had not been emotional role-players. The first analysis of variance for repeated measures (pre- and post-demonstration) considered these two groups, and a difference of borderline significance (.05 leve1) was found in test scores due to the effect of the demonstration. This analysis is presented in Table 13. The second analysis of vaxiance was also for repeated measures, and this time included the test scores before any of the preliminary trials were made (pre-treatment test scores) and the pre- and post-demonstration test scores; 1.e., three test scores for each individual subject. Also, the two groups of members of the audience who were and were not emotional role-players was considered.

\section{Table 13}

University Subjects: Analysis of Variance Considering Groups (Audience who were Non-Role-Players and Audience who Were Rolemplayers) and Pre- and Post-Demonstration Attitude Section Test Scores as Main Effects

$\begin{array}{lrrrr}\text { Source } & \text { M.S. } & \text { D.F. } & \text { F-ratio } & P \\ \text { Total } & 114.69 & 19 & & \\ \text { Between } & 230.58 & 9 & & \\ \quad \text { Groups } & .34 & 1 & .00 & .97 \\ \text { Error(B) } & 259.36 & 8 & & \end{array}$


Table 13, cont.

$\begin{array}{ccccc}\text { Source } & \text { M.S. } & \text { D.F. } & \text { F-ratio } & \text { P } \\ \text { Within } & 10.40 & 10 & & \\ \text { Trials } & 33.80 & 1 & 4.99 & .05 \\ \text { G } & 16.01 & 1 & 2.36 & .16 \\ \text { Error(T) } & 6.77 & 8 & & \end{array}$

Treatment Means

$\begin{array}{ll}\text { Pre-demonstration } & 153.50 \\ \text { Post-demonstration } & 156.10\end{array}$

A significant difference was obtained due to treatments, and a Newman-Keuls Sequential Range Test was used to determine which differences among treatment mean scores were significant. A significant difference (.05 leve1) was discovered between the pre-treatment test scores (before any experimental treatments) and the post-demonstration test scores. These analyses are presented in Table 14.

\section{Quasi-Experiments}

Differences Between High Schools A and B Although no hypotheses were made with respect to the influence of differences due to general background of the students, it was thought advisable to compare the background of the students at high schools $A$ and $B$. If significant differences were found between school populations in general background, separate analyses of data would be made for each school. 


\section{Table 14}

Analysis of Variance Considering Groups (Audiance Members Who Had Emotional Role-Pleyed and Audience Members and Demonstrators tho Ury not Enotional Role-played) and Pre-Emotional Role-Playing and Pre- and Post-Demonstration Attitude Section Test Scores as Main Effects

$\begin{array}{lrrrr}\text { Source } & \text { M.S. } & \text { D.F. } & \text { Fratio } & \text { P } \\ \text { Total } & 133.27 & 29 & & \\ \text { Between } & 402.25 & 9 & & \\ \text { Groups } & 5.36 & 2 & .01 & .91 \\ \text { Error(G) } & 451.39 & 8 & & \\ \text { Within } & 12.23 & 20 & & .03 \\ \text { Trials } & 37.73 & 2 & 4.46 & .17 \\ \text { Gris } & 16.93 & 2 & 2.00 & \\ \text { Error }(T) & 5.46 & 16 & & \end{array}$

Newwan-nads Sequential Range Test Ranked Means

1. 156.10 Eost-Demonstration Trials, $\mathrm{n}=10$

2. 153.50 Pemenonstration Iriais, $n=10$

3. 152.30 Pre-Fotione Role-playing Trials (f.e., no experimentai treatnents) $3=10$

Talo of Differences Between the Means

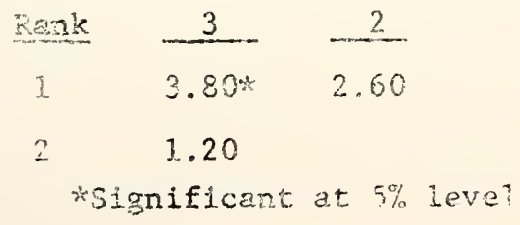


An analysis of variance was uscd to discover differences between hich schools A and B student populations as measured by scorcs on the attithde section, biographical section, or total test score. A significant tifference (.00 level) was fourd between groups on the biographical section. A Nownan-keuls Sectuential Range Test indicated significent difieronces between the experimental group of high school B and the control group of high school. A (.05 level) and between the experimental broup of high school $B$ and the experimental group of tigh school A (.01 leve1). No difference was found between the experimential and control groups at high school. A or those at high schoul B. These analyses are presented in Table 15.

\section{Tabie 1.5}

Analysis of Vaxiance Consjdering Grips (High Schools $A$ and $B$ ) and Pre-Treatment viograhical Section Test Scores as Vain Efrects

Source

Total

Groups

Error(G)
M.S.

37.04

208.47

31.79
D.F.

101

3

98
F-ratjo

P .00 
Table 15, cont.

Newman-Keuls Sequential Range Test

\section{Ranked Means}

1.50.42 $n=41$ High School B, Experimental group

$2.48 .72 n=32$ High School $B$, Control group

3.44.44 a-13 High School A, Experinental group

4.44.36 $n=11$ High Schoo1 A, Control group

Table of differences between means

$$
\begin{aligned}
& \text { Fagk } \quad 4 \quad-3 \quad 2 \quad 2 \\
& \text { I. } \quad 6.05 \% \quad 5.97 * 2.70 \\
& \text { 2. } 4.36 \quad 4.27 \\
& \text { 3. } .08 \\
& \text { * Significant at } 5 \% \text { level } \\
& \text { wrsignificant at } 1 \% \text { level }
\end{aligned}
$$

Effectiveness of Ireatment: Attitude Test Criterion

As indicated previously, there were four sections of the treatment (the developmental curricuia element) preserited to high schoo! B and three sections of the treatment prosented to $7 \mathrm{~g}_{\mathrm{g}}$ school A.

The fitst sectiot, presented at high school B only, consisted of the game "First Tmpression". This game was player to allow otudents to benome accivanted with other students in the class, as inany sudents did not lncw each other. Furthox, since students discussed personal information, it was hoped that students would teel less constrained to talk about theis personal feolings in class after playing 
this game. As students in the experimental group at high school A (a very sma11 school) were well acquainted with each other, this game was not played.

The second section of this treatment consisted of having live and video-taped models present alternative behaviors to that of driving while under the influence of strong emotions. Further, the models were presented in realistic situations (a student angry at his teacher, etc.) and the skits helped to stimulate discussion of what emotion the model felt, how his behavior reflected his emotional state, how the subjects would feel and act under emotional stress, how the stressful situation could have been prevented, etc. The game "break-in" ended this section.

The third section of this treatment consisted of demonstrators who were students from the school at which the demonstrstion was presented and who had had automobile accidents describe the circumstances surrounding their accidents. The students then discussed the driving behaviors the demonstrators could have performed to prevent their accidents, and more importantly, the emotional state of the demonstrators which may have precipitated the accident.

The fourth section was emotional role-playing. A deposition scene was enacted, in which the "accused driver" and "his passengers", etc., gave testimony as to what occurred at the time of the accident. Also, role-playing of situations was performed by subjects in the experimental groups throughout sections two (video-taped and live models) 
and three (demonstration) in order to personalize the presented situations further, and for various members of the experimental groups to develop behaviors which would enable them to eliminate situations which might tend to be emotionally stressful; i.e., a "mother" and "daughter" discussing the situation calmly rather than the "daughter" yelling at the mother, etc.

Subjects in the experimental and control groups at each school were tested immediately before the start of the treatment (the biographical section and the attitude section). They were retested at the conclusion of section two (live and video-taped models) and again at the conclusion of section four (emotional role-playing). (See Figure 2)

(Pre-treatment test: biographical and attitude sections)

Section 1: First Impression (high school B only)

Section 2: Live and Video-taped Models

(Mid-treatment test: attitude and driving behaviors sections)

Section 3: Demonstrations

Section 4: Emotional Role-Playing

(Post-treatment test: attitude and driving behaviors sections)

Figure 2

Sequence of Treatment Sections and Testing in Quasi-Experiments 
High School A. Nine analyses of variance with repeated measures were used to analyze the effectiveness of the treatments, as reflected in the attitude test scores.

The first analysis of variance considered two groups, experimental and control, and pre- and post-treatment attitude section test scores as main effects and is presented in Table 16. No significant difference was found due to main effects of to interaction between the main effects.

\section{Table 16}

High School A: Analysis of Variance Considering Groups (Experimental and Control) and Pre- and Post-Treatment Attitude Section Test Scores as Main Effects

$\begin{array}{lrrrr}\text { Source } & \text { M.S. } & \text { D.F. } & \text { F-ratio } & \text { P } \\ \text { Total } & 106.60 & 57 & & \\ \text { Between } & 182.52 & 28 & & \\ \quad \text { Groups } & 198.55 & 1 & 1.09 & .31 \\ \quad \text { Error(G) } & 181.93 & 27 & & \\ \text { Within } & 33.29 & 29 & & .71 \\ \quad \text { Trials } & 4.98 & 1 & .14 & .77 \\ \quad \text { Gx T } & 3.14 & 1 & & \\ \quad \text { Error (T) } & 35.46 & 27 & & \end{array}$

The second analysis of variance considered two groups, experimental and control, and pre-treatment, mid-treatment and post-treatment attitude section test scores as main effects and is presented in Table 17. No significant 
difference was found due to aither main effect or to an interaction between groups and txeatment test scores.

\section{Table 17}

High School A: Analysis of Variance Considering Groups (Experinental and Control) and Pre- Mid- and Postmrearnent Attitude Section Test Scores as Main Erjeces

\begin{tabular}{|c|c|c|c|}
\hline Source & M.S. & $0 . R$. & E-ratio \\
\hline Total & 97.59 & 86 & \\
\hline Between & 248.51 & 28 & \\
\hline Groups & 231.31 & 1 & .95 \\
\hline Error $(G)$ & 248.34 & 27 & \\
\hline Within & 24.72 & 58 & \\
\hline Trials & 16.17 & 2 & .63 \\
\hline$G z_{I}$ & 5.03 & 2 & .20 \\
\hline Erros(T) & 25.77 & 54 & \\
\hline
\end{tabular}

The third analysis of variance considered two groups, experimental and control, and mid-and post-treatment attitude section tast scores as main effects ard is presented in Table IC. No sogrificant differences were found.

The fourth analyis of variance considered two troups, experimental and control, and mid-and post-treatment driving behaviong section test scores as main effects and is presented in Table 19. Again, no significant differences were found. 
Table 18

High School A: Analysis of Variance Considering Groups (Experimental and Control) and Mid- and Post-Treatment Attitude Section Test Scores As Main Effects

$\begin{array}{lrrrc}\text { Source } & \text { M.S. } & \text { D.F. } & \text { F-ratio } & \text { P } \\ \text { Tota1 } & 104.81 & 57 & & \\ \text { Between } & 188.34 & 28 & & .63 \\ \quad \text { Groups } & 161.30 & 1 & .85 & \\ \quad \text { Error(G) } & 189.34 & 27 & & \\ \text { Within } & 24.16 & 29 & & .26 \\ \text { Trials } & 31.88 & 1 & 1.30 & .53 \\ \text { Gx T } & 10.01 & 1 & .41 & \\ \text { Error }(T) & 24.39 & 27 & & \end{array}$

\section{Table 19}

High School A: Analysis of Variance Considering Groups (Experimental and Control) and Mid- and Post-Treatment Driving Behaviors Section Test Scores as Main Effects

$\begin{array}{lrrrc}\text { Source } & \text { M.S. } & \text { D.F. } & \text { F-ratio } & \text { P } \\ \text { Total } & 34.87 & 57 & & \\ \text { Between } & 65.60 & 28 & & \\ \quad \text { Groups } & 16.55 & 1 & .25 & .63 \\ \quad \text { Error(G) } & 67.42 & 27 & & \\ \text { Within } & 5.19 & 29 & & .78 \\ \quad \text { Trials } & .43 & 1 & .08 & .57 \\ \text { Gx T } & 1.91 & 1 & .35 & \\ \quad \text { Error(T) } & 5.49 & 27 & & \end{array}$


The fifth analysis of variance considered two groups, experimental and control, and mid-and post-treatment combined scores of the attitude section and driving behaviors section, and is presented in Table 20. No significant differences were found.

\section{Table 20}

High School A: Analysis of Variance Considering Groups (Experimenta1 and Control) and Mid- and Post-'Treatment Combined Scores of Driving Behaviors and Attitude Sections as Main Effects

$\begin{array}{lrrrc}\text { Source } & \text { M.S } & \text { D.F. } & \text { F-ratio } & \text { P } \\ \text { Total } & 225.62 & 57 & & \\ \text { Between } & 427.15 & 28 & & \\ \text { Groups } & 74.51 & 1 & .17 & .69 \\ \quad \text { Error(G) } & 440.21 & 27 & & \\ \text { Within } & 31.03 & 29 & & .61 \\ \quad \text { Tria1s } & 24.90 & 1 & .17 & .75 \\ \quad \text { Gx T } & 3.18 & 1 & & \\ \quad \text { Error (T) } & 32.29 & 27 & & \end{array}$

The next four analyses of variance for repeated measures considered not only two groups, experimental and control, but sex, as between subjects main effects. Of these analyses of variance, the first considered pre-, mid-and post-treatment attitude section test scores as within subjects main effects, and is presented in Table 21. 
No significant differences were found due to any of the main effects, nor was any interaction of main effects significant.

Table 21

High School A: Analysis of Varlance Considering Groups

(Experimental and Control), Sex, and Pre-, Mid- and Post-Treatment Attitude Section Test Scores as Main Effects

Source

M.S.

D.F.

F-ratio

$\mathrm{P}$

Between Subjects Variance

$\begin{array}{lrrrr}\text { A(Groups) } & 319.69 & 1 & 1.21 & .28 \\ \mathrm{~B}(\text { Sex) } & 28.55 & 1 & .11 & .74 \\ \mathrm{AB} & 151.10 & 1 & .58 & .54 \\ \operatorname{Error}(B) & 262.75 & 25 & & \end{array}$

Within Subjects Varlance

$\begin{array}{lrrrr}\text { T(Tria1s) } & 16.81 & 2 & .62 & .55 \\ \text { AT } & 5.50 & 2 & .20 & .82 \\ \text { BT } & 5.20 & 2 & .19 & .83 \\ \text { ABT } & 13.70 & 2 & .51 & .61 \\ \text { E (W) } & 27.02 & 50 & & \end{array}$

The next three analyses of variance for repeated measures which considered experimental and control groups and sex as between subjects main effects also found no significant differences. The first analysis also considered mid-and post-treatment attitude section test scores as 
the within subjects main effect and is presented in Table 22. The second analysis also considered mid- and posttreatment driving behaviors test scores as the within subjects main effect, and is presented in Table 23.

Finally, the last analysis of variance also considered midand post-treatment combined scores of the attitude and driving behaviors sections and is presented in Table 24.

\section{Table 22}

High School A: Analysis of Variance Considering Groups

(Experimental and Control), Sex, and Mid- and PostTreatment Attitude Section Test Scores as Main Effects Source M.S.

D.F.

F-ratio $\mathrm{P}$

Between Subjects Variance

$\begin{array}{lrrrr}\text { A(Groups) } & 194.01 & 1 & .96 & .66 \\ B \text { (Sex) } & 9.66 & 1 & .05 & .82 \\ A B & 56.45 & 1 & .28 & .61 \\ \text { Error(B) } & 202.22 & 25 & & \end{array}$

Within Subjects Variance

$\begin{array}{lrrrr}\text { T(Trials) } & 28.89 & 1 & 1.13 & .30 \\ \text { AT } & 9.66 & 1 & .38 & .55 \\ \text { BT } & 5.67 & 1 & .22 & .65 \\ \text { ABT } & 8.29 & 1 & .33 & .58 \\ \text { Error }(W) & 25.50 & 25 & & \end{array}$


Table 23

High School A: Analysis of Variance Considering Groups (Experimental and Control), Sex, and Mid- and PostTreatment Driving Behaviors Section Test Scores as Main Effects

Source M.S. D.F. F-ratio P Between Subject Variance

$\begin{array}{lrrrr}\mathrm{A} \text { (Groups) } & 14.82 & 1 & .20 & .66 \\ \mathrm{~B} \text { (Sex) } & 1.14 & 1 & .02 & .90 \\ \mathrm{AB} & 1.65 & 1 & .02 & .88 \\ \text { Error }(B) & 72.65 & 25 & & \end{array}$

Within Subject Variance

$\begin{array}{lrrrr}\text { T(Tria1s) } & .03 & 1 & .00 & .95 \\ \text { AT } & .39 & 1 & .07 & .79 \\ \text { BT } & 1.27 & 1 & .22 & .65 \\ \text { ABT } & 3.76 & 1 & .65 & .57 \\ \operatorname{Error}(W) & 5.77 & 25 & & \end{array}$


Table 24

High School A: Analysis of Variance Considering Groups (Experimental and Control), Sex, and Mid- and PostTreatment Combined Attitude and Driving Behaviors Section Test Scores as Main Effects

Source M.S.

D.F. F-ratio P

Between Gubjects Variance

$\begin{array}{lrrrr}\text { A(Groups) } & 101.61 & 1 & .22 & .65 \\ B(\text { Sex) } & 4.16 & 1 & .01 & .92 \\ A B & 77.38 & 1 & .16 & .69 \\ \text { Error }(B) & 472.29 & 25 & & \end{array}$

Within Subjects Variance

$\begin{array}{lrrrr}\text { T(Trials) } & 27.23 & 1 & .80 & .62 \\ \text { AT } & 6.15 & 1 & .18 & .68 \\ \text { BT } & 12.30 & 1 & .36 & .56 \\ \text { A.BT } & .89 & 1 & .03 & .87 \\ \text { Error }(W) & 34.18 & 25 & & \end{array}$

In short, no significant differences due to any main effect (treatment, groups or sex) or any significant interactions were found at high school A.

High school B. Eleven analyses of variance for repeated neasures were used to analyze the effectiveness of the treatment, as reflected in the attitude test scores.

The first six analyses of variance considered two groups (expertmental and control) as a main effect. In addition, the first analysis of variance also considered 
pre-, mid- and post-treatment attitude section test scores as a main effect which is presented in Table 25 . No significant differences were found due to main effects or due to interactions between the main effects.

\section{Table 25}

High School B: Analysis of Variance Considering Groups (Experimental and Contro1), and Pre-, Mid- and PostTreatment Attitude Section Test Scores as Main Effects

$\begin{array}{lrrrr}\text { Source } & \text { M.S. } & \text { D.F. } & \text { F-ratio } & \text { P } \\ \text { Total } & 92.96 & 161 & & \\ \text { Between } & 221.43 & 53 & & \\ \quad \text { Groups } & 23.01 & 1 & .10 & .75 \\ \quad \text { Error(G) } & 225.25 & 52 & & \\ \text { Within } & 29.91 & 108 & & .58 \\ \quad \text { Trials } & 16.80 & 2 & .56 & .97 \\ \quad \text { GX T } & 29.34 & 2 & & \\ \text { Error (T) } & 30.18 & 104 & & \end{array}$

The second analysis of variance also considered preand post-treatment attitude section test scores as a main cffect which is presented in Table 26. No significant differences were found. 


\section{Table 26}

High School B: Analysis of Variance Considering Groups (Experimental and Control), and Pre- and PostTreatment Attitude Section Test Scores as Main Effects

$\begin{array}{lrrrr}\text { Source } & \text { M.S. } & \text { D.F. } & \text { F-ratio } & \text { P } \\ \text { Total } & 93.94 & 119 & & \\ \text { Between } & 149.21 & 59 & & \\ \quad 155.87 & 1 & 1.05 & .31 \\ \quad \text { Groups } & 149.09 & 58 & & \\ \text { Exror(G) } & 39.59 & 60 & & .62 \\ \text { Within } & 10.21 & 1 & .25 & .67 \\ \text { Trials } & 7.81 & 1 & .19 & \\ \text { Gx T } & 40.65 & 58 & & \end{array}$

The third analysis of variance considered pre- and midtreatment attitude section test scores, as well as groups, as main effects and is presented in Table 27. A significant (.05 leve1.) group $x$ treatment interaction effect was found. However, Newman-Keuls Sequential Mean Test found no significant differences between the means.

The fouxth analysis of variance considered mid- and post-treatment attitude section test scores, as well as groups, as main effects and is presented in Table 28. No significant differences were found as a result of this anaiysis. 
Table 27

kigh School B: Analysis of Variance Considering Groups (Experimental and Contro1), and Pre- and MidTreatment Attitude Section Scores as Main Effects

$\begin{array}{lrrrr}\text { Source } & \text { M.S. } & \text { D.F. } & \text { Fratio } & \text { F } \\ \text { TotaI } & 86.93 & 103 & & \\ \text { Between } & 145.73 & 51 & & .80 \\ \text { Groups } & 9.18 & 1 & .06 & \\ \text { Error(G) } & 148.46 & 50 & & .17 \\ \text { Within } & 29.26 & 52 & & .05 \\ \text { Tria1s } & 51.24 & 1 & 1.88 & \\ \text { Gx T } & 110.18 & 1 & 4.05 & \\ \text { Error(T) } & 27.20 & 50 & & \end{array}$

Newman-Keuls Sequential Range Test Ranked Means

\begin{tabular}{|c|c|c|}
\hline 1. 117.37 & $n=30$ & $\begin{array}{l}\text { Experimenta i Group, } \\
\text { Treatment }\end{array}$ \\
\hline 2. 115.68 & $\mathrm{n}=22$ & $\begin{array}{l}\text { Sontrol Group, Mid- } \\
\text { Treatment }\end{array}$ \\
\hline 3. 114.68 & $n=22$ & $\begin{array}{l}\text { Concrol Group, Pre- } \\
\text { Treatment }\end{array}$ \\
\hline 4. 114.20 & $n=30$ & $\begin{array}{l}\text { Experimental Group, } \\
\text { Treatment }\end{array}$ \\
\hline
\end{tabular}

mole of Differences Between Mean

$\begin{array}{lrrr}\text { Eank } & \frac{4}{1.17} & \frac{3}{2.67} & 1.67 \\ 1 . & 3.17 & -2 \\ 2 . & 1.48 & 1.00 & \\ 3 . & .48 & & \end{array}$




\section{Table 28}

High School B: Analysis of Variance Considering Groups (Experimental and Control) and Mid- and PostTreatment Attitude Section Test Scores as Main Effects

$\begin{array}{lrrrr}\text { Source } & \text { M.S. } & \text { D.F. } & \text { F-ratio } & \text { P } \\ \text { Total } & 99.61 & 119 & & \\ \text { Between } & 180.58 & 59 & & \\ \quad \text { Groups } & 34.38 & 1 & .19 & .67 \\ \quad \text { Error(G) } & 183.10 & 58 & & \\ \text { Within } & 19.98 & 60 & & .53 \\ \text { Trials } & 10.80 & 1 & .54 & .27 \\ \text { Gx T } & 24.99 & 1 & 1.25 & \\ \text { Error(G) } & 20.06 & 58 & & \end{array}$

The fifth analysis of variance also considered midand post-treatment driving behaviors scction test scores as main effects and is presented in Table 29. Once again, no significant differences were found.

Finally, the fifth analysis of variance considered groups and mid-and post-treatment combined test scores of the attitude section and driving behaviors section and is presented in Tabje 30. No significant differences were found due to mein effects and no significant interaction effects were found.

The next five analyses of variance for repeated measures considered, in addition to groups (experimental and control), sex as main effects. An analysis of variance 
Table 29

High School B: Analysis of Variance Considering Groups

(Experimental and Control), and Mid- and Post-

Treatment Driving Behaviors Section Test Scores as Main Effects

$\begin{array}{lrrrc}\text { Source } & \text { M.S. } & \text { D.F. } & \text { F-ratio } & \text { P } \\ \text { Total } & 52.04 & 119 & & \\ \text { Between } & 73.43 & 59 & & \\ \quad \text { Groups } & 130.73 & 1 & 1.81 & .18 \\ \quad \text { Error(G) } & 72.45 & 58 & & \\ \text { Within } & 31.01 & 60 & & .64 \\ \quad \text { Trials } & 7.01 & 1 & .23 & .16 \\ \text { Gx T } & 60.24 & 1 & 1.95 & \\ \text { Error(T) } & 30.92 & 58 & & \end{array}$

Table 30

High School B: Analysis of Variance Considering Groups

(Experimental and Control), and $\mathrm{Vid}$ - and Post-

Treatment Combined Test Scores of the Attitude and

Driving Behaviors Sections as Main Effects

$\begin{array}{lrrrc}\text { Source } & \text { M.S. } & \text { D.F. } & \text { F-ratio } & \text { P } \\ \text { Total } & 208.82 & 119 & & \\ \text { Between } & 357.61 & 59 & & \\ \quad \text { Groups } & 299.20 & 1 & .83 & .63 \\ \quad \text { Error(G) } & 358.62 & 58 & & \\ \text { Within } & 62.51 & 60 & & .93 \\ \quad \text { Trials } & .41 & 1 & .01 & .73 \\ \text { Gx T } & 7.63 & 1 & .12 & \\ \quad \text { Error(T) } & 64.53 & 58 & & \end{array}$


considering sex, groups and pre-, mid-and post-treatment attitude section test scores as main effects found a significant difference (.00 level) due to sex and is presented in Table 31. No significant interaction effects were found.

\section{Table 31}

High School B: Analysis of Variance Considering Groups (Experimental and Contro1), Sex, and Pre-, Mid- and PostTreatment Attitude Section Test Scores as Main Effects

Source M.S.

D.F. F-ratio

Between Subjects Variance

$\begin{array}{lrrrr}\mathrm{A} \text { (Groups) } & .73 & 1 & .00 & .95 \\ \mathrm{~B}(\text { Sex }) & 1632.28 & 1 & 8.74 & .00 \\ \mathrm{AB} & 26.39 & 1 & .14 & .71 \\ \text { Error }(B) & 186.75 & 50 & & \end{array}$

Within Subjects Variance

$\begin{array}{lrrrr}\text { T(Trials) } & 7.82 & 2 & .21 & .81 \\ \text { AT } & 51.77 & 2 & 1.41 & .25 \\ \text { BT } & 3.33 & 2 & .09 & .91 \\ \text { ABT } & 31.11 & 2 & .85 & .56 \\ \text { Error }(W) & 36.80 & 100 & & \end{array}$

B Main Effect

$$
\begin{aligned}
& \text { Boys' Mean Score } 110.48 \\
& \text { Girls'Mean Score } 117.52
\end{aligned}
$$


An analysis of variance that considered sex, groups, and pre- and post-treatment attitude section test scores found a significant difference, due to sex, and a significant groups $\mathbf{x}$ treatment interaction. A Newman-Keuls Sequential Means Test, however, found no significant differences between the means. These analyses are presented in Table 32.

\section{Table 32}

High School B: Analysis of Variance Considering Groups (Experimental and Contro1), Sex, and Pre- and MidTreatment Attitude Section Attitude Test Scores as Main Effects Source M.S. D.F. F-ratio P Between Subjects Variance

$\begin{array}{lrrrr}\text { A (Groups) } & 4.19 & 1 & .03 & .86 \\ \mathrm{~B}(\text { Sex }) & 935.19 & 1 & 6.94 & .01 \\ \mathrm{AB} & .28 & 1 & .00 & .96 \\ \operatorname{Error}(B) & 134.69 & 48 & & \end{array}$
Within Subjects Variance

$\begin{array}{lrrrr}\text { T(Trials) } & 13.12 & 1 & .47 & .50 \\ \text { AT } & 115.95 & 1 & 4.16 & .04 \\ \text { BT } & 15.06 & 1 & .54 & .53 \\ \text { ABT } & 8.74 & 1 & .31 & .59 \\ \text { Error }(W) & 27.90 & 48 & & \end{array}$

$B$ Main Effects Means

Boys 110.95

Girls 117.51 
Table 32, cont.

\section{Newman-Keuls Sequential Range Test}

\section{Ranked Means}

1. $115.99 \mathrm{n}=30$ Experimental Group, Pre-Treatment

2. $114.78 n=22$ Contro1 Group, Mid-Treatment

3. $113.24 \quad n=22$ Control Group, Pre-Treatment

4. $112.91 n=30$ Experimental Group, Mid-Treatment

Table of Differences Between the Means

\begin{tabular}{|c|c|c|c|}
\hline Rank & 4 & 3 & 2 \\
\hline 1. & 3.09 & 2.75 & 1.22 \\
\hline 2. & 1.87 & 1.53 & \\
\hline 3. & .34 & & \\
\hline
\end{tabular}

Another analysis of variance considered sex, groups, (experimental and control) and mid-and post-treatment attitude section test scores as main effects. A difference of borderline significane was found (.10 level) due to sex, and is presented in Table 33. No other significant differences were found and no significant interaction effects were found.

The third analysis of variance in this section considered sex, groups and mid-and post-treatment driving behaviors section test scores as main effects. Significant differences were found due to the main effects of groups and sex, and a significant groups $x$ sex interaction effect was found. A Newman-Keuls Sequential Range Test, however, 
Table 33

High Schoo1 B: Analysis of Variance Considering Groups (Experimental and Control), Sex, and Mid- and PostTreatment Attitude Section Test Scores as Main Effects Source M.S.

D.F. F-ratio $\mathrm{P}$

Between subjects variance

$\begin{array}{lrrrr}\text { A (Groups) } & 31.52 & 1 & .17 & .68 \\ \mathrm{~B}(\text { Sex }) & 503.54 & 1 & 2.74 & .10 \\ \mathrm{AB} & .26 & 1 & .00 & .97\end{array}$

Error(B) $\quad 183.76 \quad 55$

Within Subjects Variance

$\begin{array}{lrrrr}\text { T(Trials) } & 21.58 & 1 & 1.04 & .31 \\ \text { AT } & 40.45 & 1 & 1.96 & .16 \\ \text { BT } & 6.86 & 1 & .33 & .57 \\ \text { ABT } & 20.72 & 1 & 1.00 & .32 \\ \text { Error }(W) & 20.69 & & & \end{array}$

B Main Effect

$$
\begin{array}{ll}
\text { Boys'Mean Score } & 112.30 \\
\text { Girls'Mean Score } & 116.77
\end{array}
$$

found no significant differences between the groups $x$ sex means. These analyses are presented in Table 34.

Finally, an analysjs of variance considered sex, groups and mid-and post-treatment combined driving behaviors and attitude sections scores as main effects, and is presented in Table 35. A significant difference was again found due to the main effect sex. No other significant differences were found and no significant interaction effects were found. 
Table 34

High School B: Analysis of Variance Considering Groups

(Experimental and Control), Sex, and Mid- and PostTreatment Driving Behaviors Section Test Scores as Main Effects

Source M.S. D.F. F-ratio P

Between Subjects Variance

$\begin{array}{lrrrr}\text { A (Groups) } & 273.98 & 1 & 4.05 & .05 \\ \mathrm{~B} \text { (Sex) } & 265.17 & 1 & 3.92 & .05 \\ \mathrm{AB} & 289.26 & 1 & 4.28 & .04 \\ \text { Error }(\mathrm{B}) & 67.61 & 55 & & \end{array}$

Within Subjects Variance

$\begin{array}{lrrrr}\text { T(Trials) } & 26.85 & 1 & .84 & .63 \\ \text { AT } & 70.94 & 1 & 2.21 & .14 \\ \text { BT } & 13.32 & 1 & .42 & .53 \\ \text { ABT } & 15.45 & 1 & .51 & .52 \\ \operatorname{Error}(W) & 32.04 & 55 & & \end{array}$

A Main Effect

Experimental Group Mean 50.75

Control Group Mean $\quad 47.44$

B Main Effect
Boys Mean Score
47.47
Girls Mean Score
50.72 
Table 34, cont.

Newman-Keuls Sequential Means Test

Ranked Means

1. $50.82 \quad \mathrm{n}=11 \quad$ Experimental Group, Boys

2. $50.77 n=17$ Control Group, Girls

3. $50.67 n=23$ Experimental Group, Girls

4. $44.13 n=8 \quad$ Control Group, Boys

Table of Differences Between Means

\begin{tabular}{|c|c|c|c|}
\hline Rank & 4 & 3 & 2 \\
\hline 1. & 6.69 & .14 & .05 \\
\hline 2 . & 6.64 & .09 & \\
\hline 3. & 6.55 & & \\
\hline
\end{tabular}

Table 35

High School B: Analysis of Variance Considering Groups (Experimental and Control), Sex, and Mid- and PostTreatment Combined Driving Behaviors and Attitude Sections Test Scores as Main Effects

$\begin{array}{lcccc}\text { Source } & \text { M.S. } & \text { D.F. } & \text { F-ratio } & \text { P } \\ \text { Between Subjects } & \text { Variance } & & & \\ \text { A(Groups) } & 491.37 & 1 & 1.41 & .24 \\ \text { B(Sex) } & 1490.53 & 1 & 4.31 & .04 \\ \text { AB } & 306.89 & 1 & .88 & .65 \\ \text { Error(B) } & 348.32 & 55 & & \\ \text { Within Subjects } & \text { Variance } & & & .95 \\ \text { T(Trials) } & .29 & 1 & .00 & .80 \\ \text { AT } & 4.25 & 1 & .06 & .90 \\ \text { BT } & 1.06 & 1 & .01 & .95 \\ \text { ABT } & .25 & 1 & .00 & \\ \text { Error (W) } & 67.83 & 55 & & \end{array}$


Table 35, cont.

B Main Effect

$\begin{array}{ll}\text { Boys'Mean Score } & 159.77 \\ \text { Girls'Mean Score } & 167.49\end{array}$

The last four analyses of variance considered groups and race as main effects. The first of these analyses also considered pre-, mid- and post-treatment attitude section test scores as main effects and is presented in Table 36. The second of these analyses presented in Table 37, also considered mid-and post-treatment attitude section test scores as a main effect. The third of these analyses also considered mid- and post-treatment driving behaviors section test scores as a main effect and is presented in Table 38. The last of these analyses, presented in Table 39, also considered mid- and post-treatment combined attitude section and driving behavior section test scores as a main effect. No sfgnificant differences were found due to race, groups or treatment, and no significant interaction effects were found.

Effectiveness of Quasi-Experiment Treatment: Simulator Criterion

Driving simulators were used only at high School $B$ to test the effectiveness of the quasi-experiment treatment. Students were tested under two conditions: a regular classroom session on the simulators in mid-treatment and after 


\section{Table 36}

High School B: Analysis of Variance Considering Groups (Experimental and Control), Race, and Pre-, Mid- and Post-Treatment Attitude Section Test Scores as Main Effects

Source

M.S.

D.F.

F-ratio

P

Between Subjects Variance

$\begin{array}{lrrrr}\text { A(Groups) } & 3.27 & 1 & .02 & .90 \\ \text { B(Race) } & 2.64 & 1 & .01 & .91 \\ \text { AB } & 352.69 & 1 & 1.64 & .20 \\ \text { Error(B) } & 214.64 & 50 & & \\ \text { Within Subjects } & \text { Variance } & & & \\ \text { T(Trials) } & 22.49 & 2 & .62 & .54 \\ \text { AT } & 21.97 & 2 & .61 & .55 \\ \text { BT } & 41.91 & 2 & 1.16 & .32 \\ \text { ABT } & 7.50 & 2 & .21 & .82 \\ \text { Error (W) } & 36.27 & 100 & & \end{array}$

Table 37

High School B: Analysis of Variance Considering Groups

(Experimental and Contro1), Race, and Mid- and PostTreatment Attitude Section Test Scoses as Main Effects Source M.S. D.F. F-ratio $\mathrm{P}$ Between Subjects Variance

$\begin{array}{lrrrr}\mathrm{A} \text { (Groups) } & 26.85 & 1 & .15 & .70 \\ \mathrm{~B} \text { (Race) } & 14.08 & 1 & .08 & .77 \\ \mathrm{AB} & 285.16 & 1 & 1.64 & .20 \\ \text { Error }(\mathrm{B}) & 173.92 & 50 & & \end{array}$

Within Subjects Vaxiance

$\begin{array}{lrr}\text { T(Trials) } & 6.33 & 1 \\ \text { AT } & 2.77 & 1 \\ \text { BT } & 6.45 & 1 \\ \text { ABT } & 7.76 & 1 \\ \operatorname{Error}(W) & 28.86 & 50\end{array}$




\section{Table 38}

High School B: Analysis of Variance Considering Groups (Experimental and Control), Race, and Mid- and PostTreatment Driving Behaviors Section Test Scores as Main Effects

Source

M.S.

D.F.

F-ratio

Between Subjects Variance

$\begin{array}{lrrrr}\mathrm{A} \text { (Groups) } & 66.64 & 1 & .98 & .67 \\ \mathrm{~B} \text { (Race) } & 2.49 & 1 & .04 & .84 \\ \mathrm{AB} & 33.66 & 1 & .47 & .51 \\ \text { Error(B) } & 67.81 & 50 & & \end{array}$

Within Subjects Variance

$\begin{array}{lrrrr}\text { T(Trials) } & 25.07 & 1 & .55 & .53 \\ \text { AT } & 59.05 & 1 & 1.30 & .26 \\ \text { BT } & 6.07 & 1 & .13 & .72 \\ \text { ABT } & .61 & 1 & .01 & .90 \\ \text { Error (W) } & 45.34 & 50 & & \end{array}$

Table 39

High School B: Analysis of Variance Considering Groups (Experimental and Control), Race, and Mid-and PostTreatment Combined Driving Behaviors and Attitude Sections Test Scores as Main Effects

Source M.S.

D.F. F-ratio

Between Subjects Variance

$\begin{array}{lrrrr}\text { A (Groups) } & 8.89 & 1 & .03 & .87 \\ \mathrm{~B} \text { (Race) } & 4.73 & 1 & .01 & .90 \\ \mathrm{AB} & 514.78 & 1 & 1.50 & .22 \\ \operatorname{Error}(B) & 343.20 & 50 & & \end{array}$

Within Subjects Variance

$\begin{array}{lrrrr}\text { T(Trials) } & 6.21 & 1 & .07 & .79 \\ \text { AT } & 36.23 & 1 & .38 & .55 \\ \text { BT } & 25.04 & 1 & .26 & .62 \\ \text { ABT } & 4.01 & 1 & .04 & .83 \\ \operatorname{Error}(W) & 94.97 & 50 & & \end{array}$


being aroused to anger before a regular classroom session on the simulators post-treatment. Students made eight general types of errors; brake errors, left steering errors, accelerator up errors, right steering errors, signaling errors, parking brake errors, negative steering errors, and total errors. Analyses of variance for repeated measures which considered groups (experimental and control) and midand post-treatment error scores as main effects were computed for each general category of error score, and were used to analyze the effectiveness of the treatment.

The following results were obatined. First, no significant differences were found for the analysis of variance using brake error criterion category scores (See Table 40 for a presentation of the analysis). Second, a significant difference due to trials was found in the analysis of variance (presented in Table 41) for left steering errors, but no significant difference was found due to groups, and there were no significant interactions. Third, a difference of borderline significance (.05) was attributable to groups, but no significant differences were found due to trials in the analysis considering accelerator up errors as a main effect (presented in Table 42). Also, no significant interactions were found. There were two significant differences, one due to groups and one due to trials, found, however, in the analysis (presented in Table 43) of right steering errors, although no significant interaction was found. 
Table 40

Simulator Test Results: Analysis of Variance Considering Brake Error Scores and Groups (Experimental and Control) as Main Effects

$\begin{array}{lrrrc}\text { Source } & \text { M.S. } & \text { D.F. } & \text { F-ratio } & \text { P } \\ \text { Tota1 } & .85 & 99 & & \\ \text { Between } & 1.04 & 49 & & .91 \\ \quad \text { Groups } & .01 & 1 & .01 & \\ \quad \text { Error(G) } & 1.06 & 48 & & \\ \text { Within } & .67 & 50 & & .56 \\ \quad \text { Trials } & .25 & 1 & .36 & .84 \\ \text { Gx T } & .03 & 1 & .04 & \\ \quad \text { Error(T) } & .69 & 48 & & \end{array}$

Table 41

Simulator Test Results: Analysis of Variance Considering Left Steering Errors and Groups (Experimental and Control) Main Effects

$\begin{array}{lrrrc}\text { Source } & \text { M.S. } & \text { D.F. } & \text { F-ratio } & \text { P } \\ \text { Total } & .31 & 99 & & \\ \text { Between } & .27 & 49 & & \\ \quad \text { Groups } & .11 & 1 & .39 & .54 \\ \quad \text { Error(G) } & .27 & 48 & & \\ \text { Within } & .35 & 50 & & .00 \\ \quad \text { Trials } & 2.89 & 1 & 9.50 & .96 \\ \text { GX T } & .00 & 1 & .00 & \\ \quad \text { Error(T) } & .30 & 48 & & \end{array}$

Tria1s Means

$$
\begin{array}{ll}
\text { Mid-Treatment } & .46 \\
\text { Post-Treatment } & .12
\end{array}
$$




\section{Table 42}

Simulator Test Results: Analysis of Variance Considering Mid- and Post-Treatment Accelerator Up Error Scores and Groups (Experimental and Control) as Main Effects

$\begin{array}{lrrrc}\text { Source } & \text { M.S. } & \text { D.F. } & \text { F-ratio } & \text { P } \\ \text { Total } & .45 & 99 & & \\ \text { Between } \quad .56 & 49 & & .05 \\ \quad \text { Groups } & 2.03 & 1 & 3.80 & \\ \quad \text { Error (G) } & .53 & 48 & & .51 \\ \text { Within } & .34 & 50 & .46 & .59 \\ \quad \text { Trials } & .16 & 1 & .30 & \\ \quad \text { GX T } & .11 & 1 & & \\ \quad \text { Error(T) } & .35 & 48 & & \\ \text { Group Mean Scores } & & & & \\ \quad \text { Control Group } & .25 & & \end{array}$

\section{Table 43}

Simulator Test Results: Analysis of Variance Considering Mid- and Post-Treatment Right Steering Error Scores and Groups (Experimental and Control) as Main Effects

$\begin{array}{lrrrc}\text { Source } & \text { M.S. } & \text { D.F. } & \text { F-ratio } & \text { P } \\ \text { Total } & .32 & 99 & & \\ \text { Between } & .31 & 49 & & .01 \\ \quad \text { Groups } & 1.91 & 1 & 6.89 & \\ \quad \text { Error(G) } & .28 & 48 & & .03 \\ \text { Within } & .32 & 50 & & .62 \\ \quad \text { Trials } & 1.44 & 1 & 4.83 & .78 \\ \quad \text { G X T } & .23 & 1 & & \\ \quad \text { Error(T) } & .30 & 48 & & \end{array}$

Group Mean Scores

Control Group $\quad .44$

Experimental Group .16

Trials Mean Scores

Trial 1: Mid-Treatment .38

Trial 2: Post-Treatment .14 
The analysis of variance considering signaling error scores (presented in Table 44) as a main effect found no significant differences due to main effects, nor were any significant interaction effects found. A difference of borderline significance (.10 level) was found due to groups in the analysis of variance (presented in Table 45) considering parking brake error scores, al though no other significant differences were found.

\section{Table 44}

Simulator Test Results: Analysis of Variance Considering Signaling Error Scores and Groups (Experimental and Control) as Main Effects

$\begin{array}{lrrrr}\text { Source } & \text { M.S. } & \text { D.F. } & \text { F-ratio } & \text { P } \\ \text { Total } & .14 & 99 & & \\ \text { Between } & .13 & 49 & & .51 \\ \text { Groups } & .07 & 1 & .50 & \\ \quad \text { Error(G) } & .13 & 48 & & .60 \\ \text { Within } & .14 & 50 & & .21 \\ \text { Trials } & .04 & 1 & 1.61 & \\ \text { GX T } & .23 & 1 & & \end{array}$




\section{Table 45}

Simulator Test Results: Analysis of Variance Considering Parking Brake Error Scores and Groups (Experimental and Control) as Main Effects

$\begin{array}{lrrrr}\text { Source } & \text { M.S. } & \text { D.F. } & \text { F-ratio } & \text { P } \\ \text { Total } & .14 & 99 & & \\ \text { Between } & .15 & 49 & & .10 \\ \quad \text { Groups } & .40 & 1 & 2.80 & \\ \quad \text { Error(G) } & .14 & 48 & & .59 \\ \text { Within } & .13 & 50 & .69 & .23 \\ \text { Trials } & .09 & 1 & 1.45 & \\ \text { G x T } & .19 & 1 & & \\ \text { Error(T) } & .13 & 48 & & \\ \text { Group Mean Scores } & & & \end{array}$

No significant differences were found in the analysis of variance (presented in Table 46) considering negative steering errors as a main effect. A significant difference due to trials was found, however, in the analysis of variance (presented in Table 47) considering total errors as a main effect. No other significant differences were found in this analysis, nor were any significant interaction effects found. 
Table 46

Simulator Test Results: Analysis of Variance Considering Negative Steering Error Scores and Groups (Experimental and Control) as Mair Lefects

$\begin{array}{lrrrr}\text { Source } & \text { M.S. } & \text { D.F. } & \text { F-ratio } & \text { P } \\ \text { Total } & .04 & 99 & & \\ \text { Between } & .04 & 49 & & \\ \quad \text { Groups } & .01 & 1 & .22 & .55 \\ \quad \text { Error(G) } & .04 & 48 & & \\ \text { Within } & .04 & 50 & & 1.00 \\ \quad \text { Trials } & .00 & 1 & .00 & .31 \\ \text { GXT } & .04 & 1 & 1.07 & \\ \quad \text { Error(T) } & .04 & 48 & & \end{array}$

\section{Table 47}

Simulator Test Results: Analysis of Variance Considering Total Error Scores and Groups (Experimental and Control) as Main Effects

\begin{tabular}{|c|c|c|c|}
\hline Source & M.S. & D.F. & F-ratio \\
\hline Total & 2.42 & 99 & \\
\hline Between & 3.49 & 49 & \\
\hline Groups & 1.21 & 1 & .34 \\
\hline $\operatorname{Error}(G)$ & 3.54 & 48 & \\
\hline Within & 1.39 & 50 & \\
\hline Trials & 11.56 & 1 & 9.79 \\
\hline$G \times I$ & .79 & 1 & .66 \\
\hline $\operatorname{Error}(\mathrm{T})$ & 1.18 & 48 & \\
\hline
\end{tabular}

Trial Mean Scores Mid-Treatment 2.36 Post-Treatment 1.68 
In comparison, students in the experimental group were tested on another simulator lesson in mid-treatment, and were retested on the same lesson post-treatment. No a ttempt was made to arouse the students to anger before the retest. Eight analyses of variance were computed, one to consider each type of driving error category scores as a main effect.

The first analysis of variance (presented in Table 48) considered brake error scores as a main effect. No significant differences were found. The second analysis of variance (presented in Table 49) considered left steering error scores as a main effect. A significant difference was obtained due to trials.

A significant difference was also obtained due to trials when accelerator up error scores were considered as a main effect (presented in Table 50). No significant differences were found however, in the analysis of variance considering right steering error scores as a main effect (presented in Table 51).

A difference of borderline significance (.10 leve1) was found due to trials in the analysis (presented in Table 52) considering signaling error scores as a main effect. No significant differences were found in the analyses of variance considering parking brake error scores (presented in Table 53), negative steering error scores (presented in Table 54), or total error scores as main effects. 


\section{Table 48}

Simulator Lesson 2: Analysis of Variance Considering Mid- and Post-Treatment Brake Error Scores as a Main Effect

$\begin{array}{lrrrr}\text { Source } & \text { M.S. } & \text { D.F. } & \text { F-ratio } & \text { P } \\ \text { Total } & .84 & 57 & & \\ \text { Between } & .95 & 28 & & \\ \quad \text { Trials } & 1.40 & 1 & 1.95 & .17 \\ \text { Error(T) } & .72 & 28 & & \end{array}$

Table 49

Simulator Lesson 2: Analysis of Variance Considering Mid- and Post-Treatment Left Steering Error Scores as a Main Effect

$\begin{array}{lrccc}\text { Source } & \text { M.S. } & \text { D.F. } & \text { F-ratio } & \text { P } \\ \text { Total } & .07 & 57 & & \\ \text { Between } & .06 & 28 & & \\ \quad \text { Trials } & .28 & 1 & 4.48 & .04 \\ \quad \text { Error(T) } & .06 & 28 & & \end{array}$

Trials Mean Scores

$$
\begin{array}{lr}
\text { Mid-Treatment } & .14 \\
\text { Post-Treatment } & 0.00
\end{array}
$$


Table 50

Simulator Lesson 2: Analysis of Variance Considering Mid- and Post-Treatment Accelerator Up Error Scores as a Main Effect

$\begin{array}{lrcrc}\text { Source } & \text { M.S. } & \text { D.F. } & \text { F-ratio } & \text { P } \\ \text { Total } & .36 & 57 & & \\ \text { Between } & .34 & 28 & & \\ \text { Trials } & 1.72 & 1 & 5.20 & .03 \\ \text { Error(T) } & .33 & 28 & & \end{array}$

Trials Mean Scores

$$
\begin{array}{ll}
\text { Mid-Treatment } & .14 \\
\text { Post-Treatment } & .48
\end{array}
$$

Table 51

Simulator Lesson 2: Analysis of Variance Considering Mid- and Post-Treatment Right Steering Error Scores as a Main Effect

$\begin{array}{lrccc}\text { Source } & \text { M.S. } & \text { D.F. } & \text { F-ratio } & \text { P } \\ \text { Total } & .39 & 57 & & \\ \text { Between } & .42 & 28 & & .28 \\ \quad \text { Trials } & .43 & 1 & 1.20 & \\ \quad \text { Error(T) } & .36 & 28 & & \end{array}$


Table 52

Simulator Lesson 2: Analysis of Variance Considering Mid- and Post-Treatment Signaling Error Scores as a Main Effect

$\begin{array}{lrccc}\text { Source } & \text { M.S. } & \text { D.F. } & \text { F-ratio } & \text { P } \\ \text { Total } & .12 & 57 & & \\ \text { Between } & .14 & 28 & & \\ \quad \text { Trials } & .28 & 1 & 2.84 & .10 \\ \quad \text { Error(T) } & .10 & 28 & & \end{array}$

Trials Mean Scores

Mid-Treatment $\quad .21$

Table 53

Simulator Lesson 2: Analysis of Variance Considering Mid- and Post-Treatment Parking Brake Error Scores as a Main Effect

$\begin{array}{lrccc}\text { Source } & \text { M.S. } & \text { D.F. } & \text { F-ratio } & \text { P } \\ \text { Total } & .02 & 57 & & \\ \text { Between } & .02 & 28 & & \\ \quad \text { Trials } & .02 & 1 & 1.00 & .33 \\ \quad \text { Error(T) } & .02 & 28 & & \end{array}$


Table 54

Simulator Lesson 2: Analysis of Variance Considering Mid- and Post-Treatment Negative Steering Error Scores as A Main Effect

$\begin{array}{lcccc}\text { Source } & \text { M.S. } & \text { D.F. } & \text { F-ratio } & \text { P } \\ \text { Total } & .48 & 57 & & \\ \text { Between } & .49 & 28 & & \\ \quad \text { Trials } & .43 & 1 & .92 & .65 \\ \text { Error(T) } & .47 & 28 & \end{array}$

Table 55

Simulator Lesson 2: Analysis of Variance Considering Mid- and Post-Treatment Total Error Scores as a Main Effect

$\begin{array}{lcccc}\text { Source } & \text { M.S. } & \text { D.F. } & \text { F-ratio } & \text { P } \\ \text { Total } & 2.37 & 57 & & \\ \text { Between } & 2.14 & 28 & & \\ \quad \text { Trials } & 1.72 & 1 & .66 & .57 \\ \quad \text { Error (T) } & 2.62 & 28 & & \end{array}$

Effectiveness of Treatment: Cognitive Test Students in the experimental groups at both high schools $A$ and $B$ were asked to respond to the following question: "Did you learn anything when Mrs. Shapiro worked with you? If the answer is yes, what did you learn?" Replies to this question made by students are given below. High School A. The following replies to the above question were given by students in the experimental group. The sex and the age of the student will be indicated. 
6. Yes, that you should not drink while driving. That you should always keep your mind on your driving. (Age 15)

7. Yes, I learned what not to do because of what someone else experienced. (Age 15)

8. Don't drive when you are angry or excited. Always be careful. (Age 15)

9. Yes, be careful. (Age 15)

10. It is better to think when you are angry and not drive. (Age 17)

In addition, students were asked what things they liked best in the experimental treatment. Most students responded to this question. The items students mentioned and the number and ages of students who mentioned them are listed below:

1. The skits (role-playing) one girl (age 17) and one boy (age 18)

2. Demonstrations - six girls aged 15, and five boys aged 15

3. The game break-in - two girls aged 15

4. The video-taped modeling segments - one girl aged 15, two goys aged 15

5. The attitude test - one male, aged 15

High School B. The question "Did you learn anything when Mrs. Shapiro worked with you? If the answer is yes, what did you learn?" was asked students in the experimental group. Student replies are listed below to this question, although not all students answered. 
Females.

1. Not much because I'm never in class very long when she comes. (Age 18)

2. Yes, about safe driving. (Age 18)

3. Yes, you should not drive when excited, drunk, tired, angry or in bad weather. (Age 17)

4. I learned how some people react to driving when their attitude changes. (Age 18)

5. Yes, the ways in which are helpful in driving, and the ways to be cautious. (Age 17)

6. Yes, by the skits we did. (Age 17)

7. No. (Age 17)

8. I learned that when your driver you should have your mind on the road and not talking to someone else. (Age 18)

9. Yes, I learned a lot about major accidents and how they took place and why. (Age 18)

10. Yes, I learned what so of defensive driving tips are. (Age 17)

11. When she talked about how we would drive if we had our boyfriend or girlfriend in the car. (Age 18)

12. I learned about various situations that can sometimes affect a driver's behavior. (Age 17)

13. Yes, try not to drive when you're upset or excited are when you drink, but what to do. (Age 17)

14. 1. Drinking and driving don't mix. 2. Anger and driving don't mix. 3. Cool off before getting into an automobile. (Age 18) 
15. Yes, the way to take precautions when driving your car. (Age 17)

16. No. (Age 18)

17. No. (Age 17)

18. The different things that make you drive dangerously and some ways to avoid them. (Age 17)

19. Yes, the different conditions that you can have an accident. (Age 16)

20. No. (Age 17)

21. I just learned ways to be more careful when I drive. (Age 17)

22. Not real1y. (Age 17)

23. I learned to be more aware of my driving habits by listening to other people comments. (Age 17)

24. Yes, what some people go through when they are driving. (Age 17)

25. Not really. (Age 17)

Males.

1. Yes, I learn to never drink while driving and I learn about myself while taking these test. (Age 17)

2. Yes. (Age 18)

3. Yes, not to drive while you have been drinking. (Age 17)

4. Yes, sometime people might drive carelessly if they are angry or excited. (Age 17)

5. Watch out for the other guy. (Age 16)

6. Yes, to understand defensive driving better (Age 17) 
7. Yes, I learned about how other people, as an example of myself, have different driving habits under different conditions. (Age 17)

8. To try to think carefully and clearly because a good driver is a good thinker. (Age 17)

9. The different things about rules and laws. (Age 17)

10. I learned when you have passengers you should drive more careful. (Age 18)

11. We learned how to be safe on streets in bad weather. (Age 17)

Students in the experimental group at high school B were also asked what things they liked best in the experimental treatment. The things they named and the number, sex and age of the students who named them are listed below. Not a11 students responded to this question.

1. Role-playing situations by students in the class Three females aged 18, three females aged 17.

2. Video-taped models

Four females aged 17 , two females aged 18 Three males aged 17

3. Discussions in class

Five females aged 17 , two females aged 18 Two males aged 17

4. Observing the videotape equipment and being videotaped One female aged 17 , one female aged 18

One female aged 16 


\section{Demonstrations}

One female aged 17

6. The game "Break-in"

One female aged 17

One male aged 17

\section{Summary}

The internal consistency of each version of the three attitude tests was described. The internal consistency coefficients of the biographical sections ranged from .32 to .62. The internal consistency coefficients of the attitude sections of the attitude tests ranged from .66 to 82. Finally, the internal consistency coefficients of the driving behaviors section of version three of the attitude test ranged from .73 to .87 .

Estimates of test-retest reliability of the attitude test criterion were made. However, in many cases the number of subjects in the control group was quite smal1, and the control and experimental group subjects' test scores were combined to compute the test-retest reliability coefficient. In addition, no contro1 group was used in some of the preliminary trials. Thus, it is possible that an underestimate of the test-retest reliability coefficients was made. The reliability coefficients obtained for the attitude section of the three versions of the attitude test ranged from .56 to .94 . The reliability coefficients were also computed for the driving behaviors section of the attitude test (version three on $1 y$ ) and ranged .44 to .87 . 
Estimates of test-retest reliability of the simulator criterion were made for each error category. The reliability coefficients were generally around .00 to .20. However, the reliability coefficient for the total errors category of lesson one was .50 .

In addition, several analyses of variance were computed in order to determine the effectiveness of the preliminary trial treatments and of the quasi-experiment treatment. No differences were found due to emotional role-playing in the preliminary trial. However, a significant difference was found between the pretest attitude test scores of the demonstrators and their audience, and between the post-test scores of the audience and the pretest scores of the demonstrators during the preliminary trial of the demonstration at high school A. Also, a difference of borderline significance (.05 leve1) was found in test scores due to the effect of the demonstration at the university. Further, a significant difference was discovered between pre-treatment test results (before any experimental treatments) and postdemonstration test results at the university.

No significant differences due to any main effect (treatment, groups, or sex) or any significant interaction effect were found as a result of analyses of variance of quasi-experiment test results at high school A. However, a significant group $\mathrm{x}$ treatment interaction was found when pre- and mid-treatment attitude section test scorès were considered as main effects at high school B. No significant 
differences were found which were attributable to race, although a significant difference was found due to sex when considering pre-, mid- and post-treatment attitude section test scores at high school B. Further, a significant difference due to sex, and a significant groups $\mathrm{x}$ treatment interaction effect was found when pre- and post-treatment attitude section test scores at high school B. Further, a significant difference due to sex, and a significant groups $\mathrm{x}$ treatment interaction effect was found when preand post-treatment attitude section test scores were considered. Also significant differences were found between mid- and post-treatment driving behaviors section test scores due to groups (experimental and control), and sex and a significant groups $\mathrm{x}$ sex interaction effect was found. A Newman_Keuls Sequential Range Test, however, found no significant differences between the interaction effect means. Finally, a significant difference attributable to sex was again found when mid-and post-treatment combined driving behaviors and attitude sections test scores were considered as main effects.

Analyses of variance were also computed for simulator criterion scores. No significant differences were found due to treatment at high school B, although some significant differences were found due to groups (experimental or control) when considering test scores for lesson one. Also, although significant differences were found attributable 
to trials when considering left steering and accelerator up lesson two error scores no other significant differences were found.

Finally, students' responses to a question on a cognitive test are described. Many students at high school A but fewer students at high school B apparently became aware of the idea that lack of emotional control could be the cause of an accident.

In short, the results of the preliminary trials of emotional role-playing and demonstration and of the quasiexperiments were described. The next chapter will discuss these results. 
CHAPTER IV

DISCUSSION

The results described in the previous chapter and their implications in terms of the theory presented in the first two chapters are discussed. In particular, an analysis of the effectiveness of emotional role-playing, demonstration, modeling and reciprocal inhibition in introducing the element of emotional control in relation to driving in current driver education courses is made. Also, based on the results of the preliminary trials and the quasi-experiments, the possible general success of these treatments is indicated. In addition, the two criterion measures, attitude test scores and driving simulators are discussed.

\section{General Variables Influencing Treatment Effectiveness}

Differences in driving experience and high school driver education courses possibly can influence the effectiveness of the treatments used in the preliminary trials and the quasi-experiments. In addition, the variables of race, socio-economic level and sex might also prove suitable predictor variables of poorer drivers.

Differences in driving experience. Students at high school A generally learned to drive between the ages of 9 and 14, and drove on their parents' farms. Thus, many of 
their driving behaviors and driving attitudes had solidified before they took driver education. As none of them had ever been in a serious accident and few of them had been drivers in a minor accident they had no reason to think that they should change their driving habits or attitudes. Also, students at the university had had much driving experience. Thus, it was likely that their driving behaviors and attitudes had become fixed. However, university students reported that they had made changes in driving behaviors and attitudes after having an accident or almost having an accident.

Students at high school B, however, generally first learned to drive while taking driver education, and had little chance to practice driving. Thus, their driving habits had not solidified and their driving attitudes were not fixed. Therefore, it was more likely that the treatment would influence students at high school B than students at high school A to change their driving attitudes and behaviors.

Differences in high school driver education courses.

Students at high school A finished their classroom work in the first month and a half of the semester. Thus, the experimenter was able to work with all students in the experimental group for one hour a week. However, students may have regarded the experiment as a lark, not to be taken seriously, because they could escape from study hall when the experimenter came. 
However, students at high school $\mathrm{B}$ fell behind in classroom assignments because they could only use textbooks while in class, and may have held the experimenter responsible for this. For this reason, the experimenter had to reduce the number of treatment sessions from two a week (40 minute periods) to one \& week after the third week of the treatment. Thus, students did not receive as much treatment time as students at high school A. In addition, only two-thirds of the students were in the classroom each time the experimenter came; the others were absent, at the driving simulator trailor, or in the driver education cars. Also, diffexent students were in class each time due to the rotation of the students' assignments, and student absences. Therefore, each student in the experimental group received differing amounts of the treatment.

Race. It was interesting that no differences due to race in attitude test scores were found at high school B, the only school to have a sizable population of blacks. This suggests that, as indicated in the literature review, it is likely that socio-economic class, not race, is the significant variable in predicting which drivers tend to have more accidents. Further, this suggests that the same treatment can be used with both blacks and Caucasians.,

Soclo-economic level. It was also interesting to note that differences in background between the student populations at high schools $A$ and $B$, as indicated by scores on the biographical section of the attitude test were found. 
However, there were no differences between high schools A and $B$ attitude section test scores. This is anolier indication that socio-economic level, as indicated in the literature review, is a significant indicator of the poorer driver, as the students at both high schools $A$ and $B$ were primarily from the lower or lower middle class.

Sex. Boys had lower attitude test scores than girls at high school $\mathrm{B}$, as predicted in the literature review. Males may have feit greater frustration: mure males dropped out of school, as evidenced by the greater rumber of females in the classes, and fewer males than females had superior grades or intended to go to college.

On the other hand, no difference in attitude test scores due to sex was found at high school A. This is probably because both males and females held high expectations of success: most students planned to go to college or to a specialized vocational school, and few students dropped out of school. This suggests that expectations of success made on the basis of successful experiences in school, etc. not sex itse1 is of primary importance in predicting which students will be pcorer drivers. This also suggests that grades, and other indicators of successful experiences may be of great importance in the prediction process.

In short, although the literature review suggests that males tend to have more accidents, it appears that expectations of success as percelved by the individual compared to 
his actual successful experiences may also be a good indicator of the poorer driver. If a discrepancy exists between a person's desires and expectatinns of success, the person may tend to release his frustrations while driving.

Summary. In short, expectations of success, socioeconomic level, differences in driving background and differences between driver education courses at high schools $A$ and $B$ were variables which influenced the effectiveness of the treatments. Race, however, did not seem to be an important variable.

\section{Effectiveness of Treatments in Rejation to Driver Education}

The techniques of modeling and reciprocal inhibition, demonstration and emotional role-playing are discussed as to their effectiveness in changing driving attitudes and behaviors.

Modeling and Reciprocal Inhibition

Live and video-taped models were preserted in situations in which the mode: expressed a strong emotion such as anger, etc., and then preceeded to perform actions which precluded driving (reciprocal inhibition) while under the influence of the strongly felt emotion. In addition, the situations were used to stimulate discussions and students 
were encouraged to identify the emotion displayed by the model, what behaviors the model performed while under the influence of the emotion, and how they themselves would react when under the influence of the given emotion. Students were also encouraged to handle the original situation in such a way as not to arouse strong emotions; i.e., talking to one's parents, etc., rather than demanding one's own way. Most models also presented this approach; i.e., instead of going to a car when under the influence of a strong emotion, the model would return to the situation in which he became aroused and attempt to rectify the situation. Finally, the games "break-in" and "break-out" in, which a student tried to either get into the middle or outside of a circle formed by the other students, were played at the conclusion of this section. The purpose of playing these games was to arouse students' emotions so they would identify the emotion(s) they felt and their behavior while under the influence of the given emotion(s).

No preliminary trials were made using this procedure. However, a retest of the attitude section was made at the conclusion of this section during the quasi-experiment. No significant difference was found in attitude section test scores at high school A, but there was a significant difference in pre- and post-modeling attitude section test scores at high school $B$ due to sex, and a significant group $\mathrm{x}$ treatment interaction. A Newman-Keuls Sequential Means 
Test, however, was unable to detect significant differences among the means.

Many boys were generally absent, or driving, or at the simulators during the modeling treatment, and did not receive the entire modeling treatment. Thus, it was likely that they were little affected by the treatment.

It is interesting that the control group attitude section test scores went up approximately 1.5 points ( sigma $=9.59)$ after the modeling treatment, and the experimental group attitude test scores went down approximately three points (sigma $=9.59)$. The directions of the changes may indicate that the live modeling sequences may have been more potent than the video-taped modeling sequences. First, live modeling sequences were only performed when the videotaped machine did not work. As this was not predictable, it was generally not possible to obtain the same models who had performed the video-taped segment, nor was there time to rehearse other models. Thus, the experimenter explained the action of the skit to the new models, but on several occasions, these unrehearsed skits tended to show the models going to drive a car while under emotional stress. Second, the unrehearsed models tended to be from the same group of models (athletes) who had performed the video-taped segments, and their behaviors in the unrehearsed skits were completely opposed to the behaviors displayed in the rehearsed skits. Thus, there may have been some confusion in students' minds 
as to which alternative behavior was correct. Therefore it is possible, that if there were no change in attitude test scores, the subjects had rejected all presented alternative behaviors. However, the post-modeling attitude test scores tended to be lower, which may indicate what the literature review suggests; subjects are more Iikely to imitate aggressive behaviors.

In addition, mainly females were present in class during the modeling treatment. However, some of the presented situations generally applied to males; i.e.. athletes winning a game, etc., where mainly male models were used. Thus, it is possible that some females did not relate to these male-orientated situations, and some of the effectiveness of the modeling treatment was lost for this reason. Also, some of the alternative behaviors that were presented may have appealed mainly to males, i.e., going to play pool with other boys, etc. Finally, some of the models in the video-taped skits were not only excellent athletes, but had excellent grades. Thus, as suggested in the literature review, these models nay have acted as aversive it. muli, because they were ton dissimilar to the exporimental students. On the other hand, at high school A there were no differences in pre* and post-modeling attitude section test results, which can probably be attributed to two reasons. First, students, as previously mentioned, had driven prior to taking driver education and their driving habits and 
attitudes had generally solidified. Also, as none of the students had had an accident, students felt there was no reason to change. Second, the literature review indicated that the more similar models and observers were, the more likely the observers were to imitate the models. It is possible that this can be carried too far; i.e., students at high school A knew the models quite well and probably discarded the modeled behaviors because they felt the models would not actually perform the modeled behaviors in real 1ife. Further, the models may have served as aversive stimuli; studente may have felt that they were being manipulated because they thought the models were presenting false pictures of their behavior. Finally, it was impossible to give students a direct incentive for changing their behavior; they did not feel an accident would happen to them.

Therefore, modeling was somewhat effective at high school B but not at high school A. The analyses suggest that modeling would be effective if students had a direct incentive to change; i.e.; they had had an accident, or that they were inexperienced, and thus more mallabie in their attitudes and behaviors. Further, male athletes with average grades appeared to be effective models. However, male athletes with superior grades apparently served as aversive stimuli; they were too dissimilar to the students. In addition, models too similar to the observers or well known to the observers may become aversive stimuli; their modeled 
behaviors might not be believable and observers might feel manipulated. Also, as the 1iterature review suggests, aggressive behaviors are more likely to be imitated than non-aggressive behaviors. Finally, only behaviors which observers would believe a model might perform should be chosen to be the modeled behavior.

In short, it appears that although the techniques of modeling and reciprocal inhibition need further development, these techniques can be used to encourage students not to drive while under emotional stress. Also, students can be given alternative behaviors which preclude driving while under emotional stress (reciprocal inhibition) through the modeling technique. Athletes with average grades who are not well known to the students on a personal basis apparently made the most effective models. Further, video-tape segments appear to show more promise than live modeling segments. Models can be chosen on the basis of possible effectiveness, not because they had a study hall during the driver education period. The skits can be rehearsed. Also, audience reaction will not influence models' performance of the skit, such as at high school $B$, where the skits became longer and longer when models were stimulated by their audience. Finally, it is possible that modeling and reciprocal inhibition may have an effect which is delayed until an incentive situation, i.e., having an accident or almost having an accident, occurs. Therefore, a comparison of 
experimental and control subjects' accident records in a few years may yield differences in the number of accidents each group has had.

\section{Demonstrations}

Preliminary trials. Students with poorer driving records were chosen as demonstrators. In the preliminary trials at high school $\mathrm{A}$ and the university, the demonstrators described the circumstances of three or four accidents they had had, and then described and performed the behaviors that would have prevented the accidents. Demonstrations were made while the demonstrator and his audience were seated in a car.

Demonstrators at high school A appeared to be most influenced to change their attitudes toward driving. The demonstrators' mean score on the attitude section pretest was different from both the pre- and post-demonstration mean scores of the audience on the attitude section, but the demonstrators' mean score on the post-demonstration attitude section was not different from either the audience preor post-demonstration mean scores on the attitude section. However, no change in pre- and post-demonstration audience mean scores was found.

On the other hand, at the university, there was a possible difference (.06 leve1) between pre- and postdemonstration mean scores when considering audience and demonstrator as one group. There was also a possible 
difference (.05 level) between pre- and post-demonstration test scores when considering the members of the audience and the demonstrator who were non-role-players as one group and the members of the audience who had also been roleplayers as another group.

It would appear that two major factors played a role in effecting an attitude change. First, as suggested previously, when students played an active role in obtaining information, the information had a stronger impact. Due to lack of time at high school A, students in the audience had very little time to ask questions or make comments, and no difference in their pre- and post-demonstration attitude test scores was found. Students at the university, however, not only asked questions but related their own experiences, and there was a difference between their pre- and post-demonstration attitude test scores. Second, peer influence played a role. Demonstrators were encouraged to seriously discuss their poor driving behaviors and ways to improve their driving by the interest and presence of their peers in the audience. In addition, students in the audience are more likely to believe their peers when it is suggested that they also could have an accident, which would be an incentive to students in the audience to analyze and improve their own driving behaviors and attitudes.

The theory behind the demonstration was flawed in one respect. As car engines could not be started, because of 
the possibility of an accident for which the experimenter and the school could be held iiable, demonstrators could not adequately practice good driving behaviors although they could go through some of the motions, i.e., look at the rear view mirror, etc. Thus, it was unlikely that practice of correct driving behaviors played a part in the success of the demonstration. However, taking the attitude test itself appeared to influence students to analyze their driving behaviors probably by forcing students into active consideration of their own driving behaviors. There was a difference between audience and demonstrator pre-emotional role-playing attitude section test scores and post-demonstration attitude section test scores.

Finally, the importance of the similarity of the informant to his audience was shown. Students in the university audience who had poorer driving records and poorer grades made comments and nodded their heads when the demonstrator made a relevant point, whereas students in the audience who had good driving records and better grades did not.

Quasi-experiments. Due to the larger number of high school students involved in the quasi-experiments, demonstrations were not performed in the same manner as in the preliminary trials. Students were not seated in cars because cars could seat only four to six students each. The emphasis was not on changing the denonstrators' driving attitudes and behaviors, but on changing his audiences' attitudes 
toward driving and their driving behaviors. Also, demonstrators, not being seated in cars, did not perform the driving behaviors which would have prevented the accidents. Instead, the experimenter conducted a discussion of the causes of the accident and how the demonstrator could have prevented the situation.

No difference between the mid-and post-treatment attitude section test scores or driving behaviors section test scores or the combined total of attitude and driving behaviors sections test scores were found at high school A. These results were probably attributable to the fact that students at high school $\mathrm{A}$ had no immediate incentive to change, as they had not had accidents. Further, only two of the five demonstrators at high school $A$ had accidents related to a lack of emotional control in relation to driving.

At high school B, however, there was a difference due to sex between mid-and post-treatment combined attitude section and driving behaviors section test scores, and between mid- and post-treatment driving behaviors test scores. There was also a difference due to groups and a significant sex $\mathrm{x}$ groups interaction when considering driving behaviors section test scores.

Only one demonstrator could be found at high school B, a black female with above average grades, even though students who had had accidents were offered money to participate. Thus, the experimenter read descriptions of accidents 
which university subjects had had. Therefore, peers did not supply the information, and the one peer whe did had above average grades, so she was not too similar to many of the students in the experimental group, which probably accounts for the lack of differences in test scores due to treatment.

The difference due to groups and the significant groups $x$ sex interaction fuund when considering driving behavior section test scores, may be because the control group was composed of fewer students. Thus, students in the control group had more opportunities to use the simulators and drive in a driver education car and thereby had more opportunit:es to improve their driving. In addition, boys appeared to be absent more times than girls and, if absent, the student would loose his opportunity to drive or use the driving simulators.

In short, the lack of students who had had accidents because of a lack of emotional control, the dissimilarity between demonstrator and members of the audience in age or grades, and possibly the large disucssion groups which may have somewhat stifled discussion played a factor in the failure of the demonstrations in the quasi-experiments tc influence the attitudes of the students. In addition, the lack of change in the preliminary trial of the demonstration at high school $\mathrm{A}$ in audience attitude scores may also suggest that students felt, since they themselves had not had accidents, that they would not have accidents, and thus, 
they did not need to change their attitudes $t$ ward driving. Therefore, demonstrations may not be useful in iriver education courses, as used in the above studies. However, they appear to be a useful tool when working with students who had a lot of driving experience, particularly if the student has had an accident or almost had an accident. But some modifications in technique may make the demonstration a more useful tool in current driver education courses, such as video-taping the demonstrators seated in a car which would give more realism to the demonstration while permitting a large class to see the demonstration. This would also permit the use of students not available during the driver education period who had had accidents relating to lack of emotional control as denonstrators. Further, students chosen as demonstrators could then be better matched as to their similarity to students in the driver education class. Finally, small group discussions and more role-playing of the situations presented might further stimulate discussion and encourage students to take an active role in argu ring the information.

$$
\text { Emotional Role-Play -ng }
$$

Emotional rcte-playing required stidents io act and feel as if they vere in a severe accident and were seriously hurt, and in two minor accldents and were bruised. Also, students emotionally role-played a court-room or deposition scene, in which students played the roles of the accused 
driver and wittnesses to the accident who were giving testimony. The preliminary trials of emotional role-playing took place at high school $A$ and at the university.

Although some modifications in procedure were made during the preliminary trials, emotional role-playing appeared to have no effect in changing students' attitudes towards driving. High school A students could not imagine themselves in a severe accident or severely injured. All students, however, could imagine themselves in a minor accident and bruised or shaken up, but all students had been a passenger at the time of a minor accident. However, none of the students had been hurt in an accident, and thus, found it hard to relate their emotional role-playing experiences to changes in their driving behaviors or attitudes. Also, high school A students found it hard to act as if they were in a given situation, as most students had never acted. Finally, high school A students felt that the courtroom trial was very realistic, but several students felt that the lesson to be learned was "don't get caught".

University subjects could better identify with emotional role-playing situations. Most students had been a driver or a passenger during a minor accident, and some students had been a passenger during a severe accident. Also, most students had been seriously hurt (broken leg, etc.) while playing football or other sports. Thus, students said they could imagine themselves seriously injured in a severe accident or bruised in a minor accident. Also, several 
students had been to court and had given depositions. However, there was no difference in pre- and post-emotional role-playing attitude test scores. It may be that emotional role-playing functions as a scare tactic; reminding subjects of things they do not like to think about, so they try to think of more pleasant things and forget their emotional role-playing experiences.

Emotional role-playing, then, is a rather ineffective method for changing driving behaviors and attitudes. High school students find it difficult to imagine themselves in given situations. In addition both high school and college subjects tend to try to forget their emotional role-playing experiences because they do not like to think about having accidents or going to court.

\section{Summary}

Although demonstrations in general were quite effective in the preliminary trials, modifications in procedure during the quasi-experiences rendered this technique ineffective. However, modeling and reciprocal inhibition appear to hold much promise for use in changing driving behaviors and attitudes, although much work, particularly in the realm of the proper selection of models, needs to be done. Emotional role-playing, however, has little effect in changing attitudes or behavior, possibly because it functions as a scare tactic and subjects want to forget their unpleasant experiences. 
On the other hand, many students, either by talking in class discussions or on the cognitive test, appeared to show a cognitive knowledge that they are more likely to have accidents while driving under emotional stress. This further suggests the possibility of driving behavior and attitude change when given an immediate incentive to do so; i.e., having an accident or almost having an accident. Therefore, a follow-up study comparing the number of accidents control and experimental subjects will have had (which information could be checked by using state police accident report records) could be made in five or six years. As indicated in the literature, males have their accident peak approximately three or four years after learning to drive and taking driver education delays this accident peak approximately one or two years.

\section{Effectiveness of Treatments in Relation to}

\section{Counseling Theory}

On the basis of the results of the preliminary trials and quasi-experiments, as described in the previous chapter, the techniques of emotional role-playing demonstration, modeling and reciprocal inhibition can be viewed in light of the counseling theory presented in the literature review.

\section{Emotional Role-Playing}

Emotional role-playing has had some effectiveness in changing subjects' attitudes. However, it appears that 
emotional role-playing may be a "scare tactic" in some situations; i.e., people do not like to think about accidents and death and thus turn their attention to other matters. Furthermore, if the subject has not had previous experience in the role or a similar role, it is likely that emotional role-playing will be ineffective, i.e., students who had not had accidents found it hard to imagine themselves in a severe accident. In addition, subjects who have not acted before may find it difficult to emotionally role-play. Finally, it is possibie that some subjects may get so involved emotionally with one aspect of the situation, that the total learning situation is ignored; i.e., female students at high school B became so emotionally involved with playing the roles of a daughter "calmly" talking to her mother to obtain permission to use a car, that the students began shouting at each other, and entirely forgot the fact that they were to show how an emotional situation could be avoided.

\section{Demonstrations}

It is apparent that demonstrations, in which students take an active role in obtaining information and discovering how the information can be applied to their behavior; i.e., how students can change their driving behaviors so as not to have accidents, can be an effective means of changing attitudes, and possibly, behavior. However, demonstrators should be peers of and have somewhat similar characteristics 
as the members of the audience in order to enhance the effectiveness of the treatment. Students in the university audience who had had accidents, and had poorer grades paid most attention to the demonstrator who had had accidents and had poorer grades. In addition, it is possible that a demonstration would be most effective for an audience which had had similar experiences to the ones described by the demonstrator because members of the audience might then tend to become more involved in discussion.

\section{Modeling}

Modeling is an effective technique for inducing attitude and behavior change. However, refinements must be made in selection of effective models; i.e., models must not be too like or unlike their observers, or they may act as aversive stimuli. Also, it might well be advisable to divide students in groups so they can observe the model they are most likely to imitate.

As indicated in the literature review, males tend to be more effective models than females, as boys generally ignored scenes where female models were used. Also, aggressive behavior does tend to be more imitated than non-aggressive behavior; i.e., students ignored the video-taped models presenting non-aggressive behavior and tended to pay more attention to models presenting aggressive behaviors.

Finally, modeling sequences can command attention and stimulate class discussion. However, it appears that an 
incentive, preferably an immediate incentive, is needed to encourage subjects to change their behavior and attitudes. Thus, it is possible that modeling should be delayed until such an incentive situation arises.

\section{Reciprocal Inhibition}

It is apparent1y exceedingly important to choose an alternative behavior which not only precludes the undesired behavior, but is one the model might actually perform. For example, models at high school A were so well known to the audience that the audience could not believe that they would perform such behaviors as walking when angry instead of driving. Thus, the modeled behavior was an unbelievable behavior for members of the audience to perform.

In addition, there should be an incentive, perferably inmediate, to encourage subjects to change their behavior. Thus, it is possible here also, that the treatment might be delayed until such an incentive situation appears.

\section{Effectiveness of Criterion Measures}

The two criteria measures, the attitude test and simulator performance, must meet certain standards of validity and reliability to prove valuable.

\section{Attitude Test Criterion}

As indicated, there were three versions of the attitude test. Versions one and three were used with high school students while version two was used with university 
students. Versions one and two consisted of two sections; a biographical section and an attitude section. Version three consisted of these two sections, and a third section: driving behaviors.

The internal consistency coefficients of the biographical section ranged from .32 to .62 . Several questions were found to have been irrelevant to the prediction of accident-prone drivers; i.e., asking where students lived, their year in school, whether they had been in a severe accident, etc. In addition, the question asking the age of the student appeared to be miscaled, i.e., males aged 18-2i were more likely to have accidents thar males aged 15-17. In addition, it is possible that the low internal consistency coefficients are due to the high degree of background similarity of the students at each school.

The attitude section of version three appeared to be lower internal consistency coefficient than that of version one. However, the attitude section of version three was shorter than that of versions one or two. Thus, a lower internal consistency coefficient would be expected

Finally, it is possible that the internal consistency coefficient of the attitude section of version two (used with university studenta) was lower than that of version one although it had more questions in it than the version one attitude section. This may have been because the university students were in a driver education methods course and wanted to appear to be zood drivers on the test. 
In short, the attitude test criterion, although it could be improved, appeared to be an adequate criterion measure. In particular, questions in the attitude section and driving behaviors section appear to be most relevant to the identification of the poorer driver. The biographical section, however, needs to be revised to identify more effectively the poorer driver.

Estimates of test-retest reliability. In many cases test results of the control and experimental groups were combined to compute the test-retest reliability coefficients, because of the small number of students in the control groups. In addition, in some of the preliminary trials no control group was used. Thus, it is possible that underestimates of the test-retest reliability coefficients were made.

Most of the test-retest reliability coefficients obtained for the attitude sections of the three versions ranged from .70 to .80 . Thus, the attitude section had moderate reliability.

The test-retest reliability coefficients for the driving behaviors section in version three was .87 for high school A and .44 for high school B. As students at high school $B$ had generally not driven prior to taking driver education, they probably improved with practice, which would explain the lower reliability coefficient obtained at high schoo1 B. High school A students had learned to drive and 
had developed proficiency in driving prior to taking driver education. Thus, it is likely that there is moderately high reliability of this section if the subjects have attained a certain driving proficiency.

In short, it appears that the attitude test criterion has moderate to moderately high reliability.

\section{Driving Simulator Criterion}

Estimates of test-retest reliability. Test-retest reliability coefficients of all error categories of both lessons one and two were quite low, generally ranging from .00 to .20 . Thus, it appears the driving simulator criterion measure was unreliable.

Validity. No predictions were made as to the performance of the students on the simulators. Analysis of lesson one results (in which students were aroused to anger prior to the retest), uncovered differences over trials for the left steering, right steering and total errors categories. It appeared that students in the experimental group had better scores than students in the control group in the right steering error category, and may have had better scores in the parking brake error category. However, students in the control group may have had better scores in the accelerator up error category. This suggests that these "improvements" may have been due to random error, rather than to a definite improvement in simulator performance. 
Students improved in the left steering error category and perhaps in the signaling errors category between the pre- and re-tests of lesson two (students were not aroused to anger). Students also made more mistakes in the accelerator up error category. This also suggests chance results rather than definite improvement in simulator performance; students only improved in two error categories and made more mistakes in one.

Thus, errors in most error categories for both lessons one and two did not decrease as might be expected due to more proficiency. Further, there was no apparent pattern of simulator performance improvement. Also, as indicated, there was low reliability of lessons one and two. Thus, simulator results are inconclusive, and as suggested in the literature review, are not the best criterion measure because of their unreliability.

\section{Summary}

Based on the results depicted in the previous chapter, the effectiveness of the modeling and reciprocal inhibition, the demonstration and the emotional role-playing treatments were discussed in relation to the use of these treatments in driver education specifically, and in counseling generally. In particular, modeling appears to be an effective technique for inducing driving attitude and behavior change. However, more work needs to be done in determining the most effective model. If models are too similar or dissimilar to their 
audience, they may become aversive stimuli. In addition, aggressive behaviors are more likely to be imitated than non-aggressive behaviors. Also, reinforcement may be needed to induce observers to change their behaviors.

Reciprocal inhibition may be an effective technique for changing attitudes and behavior. However, the chosen alternative behavior must be one which the model presenting it and his audience might really perform.

Demonstration a1so appears to be an effective technique to induce attitude and possibly behavior change. If both the demonstrator and his audience take an active role in describing, discussing, etc., the information, demonstrations are most effective. However, the chosen demonstrator should be similar to his audience for this technique to be effective. In addition, discussions should be limited to small groups in order that all students have an opportunity to take an active role.

On the other hand, emotional role-playing appears to be an ineffective technique for changing attitudes and behaviors. Emotional role-playing appears to function as a scare technique when used in accident prevention, and subjects tend to repress their unpleasant emotional roleplaying experiences. Further, if subjects have not acted before, or if they have never had a similar experience to that being emotionally role-played, they find it hard to role-play or take the experience seriously. In addition, 
some subjects may become so emotionally involved by an inconsequential aspect of the emotionally role-played situation, they ignore the important learning aspects of the situation.

In addition, the two criteria measures were discussed as to their validity and reliability. It appeared that the attitude test was an adequate criterion measure, although the biographical section could be improved. However, simulator performances do not provide good criterion measures because they tend to be unreliable.

Finally, subject differences in driving experience, and differences in driver education classes may have affected the effectiveness of the treatments. Also, incongruities between expectation of success and perceived successful experiences and socio-economic class were found to be important predictor variables of the poorer driver. However, race does not appear to be an important predictor variable in this regard.

The next chapter will present conclusions drawn from the results of the preliminary trials and the quasiexperiments, and the discussion of these results. 


\section{CHAPTER V}

CONCLUSIONS

Consldering the discussion of the results and the conditions of this study, the following conclusions are drawn.

Modeling appears to be an effective technique for inducing driving attitude and behavior change. The most effective models are those who are peers of the observers, but are not well known personally to the observers. In addition, the models must not be too dissimilar, such as having superior grades when the observers have average grades, or similar to the observers. In both cases models may become aversive stimuli. Further, the effectiveness of the treatment may be delayed until an incentive situation exists.

Reciprocal inhibition shows promise as being an effective technique for inducing driving attitude and behavior change. Behaviors which preclude driving while under emotional stress can be tạght by models. The presented alternative behaviors must be behaviors which the observers might perform.

Demonstration also appears to be an effectlve technique for changing driving attitudes and behaviors. Students 
chosen as demonstrators should be similar to the students in their audience. Also, in order that all students have an active role in discussions, discussion groups should be smal1. In addition, having the demonstrator actually perform many of the driving actions he describes while he is in a car may give students a greater feeling of involvement in the demonstration. Finally, once again, the effectiveness of the treatment may be delayed until an incentive situation exists; i.e., having an accident or almost having an accident. On the other hand, emotional role-playing does not appear to be an effective technique to change driving behaviors and attitudes. It appears to function as a "scare" technique and students tend to repress their unpleasant experiences. Also, if the situation presented is too dissimilar to experiences students have had, students find it hard to emotionally role-play the given situations.

Two types of criterion measures were used. The attitude test proved itself an adequate criterion measure. Further, it is possible that taking the attitude test may induce driving attitude change, because the student is forced to evaluate, and if retested, reevaluate his own driving performance. However, simulator performances do not provide good criterion measures because they tend to be unreliable.

In short, modeling, reciprocal inhibition and demonstration appear to be effective techniques, and emotional 
role-playing an ineffective technique, for changing driving behaviors and attitudes. Driver educators should consider using these techniques to introduce the element of emotional control into driver education courses. These techniques can benefit from further developmental work to increase their effectiveness. It is further suggested that the full benefit of these techniques may have a delayed effect, i.e., appropriate driving behavior ma be elicited after the student has an accident or almost has an accident. Thus, it has been suggested that follow-up studies be done to compare the number of accidents students in the control and experimental groups have in future years, in order to further assess the effectiveness of these techniques. 
BIBLIOGRAP HY 


\section{BIBLIOGRAPHY}

Agosto, R. M. The Effects of Intensity of Modeled Aggression and Anger Arrousal on Interpersonal Aggression. Ph.D. thesis, University of Utah, 1971.

Allport, F. H. Social Psychology. Cambridge, Mass.;
Riverside

American Automobile Association, Sportsmanlike Driving 5 th Ed., New York: McGraw-Hill Book Company, 1965.

Asch, S. E. The doctrine of suggestiong, prestiage and imitation in social psychology. Psycho1. Rev., 1948 , 55, 250-277.

Asher, J. W. Do Driver Training Courses Produce Better Drivers? An Alternative hypothesis. Traf. Saf. Res. Rev., 1968, 12(1), 2-6.

Asher, W. \& Dodson, B. The Prediction of Automobile Accidents Following the Senior Year in High School. Paper read before the American Psychological Association, September, 1969.

Asher, W. \& Dodson, B. Automobile Accidents in the Year Following High School: The Predictive Value of 377 Unobtrusive Variables. Joint Highway Research Project, No. 33, Purdue University, 1969.

Asher, W. \& Dodson, B. Social, Psychological and Educational Characteristics of Adolescents and Young Adults Killed in Indiana Automobile Accidents. Progress Report, Joint Highway Research Project, October 1970.

Asher \& Shapiro (1971). Young Drivers' Severe Automobile Accidents Joint Highway Research Project, No. 19, Furdue University, 1971.

Atkinson, D. R. Effect of selected behavior modification techiques on student-initiated action. J.Counsel. Psychol., 1971, 18(5), 395-400. 
Baker, J. M. Children's Imitative Responses as a Function of Socioeconomic Class, Incentive-Orientated Set and Reinforcement. Ph.D. thesis, University of Arizona, 1970 .

Bandura, A. Principles of Behavior Modification. N.Y.: Holt, Rinehart and Winston, 1969.

Bandura, A. Influence of models' reinforcement contingencies on the acquisition of imitative responses. J.SOC. Psychol., 1965, 1, 589-595.

Bandura, A. Vicarious processes: A case of notrial learning. In $\mathrm{L}$. Berkowitz (Ed.), Advances in experimental social psychology. Vo1. II. N.Y.: Academic Press, 1965b.

Bandura, A. and Barab, P.G. Conditions governing nonreinforced imitation. Develop. Psychol., 1971, 5(2), 244-255.

Bandura, A. Blanchard, E.B. and Ritter, B. The relative efficacy of desenitization and modeling approaches for inducing behavioral affective and attitudinal changes. Unpublished manuscript, Stanford University, 1968 .

Bandura, A., Grusec, J. E. \& Menlove, F. L. Observational learning as a function of symbolization and incentive set. Child Develop., 1966, 37, 499-506.

Bandura, A. \& Huston, A.C. Identification as a process of incidental learning. J. Abnorm. Soc. Psychol., $1961, \underline{63}, 311-318$.

Bandura, A. \& Kupers, C. J. Transmission of patterns of self-reinforcement through modeling. J. Abnorm. Soc. Psychol., 1964, 69, 1-9.

Bandura, A. \& McDonald, F. J. The influence of social reinforcement and the behavior of models in shaping childrens moral judgment. J.Abnorm. Soc. Psychol., $1963,67,274-281$.

Bandura, A. \& Menlove, F.I. Factors determining vicarious extinction of avoidance behavior through symbolic modeling. J.Pers. Soc. Psychol., 1968, 으, 99-108.

Bandura, $A$. \& Mischel $\mathrm{W}$. The influence of models in modifying delay of gratification patterns. J. Pers. Soc. Psychol., 1965, 2, 698-705. 
Bandura, A. \& Perloff, B. Relative efficacy of selfmonitored and externally imposed reinforcement systems. J. Pers. Soc. Psychol., 1967, , 111-116.

Bandura, A. \& Rosenthal, T. L. Vicarious classical conditioning as a function of arousal level. J. Pers. Soc. Psychol., 1966, $\underline{3}, 54-62$.

Bandura, A., Ross, D. \& Ross, S. A. A comparative test of the status envy, social power, and secondary reinforcement theories of identification learning. J. Abnorm Soc. Psychol., 1933a, 67, 527-534.

Bandura, A., Ross, D. \& Ross, S. A. Vicarious reinforcement and imitative learning. J. Abnorm Soc. Psychol., $1963 b, \underline{67}, 601-607$.

Bandura, A., Ross, D. \& Ross, S. A. Imitation of filmmediated aggressive models. J.Abnorm. Soc. Psychol., $1963 c, 67,274-281$.

Bandura, A. \& Walters, R. Social Imitation and Personality Development. N.Y. Holt, Rinehart and Winston, 1963.

Bandura, A. \& Whalen, C.K. The influence of antecedent reinforcement and divergent modeling cues on patterns of self-reward. J.Pers. Soc. Psychol., 1966, $\underline{3}$, $373-382$.

Barmack, J. E. \& Payne, D. E. The Lackland accident counter-measure experiment, in Haddon, W. , Suchman, E. A. \& Klein, D. (eds.), Accident Research: Methods and Approaches. N.Y.: Harper \& Row Publishers, Inc., 1964, 665-672.

Beamish, J. J. \& Malfetti, J. L. A Psychological Comparison of Violator and non-Violator Automobile Drivers in the 16 to 19 year Age Group, Traff. Saf. Res. Rev., $1962, \underline{6}(1), 12-15$.

Berger, S. M. Observer perserverance as related to a model's success: A social comparison analysis. J. Pers. Soc. Psycho1. 1971, 19(3), 341-350.

Berger, S. M. Observer practice and learning during esposure to a mode1. J.Pers. Soc. Psycho1., 1966, 3, 696701 .

Berger, S. M. Conditioning through vicarious instigation. Psycho1. Rev., $1962,69,450-466$. 
Berger, S. M. Incidental learning through vicarious reinforcement. Psychol. Rep., 1961, 9, 477-491.

Blanchard, E. B. The relative contributions of modeling, informational influences, and physical contact in the extinction of phobic behavior. Ph.D. thesis, Stanford University, 1969.

Britt, D. W. Effects of probability of reinforcement and social stimulus consistency on imitation. J.Pers. Soc. Psychol., 1971, 18(2), 189-200.

Brown, D. E. Sex-role development in a changing culture. Psycho1. Bulletin, (17) 55, 232-242.

Brown, D. E. Sex-role preference in young children. Psychol. Mono., 1956 (170) (17).

Brown, P. L. \& Berdie, R. F. Driver Behavior Scores on the MMPI, J.Appl. Psychol., 1960, 44(1), 18-21.

Bruning, J. L. Direct and vicarious effects of a shift in magnitude of reward on performance. J. Pers. Soc. Psychol., 1965, 2, 278-282.

Burstein, E., Stotland, E. \& Zander, A. Similarity to a model and self-evaluation. J.Abnorm. Soc. Psychol., $1961,62,257-264$.

Carlin, M. T. The effects of modeled behavior during imposed delay on the observer's subsequent willingness to delay rewards. Unpublished doctoral dissertation, Stanford University, 1965.

Carlson, W. L. and Klein, D. Familial vs. Institutional Socialization of the Young Traffic offender, $J$. Safety Research, March 1970, pp. 13-25.

Cohen, H. N. Imitative behavior in high and low dependent preschool children as a function of nurturance and nuturance withdrawa1. Ph.D. thesis, syracuse University, 1970.

Cohen, J., Dearnaley, E. J. \& Hanse1, C. M. The Risk Taken in Crossing a Road, Cperational Research quarterly, 1955, 63, 120-127.

Coleman, J. S. The Adolescent Society. N. Y.: The Free Press of Glencoe, 1961.

Conger, J. J. Personality Factors in Motor Vehicle Accidents, Medical Times, 88, 202-284. 
Conger, J. J., Gaskill, H. S., Glad, D. D., Hassell, Rainey, R. V., \& Sawrey, W. L. Psychological and psychophysical factors in motor vehicle accidents, J.A. M. A., 1959, 169(14), 1581-1587.

Conger, J. J., Gaskil1, H. S., Glad, D. D., Rainey, R. V., Sawrey, W. L. \& Turrell, E. S. Personal and Interpersonal Factors in Motor Vehicle Accidents, Am. J. Psychiat., 1957, 113, 1-96-74.

Conger, J. J., Miller, W. C., \& Rainey, R. V. Effects of Driver Education: The Role of Motivation, Intelligence, Social Class, and Exposure, Traf. Saf. Res. Rev. $1966,10(3), 67-71$.

Coppin, See Department of Motor Vehicles, Stare of Calif.

Craig, K. D. Physiological arousal as a function of imagined, vicarious, and direct stress experiences. J. Abnorm. Psychol., 1968, 73, 513-520.

Craig, K. D. \& Weinstein, M. S. Conditioning vicarious affective arousal. Psychol. Rep., 1965, 17, 955963.

Craig, K. D. \& Wood, K. Physlologlcal differentiation of direct and vicarious affective arousal. Canadian J. Beh. Sci., 1969, 1, 98-105.

Crancer, A., Jr., \& Quiring, D. L., The Mentally IIl as Motor Vehicle Operators, Am. J. of Psychiatry, 1969, $\underline{126}(6), 807-813$.

deCharms, C. P. \& Rosenbaum, M. E. Status variables and matching behavior. J.Pers., 1960, 28, 492-502.

Denney, D. R. The effect of style and tempo of an adult model on the conceptualization of children. Ph.D. thesis, University of Washington, 1970.

Department of Motor Vehicles, State of California (1969). Coppin, R. S., Peck, R. C., Lew, A., et al. The Effectiveness of Short Individual Driver Improvement Sessions.

Department of Motor Vehicles, State of California (1969). Marsh, W. C. Modifying Negligent Driving Behavior: A Preliminary Evaluation of Selected Driver Improvement Techniques.

Department of Motor Vehicles, State of California (1969). McBride, R. A. \& Peck, R. C. Modifying Negligent Driver Behavior through Warning Letters. 
Department of Motor Vehicles, State of California (Jan. 1966). Coppin, R. W. \& Van Oldenbeek, G. The Fatal Accident Re-examination Program in California.

Department of Motor Vehicles, State of California, (Feb. 1965). Coppin, R. S., Ferdun, G. S. \& Peck, R. C. The Teenaged Driver.

Department of Motor Vehicles, State of California, (Jan., 1965). Coppin, R. S. \& Van Oldenbeek, G. Driving Under Suspension and Revocation.

Department of Motor Vehicles, State of California, the 1964 Driver Record Study.

Dilollo, V. \& Berger, S. M. Effects of apparent pain in others on observer's reaction time. J. Pers. Soc. Psychol., 1965, 2, 573-575.

Dohme, J. A. The Relative Efficacy of Vicarious and Direct Reinforcement Systems on Two Socially-Transmitted Leerning Tasks. Ph.D. thesis, University of Arizona, 1971.

Dubanoski, R. A. \& Parton, D. A. Imitative Aggression in Children as a Function of Observing a Human Model. Develop. Psycho1. , 1971, 4 (3), 489.

Edwards, D. S., Hahn, C. P. \& Fleishman, E. A. The Reaction Between Simulator and Street Performance. Report R 69-7. Washington, D.C.: American Institutes for Research, 1969.

ENO Foundation for Highway Traffic Contro1. Personal Characteristics of Traffic Accident Repeaters. Saugatuck, Conn., 1965.

Erickson, J. A. Sado-Aggression and Maso-Submission in Automobile Accidents. Department of Psychology, Chico State College, Chico, California, 1969.

Fau1s, L. B. \& Smith, W. D. Sex-role learning of five year olds. J. Genetic Psychol., 1956, 89, 105-117.

Finch, A. J., Jr. Direct and Vicarious Delivery of Social and Monetary Reinforcers. Ph.D. thesis, University of Alabama, 1970.

Frankel, M. Effects of videotape modeling and self-confrontation techniques on microcounseling behavior. J. Counse1. Psychol., 1971, 18(5), 465-471. 
Garwood, F. \& Jeffcoate, G. 0. The Influence of the Age of Driver on Various Human Factors Contributing to Accidents and on the Severity of Injury. Road Research Laboratory, Note RN/2522/FG.

Gelfand, D. M. The Influence of Self-Esteem on Rate of Conditioning and Social Matching Behavior. Ph.D. thesis, Stanford University, 1961.

Gerst, M. S. Symbolic coding processes in observational learning. J. Pers. Soc. Psychol., 1971, 19(1), 7-17.

Gerwitz, K. \& Stingle, K. G. Learning of generalized imitation as the basis for identification. Psychol. Rev. $1968, \underline{5}, 374-397$.

Goldberg, E. K. Effects of Models and Instructions on a Verbal Interviewing Behavior: An Analysis of the 2 Factors of the Micro-Counseling Paradigm. Ph.D. thesis, Temple University, 1970.

Gordon, C. W. The social system of the high school. Glencoe: The Free Press, 195.

Grinder, R. E. Peer Status, Academic Performance, and Motivation for Social Dating. A paper presented at American Educational Research Association

Symposium, Youth Culture and the High School: CoAgents of Socialization, Chicago, Feb., 1965.

Grusec, J. E. Power and the internalization of selfdenial, Child Develop., 1971, 42(1), 93-105.

Gutsha11, R. W., Harper, C., \& Burke, D. An exploratory study of the interrelations among driving ability, driving exposure and socio-economic status of low, average and high intelligence males. Exceptional Children, 1968, 35(1), 43-47.

Hamburger, E. Vehicular suicidal Ideation, Military Medicine, 1969, 134(6), 441-444.

Hamilton, J. A. \& Bergland, B. W. Interactive relationships among student characteristics and group counseling methods. Psychol. In the Schools, 1971, 8(1), 50-55.

Hannifan, J. J. The Effects of Variations of Models' Power and Nurturant Behavior on the Frequency with which Observers Imititate the Model. Ph.D. thesis, George Peabody College for Teachers, 1970. 
Harris, M. B. Models norms and sharing. Psychol. Rpts., $1971,29(1), 147-153$.

Hart, Senator Phillip. Let's Reward Good Drivers, True, July, 1969, 50(386), 16.

Havighurst, R. J. \& Neugarten, B. L. Society and Education. Boston: Aliyn and Bacon, Inc., 1962 .

Heilbrun, A. B., Jr. Parental model attributes, nuturant reinforcement and consistency of behavior in adolescents. Child Develop., 1964, 151-167.

Hicks, D. J. Imitation and retention of film-mediated aggressive peer and adult models. J. Pers. Spc. Psychol. , 1965, 2, 97-100.

Highway Safety Literature, Drivers Who Die, HSL 非9-10, March 14, 1969.

Holt, E. D. Animal drive and the learning process. Vol. 1. N. Y.: Holt, 1931.

Humphrey, G. Imitation and the conditioned reflex. Pedagogical Seminary, $1921,28,1-21$.

Janis, I. L. \& Mann, L. Effectiveness of emotional roleplaying in modifying smoking habits and attitudes. J. Exp. Res. Pers., 1965, 1, 84-90.

Jasperse, C. S. \& van Hekken, S. M. Effect of nuturance on imitative behavior. Psycho1. Rpts., 1971, 28(1), 201-202.

Kagan, J. The concept of Identification, Psychol. Review, $1958,65,296-305$.

Kanareff, V. T. \& Lanzetta, J. Effects of success-failure experiences and probability of reinforcement upon the acquisition and extinction of an imitative response. Psychol Rev., 1960, 67, 373-379.

Kanfer, F. H. \& Duerfeldt, P. H. Learner competence, model competence and number of observational trials in vicarious learning, J. Educ. Psychol. 1967, 58, 153-157.

Kanfer, F. H. \& Marston, A. R. Human reinforcement: Vicarious and direct. J. Exp. Psychol., 1963, 65, $292-296$.

Kanfer, F. H. \& Phillips, J. S. Learning Foundations of Behavior Therapy. N.Y.: Jom Wiley and Sons, Inc., 1970 . 
Kenel, F. C. A Driver Education Curriculum for the $70^{\prime} \mathrm{s}$. J. Traf. Saf. Educ., Jan. 1972, 18-20.

Kimba11, K. A., Ellingstad, V. S. \& Hagen, R. E. Effects of experience in patterns of driving skili: J. Saf. Res., $1971, \underline{3}(3), 129-135$.

Klein, D. The influence of societal values on rates of death and injury. J.Saf. Res., 1971, 3(1), 2-8.

Kleinknecht, R. A. Behavior Modification of Problem Drivers. State of Washington Department of Motor Vehicles, Report 024, 1969.

Kobasigawa, A. Observation of failure in another person as a determinant of amplitude and speed of a simple motor response. J.Pers. Soc. Psychol., 1965, 1, 626-630.

Kraus, A. S., Steele, R., Ghent, W. R. \& Thompson, M. G. Pre-driving identification of youg drivers with a high risk of accidents $v$. matched controls. J. Saf. Res., 1970, 2(2), 55-66.

Krumboltz, J. D. \& Schroeder, W. W. Promoting career exploration through reinforcement. Person and Guid. J. $1965,44,19-26$.

Krumboltz, J. D. \& Thoresen, C. E. The effect of behavioral counseling in groups and individual settings on information-seeking behavior. J.Counse1. Psycho1., $1964,11,324-333$.

Krumboltz, J. D. \& Varenhorst, B. , \& Thoresen, C. E. Nonverbal factors in effectiveness of models in counseling. J. Counse1. Psycho1., 1967, 14, 412-418.

Lanzetta, J. T. \& Kanareff, V. T. The effects of monetary reward on the acquisition of ian imitative response. J. Abnorm. Soc. Psychol., 1959, 59, 120-127.

Laver, A. R. Comparison of Group Paper-and-Pencil Tests with Certain Psychological Tests for Measuring Driving Aptitude of Army Personnel, J.App1. Psychol., 1955, $\underline{39}(5), 318-321$.

Lazarus, R. S., Speisman, J. C., Mordkoff, A. M. \& Davidson, I. A. A laboratory study of psychological stress produced by a motion picture film. Psychol., Monogr., 1962, 76, 34, whole Number 553 . 
Lefkowitz, M. M., Blake, R. R. \& Mouton, J. S. Status factors in pedestrian violation of traffic signals. J. Abnorm Soc. Psychol., 1955, 51, 704-706.

Levonian, E. Personality characteristics of juvenile driving violators. Accident Analysis and Prevention, 1969 , $1(1), 9-16$.

Lewis, M. Q. \& Baker, R. D. Model reinforcement of verbalizations vs actions. J. Counsel. Psychol., 1971, $\underline{18}(3), 283-284$.

Lewis, R. E. Driver Education: Bright light under a basket. Calif. J. Traffic Safety Educ., June, 1969, 7-8.

Lichtenstein, E., Keutzer, C. S., \& Himes, K. H. "Emotional" role-playing and changes in smoking attitudes and behavior. Psychol Rep., 1969, 25, 379-387.

Liebert, R. M. \& Allen, M. K. The effects of rule structure and reward magnitude on the acquisition and adoption of self-reward criteria. Psychol Rep., 1967, 21, 445-452.

Liebert, D. E., Swenson, S. A., \& Liebert, R. M. Risk taken by the opponent and experience of the subject as determinants of imitation in a competitive situation. Percept. Motor Ski11s, 1971, 32(3), 719-722.

Lipton, M. B. Individual differences in the imitation of models. Ph.D. thesis, State University of New York at Buffalo, 1970.

Little, Inc., Arthur D. The State of the Art of Traffic Safety. Cambridge, Mass.: Arthur D. Little, Inc., 1966.

Locke, E. A. Is "behavior therapy" behavioristic? (An analysis of Wolpe's psychotherapeutic methods.) Psychol. Bu11., 1971, 76(5), 318-327.

Lovaas, 0.I. A program for the establishment of speech in psychotic children. In J. K. Wing (Ed.), Early Childhood Autism, Pregamon, 1966, 45-144.

Lovaas, 0. I. Effect of exposure to symbolic aggression on aggressive behavior. Child Develop. 1961, 93, 37-44.

Maacoby, E. E. Role-taking in childhood and its consequences for social learning. Chlld Develop., 1959, 30, $239-252$. 
McBride, R. S. \& Peck, R. C. See Department of Motor Vehicles, State of California.

McCullough, J.P. An investigation of the effects of model group size upon response faciliation in the high school classroom. Ph.D. thesis, University of Georgia, 1970 .

McDavid, J. W. Effects of ambiguity of imitative cues upon learning by observation. J. Soc. Psychol., 1964, 62, 165-174.

McDavid, J. W. Effects of ambiguity of environmental cues upon learning to imitate. J. Abnorm. Soc. Psychol., $1962,65,381-386$.

McDonald, F. J. Relations of media to observational learning. Viewpoints, 1970, 46(5), 137-154.

MacDonald, J. M. Suicide and Homocide by Automobile, Am. J. of Psychiatry, October 1964, 121, 366-370.

McDouga11, W. An Introduction to Social Psychology, London: Methuen, 1908.

McFall, R. M. \& Iillesand, D. B. Behavior rehearsal with modeling and coaching in assertion training. J. Abnor. Psychol., 1971, 77(3), 313-323.

MacFarland, R. A. \& Moore, R. C. Youth and the Automobile, in Values and Ideals of American Youth ( $E$. Ginsberg, Ed.), Columbia University Press, N. Y.

McGlade, F. S. \& Abercrombie, S. A. Classifying Accidents by Sociological variables for educational research. Behavioral Research in Highway Safety, 1970, 1(4), $250-257$.

McGuire, F. L. \& Kersh, R. C. An Experimental Evaluation of Driver Education: A Study of History, Philosophy, Research Methodology and Effectiveness in the Field of Driver-Education, 1968, SRIS Accession 非8n 286.

Malcolm, D. B. The relative efficacy of adult and peer models on children's moral judgments. Ph.D. thesis, Case Western Reserve University, 1970.

Mann, L. The effects of emotional role playing on smoking attitudes and behavior. J. Exp. Soc. Psychol., $1967, \underline{3}, 334-348$.

Mann, L. \& Janis, I. L. A follow-up study on the long-term effects of emotional role-playing. J. Pers. Soc. Psychol., 1968, ㅇ, 339-342. 
Marsh, W. C. See Department of Motor Vehicles, State of California.

Marston, A. R. Imitation, self-reinforcement, and reinforcement of another person. J. Pers. Soc. Psychol., $1965, \underline{2}, 255-261$.

Marston, A. R. \& Kanfer, F. H. Group Size and number of vicarious reinforcements in verbal learning. J. Exp. Psychol., 1963, 65, 593-596.

Masters, J. C. \& Morris, R. J. Effects of contingent and non-contingent reinforcement upon generalized imitation. Child Develop., 1971, 92(2), 385-397.

Mausner, B. Studies in social interaction: III. Effect of votiation in one partner's prestiage in the interaction of observer pairs. J.Applied Psychol., $1953,37,391-393$.

Mausner, B. \& Bloch, B. L. A study of the additivity of variables affecting social interaction. J. Abnorm. Soc. Psychol., 1957, 54, 250-25.

Meichenbaum, D. H. Examination of model characteristics on reducing avoidance behavior. J. Pers. Soc.

Psychol., 1971, 17(3), 298-307.

Michael, D. N. \& Maccoby, N. Factors influencing the effects of student participation on verbal learning from films: Motivating versus practice effects, "feedback", and overt versus covert responding. In A. A. Lumsdaine (Ed.) Student response in programmed instruction, Washington, D.C. National Academy of Sciences, National Research Council, 1961, pp. 271-293.

Miller, N. E. \& Dollard, J. Social learning and imitation. New Haven: Yale University Press, 1941.

Mischel, W. \& Liebert, R. M. Effects of discrepancies between observed and imposed reward criteria on their acquisition and transmission. J.Pers. Soc. Psychol., $1966,3,45-53$.

Morgan, C. I. Habit and Instinct. London: E. Arnold, 1896.

Morrisett, L. N. Jr. The role of implicit practicein learning. Ph.D. thesis, Yale University, 1956.

Mowrer, 0. H. Leaming Theory and Behavior. N.Y.: Wiley, 1960a. 
Mowrer, O. H. Learning Theory and the Symbolic Processes. N. Y.: Wiley, 1960 b.

Mussen, B. H. \& Distler, L. Masculinity identification and father-son relationships. J.Abnorm. Soc. Psychol., 1959, 59, 350-356.

National Safety Council, Accident Facts, 1968 edition. New York State Department of Motor Vehicles, Fatal, Non-Fatal and Property Damage Accidents by Age and Sex, Hour of Day and Day of Week, 1963, Statistical Bulletin 非6, 1964 .

Newman, R. I. Imitative Learning and Its Relationship to observer Intelligence and Sex of Model. Ph.D. thesis, Washington State University, 1971.

O'Connor, R. D. Modification of Social Withdrawal Through Modeling, Shaping and Combined Treatments: A Comparative Study. Ph.D. thesis, University of Illinois at Urbana-Champaign, 1970.

Pattersoh, G. R., Littman, I. \& Brown, T. R. Negative set and social learning. J. Pers. Soc. Psychol., 1968, 8, $109-116$.

Pelz, D. C. \& Schuman, S. H. Are young drivers really more dangerous after controlling for exposure and experience? J. Saf. Res., 1971, $3(2), 68-79$.

Perry, H. M. The relative efficiency of actual and "imaginery" practice on five selected tasks. Archives of Psycho1., 1939, 34(243).

Pollock, W. T. Comparison of Driver Age with Number of Passengers and Passenger Ages. HIT Lab Reports, October, 1970, 11-12.

Price, F. T. Some effects of film-mediated professional models on the self-perceptions of black school children. Ph.D. thesis, Wayne State University, 1970.

Purdue University Computing Center, Document G2 TRECOR.

Purdue University Computing Center, Document G4 NKTEST.

Purdue University Computing Center, Document G4 TTEST.

Purdue University Computing Center, Document GO EDSTAT, Program A V2B1W. 
Quenault, S., Golby, C. \& Pryer, P. Age Group and Accident Rate-Driving Behaviour and Attitudes. Road Research Laboratory, Crowthorne, Berkshire, England, 1968.

Rainey, R. V., Conger, J. J. \& Walsmith, C. R., Personality Characteristics as a selective factor in driver education, Highway Res. Board Bul1., 285, 1961, 23-28.

Rimm, D. C. Systematic desentization of an anger response. Beh. Res. and Therapy, 1971, $9(3), 273-280$.

Ritter, B. The use of contact desentization demonstrationplus-participation and demonstration alone in the treatment of acrophobia. Beh. Res. and Therapy, 1969.

Ritter, B. The group treatment of children's snake phobias using vicarious and contact procedures. Beh. Res. and Therapy, $1968, \underline{6}, i-6$.

Rockwe11, T. H., Galbraith, F. D. \& Centre, Ditt., Risk Acceptance Research in Man-Machine Systems, Ohio State University, Bu1letin 187, 1961.

Rommel, R. C. S., Personality characteristics and attitudes of youthful accident repeating drivers, Traf. Saf. Res. Rev., 1959, 3(1), 13-14.

Rosenbaum, M. E. \& Tucker, I. F. The competence of the model and the learning of imitation and non-imitation. J. Exp. Psychol., 1962 .

Rosenblith, J. F. Learning by imitation in kindergarten children. Child Develop., 1959, 30, 69-80.

Sapolsky, A. Interpersonal relationships and verbal conditioning. J.Abnorm. Psychol., 1960, 60, 241-246.

Satterwhite, F. H. Interaction of model and observer's cognitive styles in an observational learning paradigm. Ph.D. thesis, University of Washington, 1970.

Schuh, J.V. The effect of adult model nuturance and competence on pre-school children's imitative behavior. Ph.D. thesis, the University of Nebraska, 1970 .

Schuman, S. H., McConochie, R. \& Pelz, D. C. Reduction of young driver crashes in a controlled pilot study: Two-year follow-up in one Michigan high school. J.A. M. A., 1971, 218. 
Schuman, S. H. Pelz, D. C., Ehrlich, N. J., \& Selzer, J. Young male drivers, J.A.M. A. June, 1967, 10261030 .

Schuster, D. H. Experimental Evaluation of the Performance Criteria on an Experimental Driving Simulator. Paper presented at the American Psychological Association Convention, Washington, D.C., Sept. 1971.

Scott, J. B. Operation Feedback: Tests Airmen for Accident proneness. Traf. Sig. Res. 1966, 14, 16-20, 23.

Shaw, L. \& Siche1, H. S. Accident Proneness Research on the Occurrence, Causaltion, and Prevention of Road Accidents. International Series of Monographs in Experimental Psychology, N. Y.: Pergamon Press; 1971.

Sheffield, F. D. \& Maccoby, N. Summary and interpretation of research on organizational principles in constructing filmed demonstrations, in Lumsdaine, A. A. (Ed.) Student Responses on Programmed Instruction. Washington, D. C., National Academy of Sciences, National Research Council, 1961, 117-131.

Skinner, B. F. Science and Human Behavior. N.Y.: Macmillan, 1953.

Slaby, R. G. \& Parke, R. D. Effect on resistance to deviation of observing a model's affective reaction to response consequences. Deve1op. Psychol., 1971, $\underline{5}(1), 40-47$.

Smith, F. J., \& Marston, A. R. Effects of inter-and intraresponse class differences upon learning via vicarious reinforcement. J. Verb. Learn. Verb. Beh., 1965, 4 , 360-364.

Solomon, R. I. \& Turner, L. H. Discriminative classical conditioning in dogs paralyzed by curare can later control discrimination avoidance responses in the normal state. Psychol Rev., 1962, 202-219.

Stanley, J. C. Reliability in Educational Measurement, Second Edition, R. L. Thorndike, Ed., Washington, D. C., American Council on Education, 1971.

Staub, E. A child in distress: The influence of nuturance and modeling on children's attempts to help. Develop. Psychol., 1971, 5(1), 124-132.

Stugart, D. B. An Experimental Study Investigating the Effects of Model Race, and Model Age-Referent Groups upon the Vocationsl Information Seeking Behaviors of Male Black Eleventh-Graders. Ph.D. thesis, Michigan State University, 1970. 
Tannebaum, A. J. Adolescent attitude toward academic brillance. Ph.D. thesis, N.Y. University, 1960.

Tarde, G. The Laws of Imitation. N.Y.: Ho1t, 1903.

Tasch, M. O. Modeling of Pro-Social Behavior by Pre-School Subjects of High and Low Self-Esteem. Ph.D. thesis, Syracuse University, 1970.

Tesser, A. \& Grossman, M. Fate orientation as a correlate of driver knowledge. J. Saf. Res. 1969, I (2), 74-79.

Thelen, M. H. \& Fryrear, J. R. Effect of observer and model race on the imitation of standards of self-reward. Develop. Psychol., 1971, 5(1), 133-135.

Thoresen, C. E. \& Hamilton, J. H. Encouraging adolescent career behavior with peer modeling and stimulus materials in counseling groups. Unpublished manuscript, Stanford, University, 1969.

Thoresen, C. E., Hamilton, J. A. \& Bergland, B. W. Using perceptual and personality differences to predict treatment effects on adolescent career behavior. Unpublished manuscript, Stanford University, 1969.

Thoresen, C. E., Hosford, R. E. \& Krumboltz, J. D. Determining effective models for counseling clients of varying competence. J. Counsel. Psychol., 1970, $17(4), 369-375$.

Thoresen, C. E. \& Krumboltz, J. D. Similarity of social models and clients in behavioral counseling: Two experimental studies. J.Counsel.Psychol., 1968, $15,393-401$.

Thoresen, C. E., Krumboltz, J. D. \& Varenhorst, B. The sex factor in model reinforcement counseling. Am. Psychol., July, 1965.

Tillman, W. A. \& Hobbs, G. E. The accident-prone automobile driver, Am. J. Psychiatry, 1949, 106, 321-331.

Twining, W. F. Mental practice and physical practice in learning a motor skill, Research Quarterly, 1949, $\underline{20}, 432-435$.

Vande11, R. A., Davis, R. A. \& Clugston, H. A. The function of mental practice in the acquisition of motor skills. J. Gen. Psychol., 1943, 29, 243-250. 
Veldman, D. J. Fortran Programming for the Behavioral Sciences. Chlcago: Holt, Rinehart and Winston. 1967.

Venn, J. R. The Vicarious Conditioning of Emotional Responses in Nursery School Children. Ph.D. thesis. University of Virginia, 1970.

Waldman, D. M. Exposure to a Non-Aggressive Model, Similarity to the Model, and Level of Prior Anger Arousal as Determinants of Adult Aggressive Behavior. Ph.D. thesis, University of South Carolina, 1971.

Waller, J. A. \& Goo, J. T., Highway Crash and Citation Patterns and Chronic Medical Conditions, J. Saf. Res. $1969,1,13-27$.

Warner, W. L. A Brief History of Driver Education. J. Traf. Saf. Educ., Jan., 1972, 13-15.

Wilkins, W. Desentization: Social and Cognitive factors underlying the effectiveness of Wolfe's procedure. Psychol. Bul1., 1971, 76 (5).

Zajonc, R. B. Social facilitation, Science, 1965, 149 , 269-274. 
APPENDICES 


\section{APPENDIX A}

THREE VERSIONS OF THE ATTITUDE TEST CRITERION MEASURE

Three versions of the attitude test criterion are presented. A scoring key, the number in parentheses following the alternatives, were not in the versions presented to the subjects. The scoring key is presented here for the reader's use.

Version 1 of Attitude Test Criterion: High School A, Biographical Section.

\section{Attitudes on Driving}

General Information

1. You are a

IA Male. (1)

1B Female. (2)

2. Your age is
2A 15 (1)
2B 16 (2)
2C 17 (3)
2D 18 (4)
$2 \mathrm{E} 19$ (5)

3. You are a

3 A freshman

3B sophomore.

$3 \mathrm{C}$ junior. (3)

3D senior. (4)

4. Your father's highest level of education is:

$4 \mathrm{~A}$ he did not graduate from grammar school (8th grade). (1)

$4 \mathrm{~B}$ he graduated from grammar school but not from high schoo1. (2)

$4 \mathrm{C}$ he graduated from high school. (3) 
4D he graduated from high school and took technical training or had two years of college, but did not graduate from a four year college. (4)

$4 \mathrm{E}$ he graduated from a four year college. (5)

5. What is your mother's highest level of education.

$5 \mathrm{~A}$ she did not graduate from grammar school (8th grade). (1)

5B she graduated from grammar school but not from high school. (2)

5C she graduated from high school. (3)

5D she graduated from high school and took special training (beauty school, etc.), but did not graduate from a four year college. (4)

$5 E$ she graduated from a four year college.

6. Your usual grades are

$6 \mathrm{~A}$ above average (A, B).

6B average (C). (2)

$6 \mathrm{C}$ below average. (3)

7. You live

$7 \mathrm{~A}$ on a fram. (1)

$7 \mathrm{~B}$ in a small town. (1)

7C in a medium sized town (Lafayette).

$7 \mathrm{D}$ in a big city (Indianapolis). (1)

8. You first learned to drive at the age of

$8 \mathrm{~A}$ under 4 . (1)

$8 \mathrm{~B}$ 4-8. (2)

8C $9-14$. (3)

8D 15 or older from your driver education teacher.

$8 \mathrm{E} 15$ or older from someone other than your driver education teacher. (5)

9. Who first taught you how to drive?

9 A your wother or father (1)

$9 B$ your grandmother or grandfather (1)

$9 \mathrm{C}$ a boy friend or a girl friend (1)

9D your driver education teacher (2)

$9 \mathrm{E}$ no one - you saw others drive and learned from this. (1)

10. How much do you drive each week, on the average?

$10 \mathrm{~A}$ over 75 miles.

10B 50-75 miles. (2)

10C 15-25 miles. (3)

10D 5-10 miles. (4)

$10 \mathrm{E}$ under 5 miles. (5)

11. Where do you usually drive.

IIA in a city

$11 B$ on a farm

(not included in data analysis) 
11C in a smal1 town and on local highways

$11 D$ on major highways such as 165 , etc.

$11 \mathrm{E}$ other

12. When do your parents let you use a car?

12A Whenever you want. (1)

$12 \mathrm{~B}$ Most of the time you want. (2)

12C Some of the time you want. (3)

12D Almost never. (4)

$12 \mathrm{E}$ You have your own car and can drive it any time you want. (I)

13. What restrictions do your parents put on your driving? Check as many as you need.

13A No restrictions. (1)

13B Must be home at a certain time. (2)

13C Can only drive in certain places. (2)

13D Not to drive when drinking. (2)

$13 \mathrm{E}$ other. (2)

14. What do you plan to do after high school?

$14 \mathrm{~A}$ go to college. (3)

$14 \mathrm{~B}$ get technical training (beauty school, electronics, etc.). (2)

$14 \mathrm{C}$ farm. (1)

$14 \mathrm{D}$ Work. (1)

$14 \mathrm{E}$ Undecided.

15. Have you ever been in accident when you were the driver?

$15 \mathrm{~A}$ Yes, once. (3)

$15 \mathrm{~B}$ Yes, 2 or 3 times. (2)

$15 \mathrm{C}$ Yes, 4 or more times. (1)

$15 \mathrm{D}$ No (4)

16. Have you ever been in accident when you were not the driver?

$16 \mathrm{~A}$ Yes, once. (3)

$16 \mathrm{~B}$ Yes, 2 or 3 times.

$16 \mathrm{C}$ Yes, 4 or more times.

$16 \mathrm{D}$ No. (4)

17. Have you ever received a warning ticket or a "regular" ticket for a moving violation (such as speeding, running a stop sign, etc.)?

17A Yes, once. (3)

$17 \mathrm{~B}$ Yes, 2 or 3 times. (2)

$17 \mathrm{C}$ Yes, 4 or more times. (1)

$17 \mathrm{D}$ No. (4)

i8. Do you think your father would come get you if you called him up and told him you had been drinking and did not want to drive? 
18 A Y'S (5)

$18 \mathrm{~B}$ Probably (4)

$18 \mathrm{C}$ Maybe (3)

$18 \mathrm{D}$ No (2)

$18 \mathrm{E}$ I would not call my father.

19. Do you think your mother would come get you if you

called her up and told her you had been drinking and did not want to drive?

19 A Yes (5)

$19 \mathrm{~B}$ Probably (4)

19C Maybe (3)

$19 D$ No (2)

19E I would not call my mother. (1)

20. What did you think of the movies you saw in your driver education course?

$20 \mathrm{~A}$ All were very good. (4)

20B Some were very good. (3)

$20 \mathrm{C}$ Most were a waste of time. (2)

20D We did not see movies in my driver education course. (1)

$20 \mathrm{E}$ We had some movies in my driver education course but I do not remember them. (1)

21. Have you ever driven when you had been drinking beer?

$21 \mathrm{~A}$ Yes, once. (3)

21B Yes, 2 or 3 times. (2)

$21 \mathrm{C}$ Yes, 4 or more times. (1)

21D No. (4)

22. Have you ever driven when you had been drinking hard alcohol?

$22 \mathrm{~A}$ Yes, once. (3)

$22 \mathrm{~B}$ Yes, 2 or 3 times. (2)

22C Yes, 4 or more times. (1)

$22 \mathrm{D}$ No. (4)

Version 1 of Attitudes Criterion: High School A, Attitude

Section.

Section II

General Attitudes START ON ITEM @C ON YOUR ANSWER CARD

26. If you were a passenger in a car and you thought the driver (a friend of your) was driving wildly, would you ask the driver to drive more safely?

26 A Yes (5)

26B Probably (4)

$26 \mathrm{C}$ Sometimes (3)

26D Probably not (2)

26E Definitely not (1) 
27. If you were drinking beer, how many cans or glasses would you have and decide not to drive?

$27 \mathrm{~A}$ I do not drink beer. (5)

$27 \mathrm{~B} 1 \mathrm{1}(4)$

$27 \mathrm{C} 2$ or 3 (3)

$27 \mathrm{D} 4$ or 5 (2)

$27 \mathrm{E} 6$ or more (1)

28. If you were really angry, would you drive?

$28 \mathrm{~A}$ Yes (1)

28B Probably (2)

28C Sometimes (3)

28D No (4)

29. If you were drinking hard alcohol, how mush would you drink and not drive?

$29 \mathrm{~A}$ I do not drink hard alcohol. (5)

29B 1 drink. (4)

29C 2 or 3 drinks. (3)

29D 4 or 5 drinks. (2)

29E 6 or more drinks.

30. Do you have a tendency to go too fast?

$30 \mathrm{~A}$ Yes (1)

30B Sometimes (2)

$30 \mathrm{C}$ Very little (3)

30D No (4)

31. Do you have a tendency to drive too close to the side of the road?

$31 \mathrm{~A}$ Yes (1)

$31 \mathrm{~B}$ Sometimes (2)

$31 \mathrm{C}$ Very little (3)

$31 D$ No (4)

32. Do you have a tendency to show off?

$32 \mathrm{~A}$ Yes (1)

$32 \mathrm{~B}$ Sometimes (2)

$32 \mathrm{C}$ Very little (3)

32D No(4)

33. Do you have a tendency to not stop completely at stop signs?

33 A Yes (1)

$33 \mathrm{~B}$ Sometimes (2)

$33 \mathrm{C}$ Very little (3)

$33 \mathrm{D}$ No $(4)$

34. Do you have a tendency to talk too much to others while driving and perhaps not keep your mind on the road?

$34 \mathrm{~A}$ Yes (1)

34B Sometimes (2) 
$34 \mathrm{C}$ Very little (3)

341 ) No (4)

35. Do you have a tendency to run off the road?

$35 \mathrm{~A}$ Yes (1)

35B Sometimes (2)

$35 \mathrm{C}$ Very little (3)

$35 \mathrm{D}$ No $(4)$

36. Do you have a tendency to not keep your mind on driving and on the road?

$36 \mathrm{~A}$ Yes (1)

$36 \mathrm{~B}$ Sometimes (2)

$36 \mathrm{C}$ Very little (3)

$36 \mathrm{D}$ No $(4)$

37. Do you have a tendency to drink and drive?

$37 \mathrm{~A}$ Yes (1)

$37 \mathrm{~B}$ Sometimes (2)

$37 \mathrm{C}$ Very little (3)

$37 \mathrm{D}$ No $(4)$

38. When you are very angry, how well do you drive?

$38 \mathrm{~A}$ Better than usual (1)

$38 \mathrm{~B}$ the same as usual (2)

$38 \mathrm{C}$ worse than usual (3)

38D I do not drive when angry. (0)

39. How well do you drive when you are excited?

$39 \mathrm{~A}$ better than usual (1)

$39 \mathrm{~B}$ the same as usual (2)

$39 \mathrm{C}$ worse than usual ( 3 )

39D I do not drive when excited. (0)

40. When you have had a couple of cans or glasses of beer, and drove, your driving was

$40 \mathrm{~A}$ better than usual. (1)

$40 \mathrm{~B}$ the same as usual. (2)

$40 \mathrm{C}$ worse than usual. (3)

40D I do not drive after drinking beer. (4)

$40 E$ I do not drink beer. (5)

41. When you have had a couple of drinks of hard alcohol, and drove, your driving was

$41 \mathrm{~A}$ better than usual. (1)

$41 \mathrm{~B}$ the same as usual. (2)

41C worse than usual. (3)

$41 D$ I do not drive after drinking hard alcohol. (4)

$41 E$ I do not drink hard alcohol. (5) 
42. How would you rate yourself as a driver?

42A Excellent (5)

$42 B$ Above average (4)

42C average ( 3 )

$42 \mathrm{D}$ below average (2)

42E Poor (1)

43. Would you call your mother to get you if you had been drinking and you did not want to drive?

$43 \mathrm{~A}$ Yes (5)

43B Probably (4)

43C Maybe (3)

43D Probably not (2)

$43 E$ Definitely not (1)

44. Would you call your father to get you if you had been drinking and you did not want to drive?

$44 \mathrm{~A}$ Yes (5)

44B Probabiy (4)

44C Maybe (3)

44D Probabiy not (2)

44E Definitely not (1)

45. Would you ask anyone else to drive if you had been drinking and you did not feel you should drive?

$45 \mathrm{~A}$ Yes (5)

45B Probably (4)

45C Maybe (3)

45D Probabiy not (2)

45 E Definitely not (1)

46. If a girlfriend (if you are a girl) or a boyfriend (if you are a boy) were in the car with you, how well

would you drive?

$46 \mathrm{~A}$ better than usual (1)

$46 \mathrm{~B}$ the same as usual (2)

$46 \mathrm{C}$ worse than usual ( 3 )

47. If a friend were riding wity you in the car, would you drive faster than the speed limit?

$47 \mathrm{~A}$ Yes (1)

47B Probably (2)

$47 \mathrm{C}$ Maybe (3)

47D Probably not (4)

$47 E$ Definitely not (5)

48. If a friend were riding with you in the car, would you show off a little?

$48 \mathrm{~A}$ Yes (1)

48B Probably (2)

48C Maybe (3)

48D Probably not (4)

48E Definitely not (5) 
49. If a friend were riding with you in the car, would you talk to your friend and not pay as much attention to the road?

49A Yes (1)

49B Probably (2)

49C Maybe (3)

49D Probably not (4)

$49 \mathrm{E}$ No (5)

50. Do you like to drive?

$50 \mathrm{~A}$ Yes, a lot. (1)

$50 \mathrm{~B}$ Somewhat (2)

$50 \mathrm{C}$ Not very much.

51. Do you ever get a feeling of power when driving a car?

$51 \mathrm{~A}$ Usually (1)

$51 B$ Often (2)

51C Sometimes (3)

51D Rarely (4)

$51 \mathrm{E}$ Never (5)

52. Did you ever want to smash someone or something with the car while driving?

$52 \mathrm{~A}$ Yes, once or twice. (3)

$52 \mathrm{~B}$ Yes, three or four times (2)

$52 \mathrm{C}$ Yes, five or more times. (1)

52D No, never. (4)

53. Does it annoy you when drivers try to cut in on you?

$53 \mathrm{~A}$ Very much (1)

$53 \mathrm{~B}$ Some (2)

$53 \mathrm{C}$ Very little (3)

53D Not at al1 (4)

54. Does it annoy you when drivers try to pass you?

$54 \mathrm{~A}$ Very much (1)

$54 \mathrm{~B}$ Some (2)

$54 \mathrm{C}$ Very little (3)

54 Dot at al1 (4)

55. Do you like to see if you can go through a yellow light before it turns red?

$55 \mathrm{~A}$ Usually (1)

$55 \mathrm{~B}$ often (2)

$55 \mathrm{C}$ Sometimes (3)

$55 \mathrm{D}$ Almost never (4)

56. Would you pull off the road if you thought you were too angry or excited to drive safely?

$56 \mathrm{~A}$ Yes (4)

56B Probably (3)

56C Maybe (2)

56D Probably not (1) 
57. If a friend in the car with you told you to slow down because they thought you were driving too fast, would you?

$57 \mathrm{~A}$ Yes (4)

57B Probably (3)

57C Maybe (2)

57D Probably not

58. If a brother or sister in the car with you told you to slow down, would you?

$58 \mathrm{~A}$ Yes (4)

58B Probably (3)

$58 \mathrm{C}$ Maybe (2)

58D Probabiy not (1)

59. If your mother or father were in a car with you and told you to slow down, would you?

59 A Yes (4)

59B Probably (3)

59C Maybe (2)

59D Probably not (1)

60. If someone were trying to pass you, would you speed up so he would not?

$60 \mathrm{~A}$ Yes (1)

60B Probabiy (2)

60C Maybe (3)

60D Probably not

61. Do you think you drive recklessly at times?

$61 \mathrm{~A}$ Yes, often. (1)

$61 \mathrm{~B}$ Yes, sometimes.

61C Rarely (3)

61D I never drive recklessly.

Do you think you would ever have a minor accident (in which no one is hurt seriously)?

$62 \mathrm{~A}$ Yes, it is possible. (3)

$62 \mathrm{~B}$ Yes, it is possible but unlikely.

$62 \mathrm{C}$ No, it is very unlikely. (1)

63. Do you think you would ever have a major accident (in which someone is seriously injured or killed)?

$63 \mathrm{~A}$ Yes, it is possible.

$63 \mathrm{~B}$ Yes, it is possible but unlikely.

$63 \mathrm{C}$ No, it is very unlikely.

64. Do you think your friends could have an accident?

$64 \mathrm{~A}$ Yes, it is possible. (3)

$64 \mathrm{~B}$ Yes, it is possible but unlikely.

$64 \mathrm{C}$ No, it is unlikely. 
65. If a friend had an accident would it bother you enough to change any of your driving habits?

$65 \mathrm{~A}$ Yes, if he were killed. (2)

65B Yes, if he were injured.

$65 \mathrm{C}$ Yes, if I heard about it. (4)

65D No, although I might feel sorry for him.

Version 2 of Attitude Test Criterion: University Subjects,

Biographical Section

General Information

1. You are a

$1 \mathrm{~A}$ Male.

IB Female. (2)

2. Your age is

$2 \mathrm{~A} 18-19$ (1)

$2 B$ 20-21 (2)

2C $22-23$ (3)

2D 24-25 (4)

2 E 26 or older (5)

3. You are a

$3 \mathrm{~A}$ freshman (1)

$3 \mathrm{C}$ junior (3)

3 D senior (4)

$3 E$ graduate student (5)

4. Your father's highest level of education is

$4 \mathrm{~A}$ did not graduate from grammar school (8th grade).

4B graduated from grammar school but not from high school (2)

4C graduated from high school. (3)

4D graduated from high school and took special training (2 years of college, technical school, etc.) but did not graduate from a 4 year college. (4)

$4 \mathrm{E}$ graduated from a four year college. (5)

$4 \mathrm{E}$ did advanced work (M.S., Ph.D., etc.) (5)

5. Your mother's highest level of education is

$5 \mathrm{~A}$ did not graduate from grammar school (8th grade).

5B graduated from grammar school but not from high school. (2)

5C graduated from high school. (3)

5D graduated from high school and took special training (beauty sc..ol etc.), but did not graduate from a four year college.

5E graduated from a 4 year college. (5)

$5 \mathrm{E}$ did advanced work (M.S., Ph.D., etc.) 
6. Your usual grades are

$6 \mathrm{~A}$ above average (A or B) (3)

$6 \mathrm{~B}$ average (c) (2)

$6 \mathrm{C}$ below average (1)

7. Your parents live

$7 \mathrm{~A}$ in a farming area (either on a farm or in a small town near a farming area, etc.). (1)

$7 \mathrm{~B}$ in a medium sized town (Lafayette) or around a medium sized town which has industries other than, or in addition to farming. (1)

7C in or near a big city (Indianapolis). (1)

8. While at school you live in

$8 \mathrm{~A}$ a dormitory. (1)

$8 B$ a fraternity or sorority. (1)

$8 \mathrm{C}$ an apartment or a rented home near schsol. (1)

$8 \mathrm{D}$ your parents' home. (2)

$8 \mathrm{E}$ other

9. You first learned to drive at the age of

9 A under 4 . (1)

9 B $4-8$. (2)

9C $9-14$. (3)

9D 15 or older from someone other than a driver education teacher. (4)

$9 \mathrm{E} 15$ or older from a driver education teacher.

10. Who first taught you to drive?

$10 \mathrm{~A}$ mother or father (1)

IOB driver education teacher (2)

10C boyfriend or girlfriend (1)

$10 \mathrm{D}$ brother or sister or a grandparent (1)

IOE other ( 1 )

11. How many miles a week, on the average, do you drive now while at school), not counting times you went out with students you were teaching how to drive?

$11 \mathrm{~A}$ over 75 miles a week. (1)

11B 50-75 miles a week. (2)

11C 25-49 miles a week. (3)

11D 5-24 miles a week. (4)

$11 \mathrm{E}$ less than 5 miles a week. (5)

12. Where do you usually drive? Mark all items you need. Do not count the times you were teaching students how to drive.

$12 \mathrm{~A}$ in a city

$12 B$ on a farm

12C in a small town

$12 \mathrm{D}$ on highways

$12 \mathrm{E}$ other

(not included in data analysis) 
13. Do you own your own car?

$13 \mathrm{~A}$ Yes (1)

$13 B$ No (2)

14. If you own your own car, is it a sports car or have you souped it up?

$14 \mathrm{~A}$ Yes (1)

$14 \mathrm{~B}$ No (2)

14C I do not own my own car.

15. If you do not own your own car, how often can you use someone else's car?

15A whenever I want. (1)

$15 \mathrm{~B}$ most of the time. (2)

15C sometimes. (3)

15D almost never. (4)

15E I own my own car and can use it when I want. (0)

16. What do you plan to do after receiving your bachelor's degree? Mark the item you paln to spend most time doing in the 3 years after graduation.

$16 \mathrm{~A}$ teach and/or coach in a school. (1)

$16 \mathrm{~B}$ to into business. (1)

$16 \mathrm{C}$ go to graduate school.

16D Undecided. (0)

$16 \mathrm{E}$ Other (0)

17. Have you ever been in a minor accident (in which no one was seriously hurt) when you were the driver of a car in the accident in the last 3 years?

$17 \mathrm{~A}$ Yes, once or twice. (3)

$17 \mathrm{~B}$ Yes, 3 or 4 times. (2) (seriously hurt = broken

17C Yes, 5 or more times. (1)bones, stitches required, $17 \mathrm{D}$ No $(4)$ etc.)

18. Have you ever been in a car which was in a minor accident (in which no one was seriously hurt) when you were not the driver of a car in the accident in the last 3 years?

18A Yes, once or twice. (3)

$18 \mathrm{~B}$ Yes, 3 or 4 times. (2)

$18 \mathrm{C}$ Yes, 5 or more times. (1)

$18 \mathrm{D}$ No (4)

19. Have you been in a serious accident (in which someone was seriously hurt) when you were a driver of a car in the accident in the last 3 years?

19A Yes, once or twice. (3)

$19 \mathrm{~B}$ Yes, 3 or 4 times. (2)

$19 \mathrm{C}$ Yes, 5 or more times. (1)

$19 D$ No (4) 
20. Have you ever been in a serlous accident (in which someone was seriously hurt) when you were not a driver of a car in the accident in the last 3 years?

$20 \mathrm{~A}$ Yes, once or twice. (3)

$20 B$ Yes, 3 or 4 times. (2)

20C Yes, 5 or more times.

$20 \mathrm{D}$ No $(4)$

21. In the past 3 years, have you ever received a warning ticket for a moving violation (speeding, etc.)?

$21 \mathrm{~A}$ Yes, once or twice. (3)

$21 \mathrm{~B}$ Yes, 3 or 4 times. (2)

21C Yes, 5 or more times. (1)

$21 \mathrm{D}$ No (4)

22. Have you ever received a regular ticket (not a warning ticket) for a moving violation (speeding, etc.) in the past 3 years?

$22 \mathrm{~A}$ Yes, once or twice. (3)

$22 \mathrm{~B}$ Yes, 3 or 4 times. (2)

$22 \mathrm{C}$ Yes, 5 or more times. (1)

22D No (4)

23. Why do you want to teach driver education?

23A I can make extra money. (1)

23B I enjoy teaching (2)

23C I do not intend to teach driver education. (1)

23D Other (1)

24. Do you think you will make a good driver education teacher?

$24 \mathrm{~A}$ Yes, a very good one.

$24 \mathrm{~B}$ Yes, a good one. (3)

$24 \mathrm{C}$ Yes, an average teacher.

$24 \mathrm{D}$ No. (1)

25. Have you ever had anything happen to you while in a car that shook you up, and in the future, in the same kind of situation, you are much more cautious, such as another car almost ramming into you because it went through a stop sign and you now are extra cautious at certain types of intersections, etc., in the last 3 years?

25A Yes, once or twice. (3)

$25 \mathrm{~B}$ Yes, 3 or 4 times. (2)

$25 \mathrm{C}$ Yes, 5 or more times. (1)

$25 \mathrm{D}$ No (4) 
Version 2 of Attitude Test Criterion: University Subjects, Attitude Section

\section{PROBLEM STATEMENT}

Traffic accidents are the leading cause of death for persons aged 15-24, equaling all other causes combined (National Safety Council, 1968). Hart (1969) said that drivers in the late teens and the first half of the twenties have one-third of all accidents, although this group of drivers constitutes only $21 \%$ of all drivers. Also, males under 25 have far more accidents than females under 25 . For example, in 1968, in Indiana, there were 4185 drivers aged 16-21 involved in an accident in which there was a serious injury or death. Seventy-eight percent of these young drivers were males, and only twenty-two percent were females. Of the male drivers, twenty-two percent had been drinking before the accident: only six percent of the female drivers had been drinking. Furthermore, $64 \%$ of these accidents occurred while going straight ahead, on a straight, level, blacktop, dry road with unobscured vision, and males were usually driving faster than females. Therefore, these is a major problem with young people and accidents, and we are trying some new things which might help reduce the accident rate for young drivers.

Please answer the following questions on your ANSWER CARD, using the PENCIL THAT IS GIVEN TO YOU TO USE. 
NOTE* Dr. Asher is a registered psychologist with the state of Indiana. This includes, by law, the right of privileged communication, such as a doctor or priest has. ALL information given to us will be kept CONFIDENTIAL. We ask you to put your name on the answer card only to make sure that all information you give us is kept together.

THANK YOU FOR YOUR HELP

\section{Attitudes on Driving}

Section II

General Attitudes START ON ITEM 26 ON YOUR ANSWER CARD

26. If you were a passenger in a car and you thought the driver (a friend of your) was driving wildly, would you ask the driver to drive more safely?

26 A Yes (5)

26B Probably (4)

$26 \mathrm{C}$ Sometimes (3)

26D Probably not (2)

26E Definitely not (1)

27. If you were drinking beer, how many cans or glasses would you have and decide not to drive?

$27 \mathrm{~A} I$ do not drink beer. (5)

$27 \mathrm{~B} 1$ (4)

27C 2 or 3

$27 D 4$ or 5

$27 \mathrm{E} 6$ or more $(1$

28. If you were really angry, would you drive?

$28 \mathrm{~A}$ Yes (1)

28B Probably (2)

$28 \mathrm{C}$ Sometimes (3)

$28 \mathrm{D}$ No $(4)$

29. If you were drinking hard alcohol, how much would you drink and not drive?

29A I do not drink hard alcohol. (5)

29B 1 drink. (4)

29C 2 or 3 drinks. (3)

29D 4 or 5 drinks. (2)

29E 6 or more drinks. (1)

30. Do you have a tendency to go too fast?

$30 \mathrm{~A}$ Yes (1)

30B Sometimes (2)

$30 \mathrm{C}$ Very little (3)

300 No $(4)$ 
31. Do you have a tendency to drive too close to the side of the road?

31 A Yes (I)

$31 \mathrm{~B}$ Sometimes (2)

$31 \mathrm{C}$ Very little (3)

$31 D$ No (4)

32. Do you have a tendency to show off?

$32 \mathrm{~A}$ Yes ( 1 )

32B Sometimes (2)

$32 \mathrm{C}$ Very little (3)

$32 \mathrm{D}$ No $(4)$

33. Do you have a tendency to not stop completely at stop signs?

$33 \mathrm{~A}$ Yes (1)

33B Sometimes (2)

33 C Very little (3)

33D No (4)

34. Do you have a tendency to talk too much to others while driving and perhaps not keep your mind on the road?

34 A Yes (1)

34B Sometimes (2)

$34 \mathrm{C}$ Very little (3)

$34 \mathrm{D}$ No (4)

35. Do you have a tendency to run off the road?

$35 \mathrm{~A}$ Yes (1)

35B Sometimes (2)

35 C Very little (3)

$35 \mathrm{D}$ No $(4)$

36. Do you have a tendency to not keep your mind on driving and on the road?

$36 \mathrm{~A}$ Yes (1)

36B Sometimes (2)

36C Very little (3)

$36 \mathrm{D}$ No $(4)$

37. Do you have a tendency to drink and drive?

$37 \mathrm{~A}$ Yes (1)

$37 \mathrm{~B}$ Sometimes (2)

$37 \mathrm{C}$ Very little (3)

$37 \mathrm{D}$ No $(4)$

38. When you are very angry, how well do you drive?

$38 \mathrm{~A}$ Better than usual (1)

$38 \mathrm{~B}$ the same as usual (2)

$38 \mathrm{C}$ worse than usual ( 3 )

38D I do not drive when angry. (0) 
39. How well do you drive when you are excited?

39 A Better than usual (1)

$39 B$ the same as usual (2)

39 C worse than usual (3)

39D I do not drive when excited. (0)

40. When you have had a couple of cans or glasses of beer, and drove, your driving was

$40 \mathrm{~A}$ better than usual. (1)

$40 \mathrm{~B}$ the same as usual. (2)

$40 \mathrm{C}$ worse than usual. (3)

$40 \mathrm{D}$ I do not drive after drinking beer. (4)

$40 \mathrm{E}$ I do not drink beer. (5)

41. When you have had a couple of drinks of hard alcohol, and drove, your driving was

$41 \mathrm{~A}$ better than usual. (1)

$41 B$ the same as usual. (2)

$41 \mathrm{C}$ worse than usual. (3)

41D I do not drive after drinking hard alcohol.

$41 E$ I do not drink hard alcohol. (5)

42. How would you rate yourself as a driver?

42A Excellent (5)

42B Above average (4)

$42 \mathrm{C}$ average (3)

$42 \mathrm{D}$ below average

$42 \mathrm{E}$ poor. (I)

43. Would you call a friend to come get you if you had been drinking and did not want to drive?

$43 \mathrm{~A}$ Yes (5)

43B Probably (4)

43C Maybe (3)

43D Probabiy not (2)

43E Definitely not (1)

44. Would you leave your car and call a cab (taxi) to get you if you had been drinking and you did not want to drive and no friend of your was with you or was in condition to drive?

$44 \mathrm{~A}$ Yes (5)

44B Probabiy (4)

44C Maybe (3)

44D Probabiy not (2)

44E Definitely not (1)

45. Would you ask anyone else to drive if you had been drinking and you did not feel you should drive?

$45 \mathrm{~A}$ Yes (5)

45B Probably (4)

45C Maybe (3) 
45D Probably not (2)

45E Definitely not (1)

46. If a girlfriend (if you are a girl) or a boyfriend (if you are a boy) were in the car with you, how well would you drive?

$46 \mathrm{~A}$ better than usual (1)

$46 \mathrm{~B}$ the same as usual (2)

$46 \mathrm{C}$ worse than usual (3)

47. If a friend were riding with you in the car, would you drive faster than the speed limit?

47 A Yes (1)

47B Probably (2)

47C Maybe (3)

$47 D$ Probably not (4)

$47 \mathrm{E}$ Definitely not (5)

48. If a friend were riding with you in the car, would you show off a little?

$48 \mathrm{~A}$ Yes (1)

48B Probably (2)

48C Maybe (3)

48D Probably not (4)

48 E Definitely not (5)

49. If a friend were riding with you in the car, would you talk to your friend and not pay as much attention to the road?

49A Yes (1)

49B Probably (2)

49C Maybe (3)

49D Probably not (4)

$49 \mathrm{E}$ No (5)

50. Do you like to drive?

$50 \mathrm{~A}$ Yes, a lot. (1)

$50 \mathrm{~B}$ Somewhat (2)

$50 \mathrm{C}$ Not very much (3)

51. Do you ever get a feeling of power when driving a car? $51 \mathrm{~A}$ Usualiy (1)

51 B often (2)

$51 \mathrm{C}$ Sometimes (3)

51D Rarely (4)

$51 \mathrm{E}$ Never (5)

52. Did you ever want to smash someone or something with the car while driving?

$52 \mathrm{~A}$ Yes, once or twice. (3)

52B Yes, three or four times. (2)

52C Yes, five or more times. (1)

52D No, never. (4) 
53. Does it annoy you when drivers try to cut in on you?

$53 \mathrm{~A}$ Very much (1)

$53 \mathrm{~B}$ Some (2)

$53 \mathrm{C}$ Very little (3)

53D Not at a11 (4)

54. Does it annoy you when drivers try to pass you?

$54 \mathrm{~A}$ Very much (1)

$54 \mathrm{~B}$ Some (2)

$54 \mathrm{C}$ Very little (3)

54 Dot at all (4)

55. Do you like to see if you can go through a yellow light before it turns red?

$55 \mathrm{~A}$ Usually (1)

$55 \mathrm{~B}$ Often (2)

$55 \mathrm{C}$ Sometimes

55D Almost never

56. Would you pull off the road if you thought you were too angry or excited to drive safely?

56 A Yes (4)

56B Probably (3)

$56 \mathrm{C}$ Maybe (2)

560 Probabiy not (1)

57. If a friend in the car with you told you to slow down because he (they) thought you were driving too fast, would you?

57A Yes (4)

57B Probably (3)

57C Maybe (2)

57D Probabiy not

58. If a brother or sister in the car with you told you to slow down, would you?

58 A Yes (4)

58B Probably (3)

$58 \mathrm{C}$ Maybe (2)

58D Probably not (1)

$58 \mathrm{E}$ I do not have a brother or a sister. (0)

59. If your mother or father were in a car with you and told you to slow down, would you?

$59 \mathrm{~A}$ Yes (4)

59B Probab1y (3)

59 C Maybe (2)

59D Probabiy not

60. If someone were trying to pass you, would you speed up to try to stop him?

$60 \mathrm{~A}$ Yes (1)

60B Probably 
60C Maybe (3)

60D Probably not (4)

61. Do you think you drive recklessly at times?

61A Yes, often. (1)

61B Yes, sometimes.

61C Rarely (3)

61D I never drive recklessly.

62. Do you think you would ever have a minor accident in which no one is seriously hurt?

$62 \mathrm{~A}$ Yes, it is possible and likely. (3)

$62 \mathrm{~B}$ Yes, it is possible but unlikely. (2)

$62 \mathrm{C}$ No, it is very unlikely. (I)

63. Do you think you would ever have a serious accident in which some one required stitches or broke a bone, etc.? $63 \mathrm{~A}$ Yes, it is possible and likely. (3) 63B Yes, it is possible but unlikely. (2) $63 \mathrm{C}$ No, it is very unlikely. (I)

64. Do you think your friends could have a minor accident in which no one is seriously hurt?

$64 \mathrm{~A}$ Yes, it is possible and likely. (3)

$64 \mathrm{~B}$ Yes, it is possible but unlikely. (2)

$64 \mathrm{C}$ No, it is very unlikely. (1)

65. If a friend had an accident, would it bother you enough to change any of your driving behaviors? (Mark the item that tells how seriously hurt your friend must be before you would change)

$65 \mathrm{~A}$ Only if my friend was killed (2)

$65 \mathrm{~B}$ If my friend were seriously injured (Broken bone, etc.) I would be more careful in the type of situation his accident occurred in.

65C If my friend were hurt, but not seriously (shaken up, a bump or two, etc.). (4)

$65 \mathrm{D}$ It would not change my driving behavior if I heard about a friend of mine having an accident.

66. Do you consider yourself the kind of person who wants

to win no matter what?

$66 \mathrm{~A}$ Yes, all the time. (1)

$66 \mathrm{~B}$ Yes, most of the time.

$66 \mathrm{C}$ Yes, sometimes.

(3)

66D Rarely (4)

$66 \mathrm{E}$ No (5)

07. Do you drive defensively (watch out for other driver's mistakes)?

$67 \mathrm{~A}$ Yes, a11 the time. (5)

$67 \mathrm{~B}$ Yes, most of the time. 
$67 \mathrm{C}$ Yes, some of the time. (3)

67D Rarely (2)

$67 \mathrm{E}$ No (1)

68. Do you try to see the other person's point of view, even if you are angry at him (or her)?

$68 \mathrm{~A}$ Yes, all the time. (5)

$68 \mathrm{~B}$ Yes, most of the time. (4)

$68 \mathrm{C}$ Yes, sometimes. (3)

68D Rarely (2)

$68 \mathrm{E}$ No (1)

69. If your friends were drag-racing, would you drag-race

too even if you knew that the road they were drag-

racing on had other cars on it and it was dangerous to drag-race there?

$69 \mathrm{~A}$ Yes, a11 the time. (1)

$69 \mathrm{~B}$ Yes, most of the time.

69C Yes, sometimes. (3)

69D Rare1y. (4)

$69 \mathrm{E}$ No $(5)$

70. When you get very angry, what do you tend to do most of the time?

$70 \mathrm{~A}$ Stay and scream and yell. (1)

70B Take off, preferably in a car. (3)

70C Take off, but walk away, and keep on walking. (2)

70D Take off, and go to a quiet spot and think about it or tell someone about it. (2)

$70 \mathrm{E}$ Other (0)

71. How would you describe yourself as a driver?

$71 \mathrm{~A}$ Very calm, very little bothers me. (5)

$71 \mathrm{~B}$ Calm, sometimes things bother me. (4)

$71 C$ Undecided (0)

$71 \mathrm{D}$ Not very calm, a lot of things bother me.

$71 \mathrm{E}$ Not very calm, most things bother me. (1)

72. Have you ever driven after you have had a few drinks of hard alcohol or a few beers in the past year?

$72 \mathrm{~A}$ Yes, once or twice. (4)

$72 \mathrm{~B}$ Yes, $3-5$ times. (3)

72C Yes, 6-10 times. (2)

72D Yes, 11 or more times. (1)

$72 \mathrm{E}$ No $(5)$

73. Have you ever driven when you were very angry or very excited in the past year?

$73 \mathrm{~A}$ Yes, once or twice. (4)

73B Yes, 3-5 times. (3)

73C Yes, 6-10 times. (2)

73D Yes, 11 or more times. (1)

$73 \mathrm{E}$ No (5) 
74. What does uriving a car mean to you? Check all items that apply.

$74 \mathrm{~A}$ a status symbol, especially if the car is a sports car, or a real expensive car, etc. (1)

$74 \mathrm{~B}$ a means of transportation (2)

$74 \mathrm{C}$ a means to get away from troubles and unpleasant situations (1)

$74 \mathrm{D}$ a place where you can be alone (1)

$74 \mathrm{E}$ something to take out anger and other strong emotions on .

75. Do you tend to plan ahead while driving, or do you decide things at the last moment?

$75 \mathrm{~A}$ Most of the time I plan ahead. (3)

75B Some of the time I plan ahead. (2)

$75 \mathrm{C}$ Undecided (1)

75D Most of the time I decide things at the last moment. (0)

76. Do you tend to wear a seat belt while driving? Do not include the times you are teaching others to drive.

$76 \mathrm{~A}$ Most of the time (4)

$76 \mathrm{~B}$ Some of the time. (3)

76C Rarely (2)

76D I almost never wear a seat belt.

77. As a result of teaching others how to drive, has your driving improved at all?

$77 \mathrm{~A}$ a lot (4)

$77 \mathrm{~B}$ some ( 3 )

$77 \mathrm{C}$ It's the same as a1ways. (2)

$77 \mathrm{D}$ My driving has gotten worse. (1)

$77 \mathrm{E}$ other $(0)$

78. WIIl answering this questionnaire make you change your driving behavior?

$78 \mathrm{~A}$ A lot (4)

$78 \mathrm{~B}$ Some (3)

78C Very little (2)

78D Not at all (1)

Version 3 of Attitude Test Criterion: High Schools A and B, Biographical Section.

\section{PROBLEM STATEMENT}

Traffic accidents are the leading cause of death for persons aged 15-24, equaling all other causes combined 
(National Safety Council, 1968). Hart (1969) said that drivers in the late teens and the first half of the twenties have one-third of all accidents, although this group of drivers constitutes only $21 \%$ of all drivers. Also, males under 25 have far more accidents than females under 25. For example, in 1968, in Indiana, there were 4185 drivers aged 16-21 involved in an accident in which there was a serious injury or death. Seventy-eight percent of these young drivers were males, and only twenty-two percent were females. of the male drivers, twenty-two percent had been drinking before the accident: only six percent of the female drivers had been drinking. Furthermore, $64 \%$ of these accidents occurred while going straight ahead, on a straight, level, blacktop, dry road with unobscured vision, and males were usually driving faster than females. Therefore, there is a major problem with young people and accidents, and we are trying some new things which might help reduce the accident rate for young drivers.

\section{Attitudes on Driving}

Section I

General Information

1. You are a

1A Male (1)

1B Female (2)

2. Your age is

$2 \mathrm{~A} 15$ (1)

2B 16 (2)

2C 17 (3)

2D 18 (4)

2E 19 (5) 
3. You are a

3 A freshman (1)

$3 B$ sophomore (2)

$3 \mathrm{C}$ junior (3)

3D senior (4)

4. Your father's highest level of education is:

$4 \mathrm{~A}$ he did not graduate from grammar school (8th grade)(1)

$4 \mathrm{~B}$ he graduated from grammar school but not from high school. (2)

4C he graduated from high school (3)

$4 D$ he graduated from high school and took technical training or had two years of college, but did not graduate from a four year college. (4)

$4 \mathrm{E}$ he graduated from a four year college or he did advanced work (M.S., Ph.D., M.D., etc.). (5)

5. What is your mother's highest level of education?

$5 \mathrm{~A}$ she did not graduate from grammar school (8th grade)(1)

$5 \mathrm{~B}$ she graduated from grammar school but not from high school (2)

5C she graduated from high school (3)

5D she graduated from high school and took special training (beauty school, etc.), but did not graduate from a four year college. (4)

$5 \mathrm{E}$ she graduated from a four year college or she did advanced work (M.S., Ph.D., M.D., etc.). (5)

6. Your usual grades are

$6 \mathrm{~A}$ above average (A or $B$ ).

$6 \mathrm{~B}$ average (C). (2)

$6 \mathrm{C}$ below average. (1)

7. You Iive

$7 \mathrm{~A}$ on a farm or in a small town in a farming area (1)

$7 \mathrm{~B}$ in or very near a medium sized town (Lafayette) where there are other industries beside, or instead of, farming. (1)

7C in or very near a big city (Indianapolis) (1)

8. You first learned to drive at the age of

8 A under 4 (1)

8 B $4-8$ (2)

$8 \mathrm{C} 9-14$ (3)

8D 15 or older from your driver education teacher (5)

$8 \mathrm{E} 15$ or older from someone other than your driver education teacher (4)

9. Who first taught you how to drive?

$9 \mathrm{~A}$ your mother or father (1)

$9 B$ your grandmother or grandfather (1)

$9 \mathrm{C}$ a boy friend or a girl friend (1) 
90 your driver education teacher (2)

$9 \mathrm{E}$ no one - you saw others drive and learned from this (1)

10. How much do you think you will drive each week, after you get your driver's license, on the average?

$10 \mathrm{~A}$ over 75 miles (1)

$10 \mathrm{~B}$ 50-75 miles (2)

10C $15-25$ miles (3)

10D 5-10 miles (4)

$10 \mathrm{E}$ under 5 miles

11. Where do you think you will do most of your driving?

$11 \mathrm{~A}$ in a city (not included in data analysis)

11C in a small town and on local highways

$11 D$ on major highways such as I65, etc.

$11 E$ other

12. After you get your driver's license, when will your parents let you use a car?

$12 \mathrm{~A}$ whenever you want ( 1 )

$12 \mathrm{~B}$ most of the time you want (2)

$12 \mathrm{C}$ some of the time you want (3)

$12 \mathrm{D}$ almost never (4)

$12 \mathrm{E}$ My parents do not have a car (5)

13. What restrictions will your parents put on your driving after you get your license? Check as many as you need. $13 \mathrm{~A}$ no restrictions

$13 \mathrm{~B}$ must be home at a certain time

$13 \mathrm{C}$ can only drive in certain places (not included

$13 \mathrm{D}$ not to drive when drinking

$13 \mathrm{E}$ other

in data analysis)

14. What do you plan to do after high school?

$14 \mathrm{~A}$ go to college (3)

$14 \mathrm{~B}$ get technical training (beauty school, electronics, etc.). (2)

$14 \mathrm{C}$ farm. (1)

14 D work. (1)

$14 \mathrm{E}$ undecided. (0)

15. Have you ever been in a serious accident in a car in which a death or bad injury (such as broken bones, stitches, etc.) occurred?

$15 \mathrm{~A}$ Yes, once. (3)

$15 \mathrm{~B}$ Yes, 2 or 3 times (2)

$15 \mathrm{C}$ Yes, 4 or more times. (1)

15 Do. (4)

16. Have you ever been in a minor accident in a car in which no one was seriously hurt although the car might be dented, etc.? 
$16 \mathrm{~A}$ Yes, once (3)

$16 \mathrm{~B}$ Yes, 2 or 3 times (2)

$16 \mathrm{C}$ Yes, 4 or more times.

$16 \mathrm{D}$ No. (4)

17. Do you think your father would come get you if you

called him up and told him you had been drinking and did not want to drive?

$17 \mathrm{~A}$ Yes (5)

$17 \mathrm{~B}$ Probabiy (4)

17C Maybe (3)

$17 \mathrm{D}$ No (2)

$17 \mathrm{E}$ I would not cali my father (1)

18. Do you think your mother would come and get you if you called her up and told her you had been drinking and did not want to drive?

$18 \mathrm{~A}$ Yes (5)

$18 B$ Probably (4)

$18 \mathrm{C}$ Maybe (3)

$18 \mathrm{D}$ No (2)

$18 \mathrm{E}$ I would not call my mother (1)

19. After you get your driver's license, what car will you drive?

19A I am saving up and will buy my own car. (1)

19B Someone will give me my own car. (2)

19C I will not have my own car, but will use my parents' car (3)

19D I will not have my own car, but will use someone else's (such as a friend's) car.

19E There will not be a car I can use to drive. (5)

20. Have you ever had anything happen to you while in a car that shook you up, and in the future, in the same kind of situation, you will be much more cautious, such as another car almost ramming into you because it went through a stop sign, and you now will be extra cautious at certain types of intersections, etc.?

$20 \mathrm{~A}$ Yes, once or twice. (2)

$20 \mathrm{~B}$ Yes, 3 or 4 times (1)

$20 \mathrm{C}$ Yes, 5 or more times (0)

2OD No. (2)

21. Will you be driving a "souped up" car or a sports car? $21 \mathrm{~A}$ Yes. (1)

$21 \mathrm{~B}$ Probably (2)

21C Maybe (3)

$21 \mathrm{D}$ No (4) 
Version 3 or Attitude Test Criterion: High Schools A and B, Attitude Section.

Section II Attitudes

\section{START ON ITEM 26 ON YOUR ANSWER CARD}

26. If you were a passenger in a car and you thought the driver (a friend of yours) was driving wildly, would you ask the driver to drive more safely?

26 A Yes (5)

26B Probably (4)

26C Sometimes (3)

26D Probably not (2)

26E Definitely not (1)

27. How many cans or glasses of beer do you think you could drink and still drive safely?

$27 \mathrm{~A}$ I do not drink beer (5)

$27 \mathrm{~B}$ One (4)

$27 C 2$ or 3 (3)

$27 \mathrm{D} 4$ or 5 (2)

$27 \mathrm{E} 6$ or more (1)

28. If you were really angry, do you think you should drive? $28 \mathrm{~A}$ Yes (1)

$28 \mathrm{~B}$ Maybe (2)

$28 \mathrm{C}$ No $(3)$

29. If you were drinking hard alcohol, how many drinks do you think you could have and still drive safely?

29A I do not drink hard alcohol (5)

29B One drink (4)

29C 2 or 3 drinks

29D 4 or 5 drinks (2)

$29 \mathrm{E} 6$ or more drinks

30. If you were really angry and drove, how well do you

think you would drive?

$30 \mathrm{~A}$ better than usua 1

$30 \mathrm{~B}$ the same as usual (2)

$30 \mathrm{C}$ worse than usual (3)

$30 \mathrm{D}$ I would not drive if I were really angry (4)

31. If you had had a couple of cans or glasses of beer and drove, how we11 do you think you would drive?

31 A better than usual (1)

$3 I B$ the same as usual (2)

$31 \mathrm{C}$ worse than usual (3) 
32. If you had had a couple of drinks of hard alcohol, and drove, how well do you think you would drive?

$32 \mathrm{~A}$ better than usual (1)

$32 \mathrm{~B}$ the same as usual (2)

$32 \mathrm{C}$ worse than usual (3)

33. If you were very excited and drove, how well do you think you would drive?

$33 \mathrm{~A}$ better than usual

$33 \mathrm{~B}$ the same as usual (2)

$33 \mathrm{C}$ worse than usual (3)

34. What kind of driver do you think you will be?

$34 \mathrm{~A}$ an excellent driver (4)

$34 \mathrm{~B}$ an above average driver (4)

$34 \mathrm{C}$ an average driver (3)

$34 \mathrm{D}$ a below average driver

$34 \mathrm{E}$ a poor driver (1)

35. Do you think you will like to drive?

$35 \mathrm{~A}$ yes, a lot (1)

$35 \mathrm{~B}$ some (2)

$35 \mathrm{C}$ not very much (3)

36. Will driving a car give you a sense of power?

$36 \mathrm{~A}$ definitely yes (1)

$36 \mathrm{~B}$ probably yes (2)

$36 \mathrm{C}$ maybe (3)

36 probabiy not (4)

$36 \mathrm{E}$ definitely not (5)

37. Will you ever feel like smashing something or someone with a car?

$37 \mathrm{~A}$ definitely yes (1)

$37 \mathrm{~B}$ probably yes (2)

$37 \mathrm{C}$ maybe (3)

$37 \mathrm{D}$ probabiy not (4)

37 E definitely not (5)

38. Do you think you would show off if a friend were riding with you?

$38 \mathrm{~A}$ yes ( 1 )

$38 \mathrm{~B}$ probably (2)

$38 \mathrm{C}$ maybe (3)

$38 \mathrm{D}$ no (4)

39. If you were driving a car, and you had a passenger, would you drive more carefully if the passenger were a boy or a girl?

39 A with a boy I would drive more carefully (1)

$39 \mathrm{~B}$ with a girl I would drive more carefully (1)

39C I would drive very carefully if I had a passenger no matter if the passenger were a boy or a girl. 
40. When do you think you would drive more safely and carefully?

$40 \mathrm{~A}$ if I were alone in the car (1)

$40 \mathrm{~B}$ if I had a passenger with me in the car (2)

41. Do girls think boys are sissies if boys drive safely and carefully?

41A definitely yes (1)

41 p probably yes (2)

$41 \mathrm{C}$ maybe (3)

41D probably not (4)

$41 D$ definitely not (5)

42. Would you call a friend to come get you if you had been drinking and did not want to drive?

$42 \mathrm{~A}$ yes $(5)$

$42 \mathrm{~B}$ probably (4)

$42 \mathrm{C}$ maybe (3)

42D probably not (2)

$42 \mathrm{E}$ definitely not (1)

43. Would you leave your car and call a cab (taxi) to get you if you had been drinking and you did not want to drive, and no friend of yours was with you or was sober enough to drive?

43 A yes (5)

$43 \mathrm{~B}$ probably (4)

$43 \mathrm{C}$ maybe (3)

43D probably not (2)

$43 \mathrm{E}$ definitely not (1)

44. Would you ask anyone else to drive if you had been

drinking or were very angry and you did not feel you should drive?

$44 \mathrm{~A}$ yes $(5)$

44B probably (4)

$44 \mathrm{C}$ maybe (3)

$44 \mathrm{D}$ probably not (2)

$44 \mathrm{E}$ definitely not (1)

45. Would you pull off the road if you thought you were too angry or excited to drive safely?

$45 \mathrm{~A}$ yes ( 5 )

45B probabiy (4)

45C maybe (3)

$45 \mathrm{D}$ probably not (2)

45 E definitely not (1)

46. If a friend in the car with you told you to slow down because your friend thought you were driving too fast, would you?

46 A yes (5)

46B probably (4) 
46C maybe (3)

$46 \mathrm{D}$ probabiy not (2)

$46 \mathrm{E}$ definitely not (1)

47. If a brother or sister were in the car with you and told you to slow down and not drive so recklessly, would you?

$47 \mathrm{~A}$ yes (4)

$47 \mathrm{~B}$ probably (3)

47C maybe (2)

47 D probabiy not (1)

$47 \mathrm{E} I$ do not have a brother or sister $(0)$

48. If your mother or father were in a car with you and told you to slow down, would you?

$48 \mathrm{~A}$ yes (4)

$48 \mathrm{~B}$ probably (3)

$48 \mathrm{C}$ maybe (2)

48D probably not (1)

49. Do you think you might drive recklessly at times?

$49 A$ yes ( 4 )

49B probably (3)

$49 \mathrm{C}$ maybe (2)

49D probabiy not (1)

50. What does driving a car mean most to you?

Pick only one answer

$50 \mathrm{~A}$ a status symbol-others will look up to me (4)

$50 B$ an escape - I can take off when I want to (2)

$50 \mathrm{C}$ a place to be alone (3)

$50 D$ a way to get from one place to another (5)

$50 \mathrm{E}$ a way to get rid of my anger (1)

51. Do you think you would ever have a minor accident in which no one is seriously hurt?

$51 \mathrm{~A}$ Yes, it is possible and likely (3)

$51 \mathrm{~B}$ Yes, it is possible but unlikely (2)

51C No, it is very unlikely (I)

52. Do you think you would ever have a serious accident in which some one required stitches or broke a bond, etc.? $52 \mathrm{~A}$ Yes, it is possible and likely (3)

$52 \mathrm{~B}$ Yes, it is possible but unlikely (2)

$52 \mathrm{C}$ No, it is very unlikely (I)

53. Do you think your friends could have a minor accident in which no one is seriously hurt?

$53 \mathrm{~A}$ Yes, it is possible and likely (3)

$53 \mathrm{~B}$ Yes, it is possible but unlikely (2)

$53 \mathrm{C}$ No, it is very unlikely (I) 
54. If a friend had an accident, would it bother you enough

to change any of your driving behaviors? (Mark the item that telis how seriously hurt your friend must be before you would change.)

$54 A$ Only if my friend was killed (2)

$54 \mathrm{~B}$ If my friend were seriously injured (broken bone, etc.) I would be more careful in the type of situation his accident occurred in (3)

$54 \mathrm{C}$ If my friend were hurt, but not seriously (shaken up, a bump or two, etc.) (4)

$54 \mathrm{D}$ I would not change my driving behavior if I heard about a friend of mine having an accident (1)

55. Do you consider yourself the kind of person who wants

to win or be right no matter what?

$55 \mathrm{~A}$ Yes, all the time (1)

$55 \mathrm{~B}$ Yes, most of the time

$55 \mathrm{C}$ Yes, sometimes (3)

55D Rarely (4)

$55 \mathrm{E}$ No (5)

56. Will you drive defensively (watch out for other driver's mistakes)?

$56 \mathrm{~A}$ Yes (4)

56B Probably (3)

56C Maybe (2)

$56 \mathrm{D}$ No $(1)$

57. Do you try to see the other person's point of view, even if you are angry at him (or her)?

$57 \mathrm{~A}$ Yes, all the time (5)

$57 \mathrm{~B}$ Yes, most of the time

57C Yes, sometimes ( 3 )

57D Rarely (2)

$57 \mathrm{E}$ No (1)

58. If your friends were drag-racing, would you drag-race too even if you knew that the road they were dragracing on had other cars on it and it was dangerous to drag-race there?

$58 \mathrm{~A}$ Yes, all the time (1)

$58 \mathrm{~B}$ Yes, most of the time (2)

$58 \mathrm{C}$ Yes, sometimes (3)

58D Rarely (4)

$58 \mathrm{E}$ No $(5)$

59. When you get very angry, what do you tend to do most of the time?

$59 \mathrm{~A}$ Stay and scream and yell (3)

59B Take off, preferably in a car (1)

59C Take off, but walk away, and keep on walking (2)

59D Take off, and go to a quiet spot and think about it or tell someone about it. (2)

59E Other (0) 
60. How do you think you would be as a driver?

$60 \mathrm{~A}$ Very calm, very little bothers me (4)

$60 \mathrm{~B} \mathrm{Calm}$, sometimes things bother me (3)

60C Undecided (0)

60D Not very calm, a lot of things bother me (2)

$60 \mathrm{E}$ Not very calm, most things bother me (1)

61. Do you think boys will think other boys are sissies if they drive carefully and do not show off?

$61 \mathrm{~A}$ Yes (1)

61 B Probabiy yes (2)

61C Maybe (3)

61D Probably not (4)

$61 \mathrm{E}$ Definitely not (5)

Version 3 of Attitude Test Criterion: High Schools A and B,

Driving Behaviors Section

START ON ITEM 75 ON YOUR ANSWER CARD

75. Do you have a tendency to show off?

$75 \mathrm{~A}$ Yes (1)

$75 \mathrm{~B}$ Sometimes (2)

$75 \mathrm{C}$ Very little (3)

$75 \mathrm{D}$ No $(4)$

76. Do you have a tendency to not stop completely at stop signs?

$76 \mathrm{~A}$ Yes (1)

$76 \mathrm{~B}$ Sometimes (2)

$76 \mathrm{C}$ Very little (3)

$76 \mathrm{D}$ No (4)

77. Do you have a tendency to talk too much to others while driving and perhaps not keep your mind on the road?

$77 \mathrm{~A}$ Yes (1)

$77 \mathrm{~B}$ Sometimes (2)

77 C Very little (3)

770 No $(4)$

78. Do you have a tendency to run off the road?

$78 \mathrm{~A}$ Yes (1)

$78 \mathrm{~B}$ Sometimes (2)

$78 \mathrm{C}$ Very little (3)

$78 \mathrm{D}$ No $(4)$

79. Do you have a tendency to not keep your mind on driving and on the roac?

79 A Yes (1)

$79 \mathrm{~B}$ Sometimes (2)

79C Very little (3)

$79 D$ No (4) 
80. Do you have a tendency to drink and drive?

$80 \mathrm{~A}$ Yes (1)

$80 \mathrm{~B}$ Sometimes (2)

$80 \mathrm{C}$ Very little (3)

80D No (4)

81. Do you have a tendency to go too fast?

$81 \mathrm{~A}$ Yes (1)

$81 \mathrm{~B}$ Sometimes (2)

$81 \mathrm{C}$ Very little (3)

$81 \mathrm{D}$ No $(4)$

82. Do you have a tendency to drive too close to the side of the road?

$82 \mathrm{~A}$ Yes (1)

$82 \mathrm{~B}$ Sometimes (2)

$82 \mathrm{C}$ Very little (3)

$83 \mathrm{D}$ No (4)

83. If someone were trying to pass you, would you tend to speed up to try to stop him?

$83 \mathrm{~A}$ Yes (1)

$83 \mathrm{~B}$ Probabiy (2)

83C Maybe (3)

83D Probably not(4)

84. Do you think you tend to drive recklessly at times?

$84 \mathrm{~A}$ Yes, often (1)

$84 \mathrm{~B}$ Yes, sometimes (2)

$84 \mathrm{C}$ Rarely (3)

84D I never drive recklessly (4)

85. Do you tend to take off in a car when you are angry?

$85 \mathrm{~A}$ Yes (1)

$85 \mathrm{~B}$ Sometimes (2)

$85 \mathrm{C}$ Very little (3)

$85 \mathrm{D}$ No $(4)$

86. Do you tend to cut in on other drivers?

$86 \mathrm{~A}$ Yes (1)

$86 \mathrm{~B}$ Sometimes (2)

$86 \mathrm{C}$ Very little (3)

$86 \mathrm{D}$ No (4)

87. Do you tend to try to pass other drivers?

$87 \mathrm{~A}$ Yes (1)

$87 \mathrm{~B}$ Sometimes (2)

$87 \mathrm{C}$ Very little (3)

$87 \mathrm{D}$ No $(4)$ 
88. Do you tend to try to see if you can go through a yellow light before it turns red?

$88 \mathrm{~A}$ Yes (1)

$88 \mathrm{~B}$ Sometimes (2)

$88 \mathrm{C}$ Very iittle (3)

$88 \mathrm{D}$ No (4)

89. If you are driving down a street you have driven down a lot before, do you tend to pay as much attention to the road as the first time you drove on the street?

$89 \mathrm{~A}$ Yes (3)

$89 \mathrm{~B}$ Sometimes (2)

$89 \mathrm{C}$ I do not pay as much attention to the road as I did the first time. 


\begin{abstract}
APPENDIX B
SEQUENCE OF TREATMENT IN QUASI-EXPERIMENT AT HIGH SCHOOL A
\end{abstract}

The following pages are a description of the treatment used in the quasi-experiment at High School A. In addition, some observations made by the experimenter of student reaction to the treatment are included.

\title{
High Schoo1 A: Session 1
}

To familiarize students with the video-tape equipment, the experimenter video-taped each student in the experimental group and replayed the tape for the students. In addition, the video-tape segments of the attractive girls talking about reckless drivers, and of the male athletes talking about reckless drivers were shown.

\section{High School A: Session 2}

Two video-tape segments were shown. In the first segment, a male athlete told his friend that a teacher had given him a lower mark on a test than he deserved. He then threw the test paper on the floor, took car keys out of his packet, went out to his car and opened the car door. However, he did not get in the car but stood outside of it thinking, while he played with his car keys. He then slammed the car door shut, walked back inside and picked up his test paper 
from the floor. He then walked off in the direction of the teachers' classroom.

After seeing the video-tape segment students were asked to list the athlete's behaviors. The experimenter then asked what emotion the athlete felt, and when students replied he felt angry, asked how students knew the athiete felt angry. Thus, students were encouraged to identify the emotion of anger and what behaviors might be performed while under the influence of anger. In addition, students indicated that the athlete's friend was not a good friend because as a friend, it was his responsibility to make sure his friend did not drive when angry. Students also indicated that they would tell a friend of theirs not to drive if he was too angry to drive, but that they would be angry at a friend if he told them not to drive because they were too angry to drive safely.

The second video-tape situation portrayed a son who was angry at his father, because his father did not want him to drive to see his girlfriend because the weather was quite bad. Male students then role-played the same situation. However, the male students were still angry at the "father" for not permitting his sou to drive. Also, girls indicated that if they were the son's girlfriend, they would understand why their boyfriend did not come, but they would still be angry at the boyfriend for not coming. Final1y, most students indicated their parents would not listen to them if they asked their parents to change their 
decisions, even if the students had good reasons for questioning their parents decisions.

\section{High School A: Session 3}

The high school A basketball team won their first game in the sectional toumament. Thus, class was shortened by 40 minutes in order to have a pep rally. No video-tape segment was shown as time would not permit a discussion after it. Instead, a demonstrator described an accident he had almost had. Students were divided into four groups to analyze the cuases of the "almost-accident". Only one group had time to report back to the class on the role of a passenger in a car. Passengers can influence a driver's driving, but if a passenger told a driver not to go so fast the driver might go even faster. The experimenter suggested that students not to tell a driver anything, but rather ask the driver not to go so fast or tell the driver the passenger was scared, in order not to imply that the Uriver was a poor driver. Unfortunately, the pep rally was announced and class was called off at this point.

\section{High School A: Session 4}

The video-tape machine did not work. Therefore, two male athletes were rehearsed in the skits prior to the class. The first skit consisted of the two athletes talking about winning their regional basketball tournament. The two athletes wanted to tell all their friends the news and went to a car to go to their friends' homes. However, the driver 
was so excited that he could hardly get the keys out of his packet, and the other athlete suggested that they go to a neighborhood place and get a coke to cool off before driving. They got out of the car and went off in the direction of the neighborhood place.

Student were asked to identify the emotions the boys felt. Students indicated that the boys felt excited and happy. When asked how the students decided what emotions the boys felt the students indicated that the athletes jumped around, talked faster, etc. The experimenter asked how the boys would drive while feeling so excited, and students indicated that the boys would drive poorly; their minds would be on the basketball game, not on driving.

In the second skit, the male athletes talked about how they would like to kill the referee at the regional basketball game; they would like to run over him. One athlete then took the car key out of his pocket to drive home, but then said that maybe they should cool off first because he was so mad. His friend then agreed with the driver and said that if they drove now they would probably smash up and not be able to play next year. Further, the driver's father would be very angry if the car were smashed. Therefore, the athletes decided to play a game of pool and have a coke in town before driving, and started to walk in the direction of town.

When asked to identify the emotions the athletes felt, students said they felt anger, disappointment and frustration. 
The experimenter asked students how they knew what emotions the athletes felt, and the students said they could tell from the way the athletes were talking and moving around in uncontrolled movements. The experimenter asked students how they felt when the team had lost and several girls said they cried, and a boy mentioned he kicked some bleachers so hard the police told him to stop. The experimenter asked the students how they would drive when they felt that way, and students said they would "squeal their tires", etc. The experimenter asked students how they would drive if they had kicked the bleachers or otherwise relieved their frustraiion and most students indicated they still would not drive as well as usual.

Students then indicated that they became less mad at people they thought would listen to them and who cared for them. Half the students felt their teachers, and half felt their parents would fit into this category. All students felt they would drive poorly if they drove while angry. However, many students indicated that the second skit was contrived; i.e., the athletes would drive while they were angry, even though they might cool off somewhat after the game by taking a shower before getting dressed, etc.

\section{High School A: Session 5}

Students played the games "break-in" in which one student tried to get within a circle of students who tried to keep him out, and "break-out" in which a student tried 
to get outside the circle, for the first 25 minutes of the period. Then students rested for a few minutes and got drinks of water.

The experimenter asked students why they were asked to play the games. A girl said that students felt angry, etc., when they could not get into the circle. The experimenter asked students who had tried to break in or break out of the circle how they felt and most students said they felt angered and discouraged. Students who had composed the circle said they felt nervous and excited. The experimenter asked students how they felt they would drive while under the influence of the strong emotions they had felt and students indicated their minds would not be on driving, and thus, they would drive poorly. Also, the experimenter asked students how forming the circle was like driving. Students indicated that it was like defensive driving, because one always had to keep an eye out for the movements of the others.

The experimenter asked students if they had felt similar to any of the boys in the video-taped segments while playing the games. A boy who had had trouble getting within the circle said he felt as angry and uncontrolled as some of the athletes. The experimenter asked how students thought they would perform on a test or while driving immediately after playing the game. Most students felt they would do poorly. One student indicated that a time-out was important in order to cool off, just like they did when they rested for a few minutes after playing the games. 
All students participated in the discussion; before, some students rarely said anything during the discussions.

\section{High School A: Session 6}

Students in both the experimental and control groups were retested on the attitude section, and were tested on the driving behaviors section of the attitude test.

\section{High School A: Session 7}

Two male student demonstrators described automobile accidents they had had or had almost had. Unfortunately, students were well acquainted with both demonstrators and joked with them. However, students agreed that they should still be careful while driving in familiar places, that talking to friends was not conducive to careful driving, etc. In addition, some students felt that their fathers would be angry at them if they had an accident, not because the car was smashed, but because their fathers did not want them to be hurt. On the other hand, some students felt that there fathers would only be mad at them if they had an accident if the car was damaged.

One male student in the experimental group had been in the backseat of a car when an accident occurred. His mother's boyfriend had been drinking, but still drove, and the car went into a ditch. Students agreed that one drove poorly after drinking. 


\section{High School A: Session 8}

A male demonstrator and a female demonstrator described the circumstances of accidents they had almost had. However, all six accident-producing situations were the result of inattention, while talking to friends, etc., rather than being caused by a lack of emotional control while driving. In addition, one student demonstrator was absent from school, and the experimenter read his description of accidents he had almost had. One accident almost occurred when his passenger dared him to go closer to a bridge. Students indicated that they would either ignore the taunt and tell their passenger to shut up, or would respond to the taunt even though they knew they might have an accident. Also, one accident occurred while the driver had been drinking. However, students did not relate to these latter accidents because the male demonstrator who had had them (who was absent) had lower grades, and was generally thought of as a person with whom the students would not be friends.

Finally, students emotionally role-played a deposition scene. However, students did not appear to feel such a thing could happen to them, and most students indicated they had never heard of giving a deposition.

\section{High School A: Session 9}

The experimenter read descriptions of two university students' accidents, which involved drivers who had had too much to drink, as only one incident was previously 
described in which a driver had had too much to drink. There was no discussion of the incidents.

Students in both the experimental and control groups were retested during their regular driver education class period on the attitude section and the driving behaviors sections. 
APPENDIX C

SEQUENCE OF TREATMENT IN QUASI-EXPERIMENT AT HIGH SCHOOL B

A description of the treatment used in the quasiexperiments is given in the following pages. Also, some observations made by the experimenter of student reaction to the treatment are included.

\section{High School B: Session 1}

Students played the game "First Impression". However, only two-thirds of the class was present. Also, after role was taken and students given assignments to drive in the cars, only 30 minutes was left to play this game. In addition, several students came to class late. Thus, "First Impression" may not have been as effective as it could have been in encouraging students to become better acquainted with each other.

\section{High School B: Session 2}

As some of the cideo-tape equipment was missing, it was not possible to video-tape students in order to familiariac them with the equipment, although the prepared videotape segments could be shown.

Students moved to one side of the room in order to be able to see the television screen. Students saw two videotape segments; cheerleaders talking about their boyfriends' 
driving behaviors and male athletes talking about their driving behaviors. Unfortunately, students did not see the last two or three minutes of the seçond videotape segment because the bell rang, indicating the end of the period.

A11 but five girls who read their driver education text books watched the video-tape segments. Students appeared to be restless during most of the second segment.

\section{High School B: Session 3}

Although two-thirds of the students came to class, only one-third of these students had seen the video-tape segments shown previously; i.e., the boys and the girls talking about reckless drivers. The experimenter told four girls to sit together, and told the only boys in the class (four boys) to sit together. The experimenter asked the girls what they would do if their boyfriend started driving fast and wildly. The girls indicated that they would tell their boyfriend to slow down. The boys said that they would either go faster or tell their girlfriend to get out of the car if the girl told them to slow down. Then the girls said that if the boy respected them the boy would slow down. Girls in the audience suggested that the girls should ask, not tell the boys to go slower.

The experimenter asked the boys in which situation they would drive more safely, with a passenger or by themselves. The boys were equally split between the alternatives. The experimenter asked the girls in which situation 
they would drive more safely, with a passenger or by themselves. The girls indicated that they would drive most safely with no passengers, because they would talk and turn their heads to see their passenger, and they might try to get their passenger's attention.

The experimenter asked the students what they did when they were angry. Most students said they would take off, or walk around. The experimenter asked the students how they would drive if angry. The boys said that anger would not influence their driving. The girls said that they would think about why they were angry and would drive poorly.

The experimenter then had a boy and a girl role-play respectively the parts of driver and passenger, and to imagine the boy was starting to go really fast. The girl (Passenger) told him to slow down. He told the girl to shut up.

The experimenter then had three girls role-play the situation of a driver with two passengers who was starting to go really fast. The female "driver" indicated that she might slow down or get mad if her girlfriends told her to slow down, depending how she felt toward her friends at the tine.

The purpose of this session was to express the same ideas as in the video-tapes shown previously (boys and girls talking), to the students who had not seen the video-tapes. 


\section{High School B: Session 4}

The class moved to the gym stage. The experimenter video-taped all students present, and replayed the tape for the students to further familiarize students with the equipment. Then, though the experimenter had trouble getting .. picture on the television, the video-tape segment in which a student became angry at his teacher because he thought the grade the teacher gave him on his test was unfair was shown. The teacher told the student to look through his test again. The student stomped off with the teacher going after him, and met a friend in the hall. He told his friend what happened and that he was so mad he was going to take off in a car and smash something. His friend told him to cool off. The student went off playing with his car keys, hesitated, and then came back to talk to his teacher. The experimenter asked the students how the student in the segment felt. The girls said the student felt mad, but the boys had trouble identifying the expressed emotion. The experimenter then asked the students if the teacher was fair. All students felt the teacher was not fair because he did not listen to the student. The experimenter asked if the "friend" acted as a friend should act. The students said he did, because the friend told the student not to take off in a car until he cooled off.

The experimenter asked how one could tell if a person was angry. Students did not say anything for a while, and 
then some girls said you could tell by a person's behavior and facial cxpression.

The experimenter asked the boys the same question. The boys did not respond. The experimenter asked the boys what the difference was between being angry and being really mad. One boy said that when he was angry he did not talk to others. The experimenter asked the boy if he thought about who or what he was mad at when he was very angry. The boy said he did. The experimenter asked the boys how they would drive a car if they were mad because if a boy were mad he might think about what he was mad at; not about his driving .

Students did not seem to get the idea that the interpretation of an action is generally inferred from the situation, i.e., if a person crunched up a piece of paper, he might have been throwing it out and he might not have been angry. Also, girls appeared to be much more perceptive than boys and were able to label and describe emotions. Some girls looked bored and talked among themselves when the experimenter tried to emphasize a point they already understood.

\section{High School B: Session 5}

The experimenter was informed that the students in the experimental group were far behind in their assignments, and was asked to come only one day a week. Also, the experimenter was informed that students who had had really 
bad accidents, were hard to contact because they did not generally come to school very much, and when contacted, even if offered payment, did not want to participate in the experiment as demonstrators.

Students played the game "Break-in". The experimenter asked students why the game was played. Students did not know.

Girls in one group playing the game helped a friend in the other group get within the other circle. Girls agreed that it was their responsibility to help their friends. The experimenter suggested that if a friend was driving poorly while under the influence of a strong emotion, it was their duty, as a friend, to tell the person they were not driving as well as they could.

The experimenter asked students how they felt when they could not break into the circle. Most students said they would only think of revenge, etc., and would not drive very well.

The experimenter asked students how they felt when they tried to keep a person from breaking into the circle. Most students said they felt excited. The experimenter then asked students how they would drive if they felt excited. Some said they would drive we11, others said they would not drive as well as usual because their mind would not be on driving.

Many of the male students particularly black male students, did not appear to be able to identify emotions of 
their behavior while under emotional stress. On the other hand, many of the girls were able to identify their emotions and emotional behavior with ease.

\section{High Schoo1 B: Session 6}

Students saw the video-tape segment in which a son is angry at his father. The son tells his father that he is going to pick up his girl friend and go to a double feature at a drive-in. The father then says that it is bad weather outside, and the son has a test the next day and should stay in and study. The son says he is going anyway, and walks away. Then the son turns and walks back to his father and says that the weather is bad and he should study, so he will still go out on his date but will only stay for one feature, and then come back and study. The father says the son could do what he wanted.

The experimenter asked students how the father felt. The students felt that the father in the segment was reasonable, sympathetic and understanding and cared about the boy. Most students felt that the son was angry at the beginning and did not even listen to what the father was saying. Also, most students indicated that they would not go off on a school night.

As very few boys were in the class, the experimenter asked two girls to role-play the situation in which a girl was talking to her mother about going out on a date on a school night. Both role-players became quite immersed in 
their roles and became quite angry. The experimenter then asked two other girls to role-play the situation, but to show how the situation would better be handled. However, the girl playing the part of the daughter became so mad at her "mother" that the situation became just as explosive as the first role-playing situation.

The experimenter then asked students how they would drive after such a siguation. Most students indicated that their minds would be on the situation, not on their driving.

It was interesting that no giris said that they did not believe the models would perform such actions, as some girls, who knew the models personally said at the conclusion of previous sessions. Also, girls who had previously read books when they were bored with the proceedings now paid close attention.

\section{High School B: Session 7}

The experimenter could not obtain the use of the videotape equipment, and thus, it was necessary to have live skits. Unfortunately, it was not possible to rehearse the models.

The two skits presented portrayed excited students who had won the sectional basketball tournament, and disappointed students who had lost the regional basketball tournament. However, the skits became Iong and involved, and an alternative behavior which precluded driving while under the influence of a strong emotion (reciprocal inhibition) was not presented. 
After seeing each video-tape segment, students were asked to identify the emotions and the emotional behaviors portrayed. All students agreed that the driver in the excitement skit was too excited to drive safely, and several students suggested that one of the other athletes should have driven. Students also felt that the model would drive poorly after loosing the game because their minds would be on the game, not on driving. However, only three or four students had gone to either the regional or sectional basketball tournament.

The experimenter asked students if they could do anything to drive more safely when angered. Several girls said they would not drive when angered, but most boys felt that if they were extra-cautious while driving they could drive safely. Also, students agreed that each person made different responses to each emotional state, and thus, some students might be more able to drive safely than others. In addition, it appeared that particularly black males had trouble identifying their behaviors while under the influence of anger or excitement.

\section{High School B: Session 8}

Students in both the experimental and control groups were retested on the attitude section, and tested on the driving behaviors section of the attitude test. However, as not all students were present, the driver education teacher said he would try to get the absent students to complete the test when they next returned to class. 


\section{High School B: Session 9}

A female demonstrator described and circumstances of one accident she had had. Then students were divided into four groups to discuss the difference a passenger makes in a driver's behavior, how the accident could have been prevented, or what precautions one can take in bad weather to avoid accidents. However, students gathered in their assigned groups but either remained silent, or talked about other things of interest. Therefire, the reports made by each group were very short and did not cover much ground.

\section{High School B: Session 10}

The female demonstrator described the circumstances of two more accidents she had had. She had been traveling on a one way street when a car to her left speeded up and cut in front of her. She pulled right, into the parked car lane and hit a parked car. She was thrown into the steering wheel and hurt her 1ip, etc. It had been snowing, on a Friday night when the accident occurred. The experimenter asked the class why the accident occurred. Students indicated that the other car should not have cut in front of the demonstrator's car.

The experimenter asked various students to name a familiar street near their homes and then asked the students if they paid much attention while they walked or rode as a passenger in a car down the street. Most students said they did not because they knew the street we?1. The 
experimenter asked the students if they had ever had an unexpected thing happen while going down the street. Only one student replied in the affirmative: a friend had been driving when a dog ran out and her friend slammed on the brakes. She said that she always was extra careful going down that street. The experimenter then suggested to the students that when going down a familiar street they expected certain things to happen and did not pay that much attention to the street. Thus, if something unexpected happened they might not see it until too late to do something to prevent an accident.

The experimenter also asked the students why the other driver cut in front of the demonstrator's car. Students suggested that the other driver was careless and may have been drunk. The experimenter asked the students if the demonstrator was correct in running into the parked car, and several students mentioned that she should have run into the car that cut in front of her. However, other students mentioned that while they would have been mad at the driver who cut in, the demonstrator was correct in running into the parked car because she could have been hurt running into a moving vehicle and/or the other driver could have been hurt, and the demonstrator would have had to pay for his injuries.

Some students mentioned that the demonstrator was going too fast for conditions. The experimenter suggested that the demonstrator expected certain things to happen 
and thus, was not overly careful. Also, the experimenter asked the students if they would feel they had to go the speed limit, regardless of conditions. Most students said no.

The experimenter also asked the students if they wore seatbelts while driving (not in driver education cars where they were required to wear seatbelts). Most students said they did not, or if they wore seatbelts, it was only when they were on a highway because a highway was more dangerous than city streets because cars were going faster. The experimenter suggested that students did not wear seatbelts because it reminded them they might have an accident.

The demonstrator then described another incident. Her mother had been driving on a highway, and was the last car in a traffic jam. Another car pulling a grailor smashed into the demonstrator's mother's car, and her mother steered the car into the ditch on the side of the road. Although no one was injured, the demonstrator's mother's car was wrecked. The experimenter asked the students if they had ever been in a traffic jam. No student had. The experimenter asked the students if they had seen a traffic jam; most students had. The experimenter asked the students how they should drive in a traffic jam, and the students asked the experimenter how they should drive. The experimenter reminded the students of their experiment with reaction times (each students' reaction time-getting their left foot 
from gas pedal to brake-had been determined), and asked if each student had the same reaction time. Students said they al1 had different reaction times. The experimenter suggested that if people had different reaction times, if a car three cars ahead started up, even if the student was impatient and angry about being in the traffic jam, it would take a while before the student could go ahead. The experimenter then asked the students if the demonstrator's mother was correct in going off the road into the ditch. AII students agreed it was the correct thing to do, because if she had not, she would have run into the car in front of her, and possibiy injured the people in the car, and she would have had to pay for their injuries.

This session went far better than the last session. Al1 students listened and seemed to be alert for the discussion. In this session, students were told to sit in the front of the room, and students were not broken up into groups, but rather, the experimenter went around the room and asked various students the above questions.

\section{High School B: Session 11}

The experimenter read the circumstances of three accidents that university students had had in which drinking played a role. Then, a deposition scene was emotionally role-played. A male played the role of the accused driver, and females played the roles of witnesses to the accident. 


\section{High School B: Sessions 12-16}

Students in both the experimental and control groups retook the attitude section and the driving behaviors section of the attitude test. As many students were not there the first day, the experimenter came everyday for one week in the hope of retesting as many students as possible. In addition, students were retested on simulator lesson 1 . 
VITA 
VITA

Michelle Kaylin Shapiro received the A.A. degree in 1967 from Kendall College. She received the B.S. degrec (Psychology), in 1969, and the M.S. degree (Guidance arid Counseling) in 1971 from Purdue University. She has been a dormitory counselor at Purdue University, a psychologist for the Purdue University Compuing Center, a psychologist for Bell Labs, and a teacher at Purclue University. She is currently employed as a research psychologist for the Purdue Educationa] Research Center.

Mrs. Shapiro has had two journal articles published with her major professor as second author: 1) "Toward Accident Reduction Innovatjons In Driver Fducation", in Traffic Safety (in press); and 2) "Students Who Seldom Discuss Their Post-School Plans", in The School Counselor (in press). In addition, she and her major professor, William Asher, co-authored an Indiana Jolnt Highway Research Project technical report: (Project 非 C-36-59K) "Young Drivers' Severe Automobjle Accidents".

Mrs. Shapiro was born December 11, 1946, in Chicago, Illinois. She attended high school in a suburb of Chicago. Her hobbies axe playing the violin and the viola. She is a member of Psi Chi. Her husband Michael has a Ph.D. in Computer Science. 

